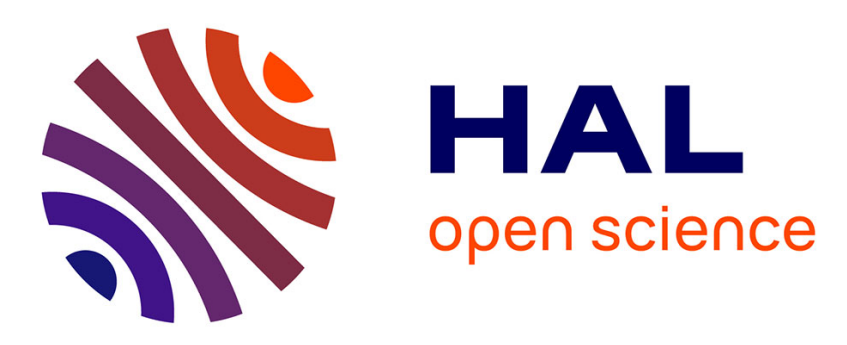

\title{
Structure-property relationship of 4-substituted-spirobifluorenes as hosts for phosphorescent organic light emitting diodes: an overview
}

Cyril Poriel, Joëlle Rault-Berthelot

\section{To cite this version:}

Cyril Poriel, Joëlle Rault-Berthelot. Structure-property relationship of 4-substituted-spirobifluorenes as hosts for phosphorescent organic light emitting diodes: an overview. Journal of Materials Chemistry C, 2017, 5 (16), pp.3869-3897. 10.1039/c7tc00746a . hal-01532178

HAL Id: hal-01532178

https://hal-univ-rennes1.archives-ouvertes.fr/hal-01532178

Submitted on 25 Sep 2017

HAL is a multi-disciplinary open access archive for the deposit and dissemination of scientific research documents, whether they are published or not. The documents may come from teaching and research institutions in France or abroad, or from public or private research centers.
L'archive ouverte pluridisciplinaire HAL, est destinée au dépôt et à la diffusion de documents scientifiques de niveau recherche, publiés ou non, émanant des établissements d'enseignement et de recherche français ou étrangers, des laboratoires publics ou privés. 


\title{
Structure-Properties Relationship of 4-Substituted-Spirobifluorenes as Hosts for Phosphorescent Organic Light Emitting Diodes : An overview
}

\author{
Cyril Poriel, $^{+*}$ Joëlle Rault-Berthelot ${ }^{\dagger}$ \\ † Université de Rennes 1-UMR CNRS 6226 "Institut des Sciences Chimiques de Rennes"- MaCSE group, \\ Bat 10C, Campus de Beaulieu - 35042 Rennes cedex, France
}

KEYWORDS. 4-substituted-spirobifluorenes, spiro compounds, Phosphorescent OLEDs, Host Material, Pure Hydrocarbons, triplet energy, organic electronics

\section{Abstract}

The aim of the present review is to report the state of the art of an emerging family of molecules, namely the 4-substituted spirobifluorenes (SBFs). The syntheses, physico-chemical and photophysical properties and applications as host in Phosphorescent Organic Light-Emitting diodes (PhOLEDs) are described through a structure-properties relationship approach. If the substitution in position 2 of a SBF core has widely been developed, the substitution in position 4 is very recent (less than that 10 years) and still need to be explored.

\section{Introduction}

Spiro-configured compounds constitute one of the most important class of Organic Semi-Conductors (OSCs). ${ }^{1,2}$ In such compouds, at least two molecular $\pi$-systems with equal or different functions (emission, charge transport) are connected via a shared sp $^{3}$-hybridized atom. Such an architecture has several benefits due to the perpendicular arrangement of the $\pi$-systems and the resulting spiroconfigured OSCs present many appealing properties such as high thermal/morphological and emission colour stability, which are key properties for Organic Light-Emitting Diodes (OLED) applications. ${ }^{1-4}$

Since the discovery of the 'spiro-concept' introduced in the nineties by Salbeck et al., 9,9'spirobifluorene (SBF), which is constituted by the orthogonal junction of two fluorenyl cores via a spiro carbon, has become a central scaffold in organic electronics. ${ }^{1,2}$ Indeed, SBF is a key building block in the design of blue emitting fluorophores or host materials for blue OLEDs, which are still the weakest link of the technology. ${ }^{5}$ The SBF fragment is nevertheless not only used in the OLED technology but is also a key fragment in Organic Photovoltaic. Indeed, 2,2',7,7'-Tetrakis[N,N-di(4methoxyphenyl)amino]-9,9'-spirobifluorene (Spiro-OMeTAD) is the prevalently used hole transporting material in solid-state dye-sensitized solar cells and, more recently in perovskite-absorber solar cells. ${ }^{6,7}$ From a more fundamental point of view, the orthogonal configuration induced by the spiro carbon also allows to design shape persistent molecules with specific arrangements, which in turn has peculiar electronic consequences., 4, 8-15 In addition, the application field of the SBF scaffold is not only restricted to electronics and SBF has also found many other appealing applications as chiral ligand, ${ }^{16-19}$ electropolymerizable building block, ${ }^{20-26}$ homogeneous ${ }^{27}$ and heterogeneous ${ }^{23-25,28,29}$ catalysts or as building unit in coordination polymers, ${ }^{30-32}$ clearly showing the versatility of this fragment.

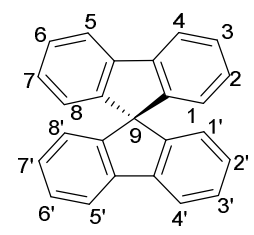

Figure 1. Nomenclature of the 9,9'-Spirobifluorene (SBF)

Sixteen positions of substitutions are available on the SBF backbone, eight on each fluorene unit (figure 1). In terms of nomenclature, the bridged carbon atom also called spiro carbon is the carbon 
numbered 9 (or 9,9' in SBF) and the eight other carbon atoms are numbered from 1 to 8 and from $1^{\prime}$ to $8^{\prime}$ for each fluorene. In this review, we will only focus on the mono-substitution of the SBF derivatives. Thus, 2-substituted SBFs remain undoubtedly the most developed class of SBF-based polymers and oligomers. ${ }^{2}$ The para linkage between the pendant substituent in position 2 and the constituted phenyl ring of the fluorene ensures a good delocalization of $\pi$-electrons, essential to develop efficient fluorophores. ${ }^{2}$ However, in recent years the growing necessity to design efficient host materials for blue PhOLED has led to a huge demand of new generations of SBF based materials with wide band gap ( $c a 4 \mathrm{eV}$ ) and hence a restricted $\pi$-conjugation. Indeed, to obtain a very high triplet energy $\left(\mathrm{E}_{\mathrm{T}}\right.$ ), key requirement in the design of host materials for blue PhOLEDs, it is mandatory to restrict the $\pi$ electrons delocalization within the OSC. To date, many successful design strategies, briefly exposed below, have been developed to disrupt the $\pi$-conjugation. First, it is known that electronic coupling through a meta linkage is inherently weaker than through a para one ${ }^{3,4,33-37}$ and this strategy has often been used to connect a hole transporting and an electron transporting unit in a host material. ${ }^{38-43}$ This meta linkage avoids strong electronic coupling between the two molecular fragments and hence keeps a high $\mathrm{E}_{\mathrm{T}}$. Using an insulating heteroatom is also an efficient strategy to obtain high $\mathrm{E}_{\mathrm{T}}$ materials with short $\pi$-conjugated pathway. Thus, silicium (silane), ${ }^{44-49}$ and phosphoryl group $(P=O),{ }^{40,44,47,50-53}$ may act as an effective breaking point of the $\pi$-conjugation between the main core of the molecule and the outer groups linked to the heteroatom (phenyl for example in the case of the efficient electron transporting diphenylphosphine oxide unit). More recently, another efficient molecular design based on a $\pi$-conjugation breaking induced by an insulating spiro bridge (Called Donor-Spiro-Acceptor design) has been also successfully introduced in literature. ${ }^{46,54-63}$ Finally, another approach widely developed in literature consists to introduce a steric congestion within the dye in order to hinder the planarization between two connected $\pi$-systems, which in turn breaks the $\pi$-conjugation between them. ${ }^{64-66}$ This 'steric hindrance' strategy is most of the time performed through the incorporation of a sterically hindered ortho linkage ${ }^{65,67,68}$ efficiently leading to a $\pi$-conjugation restriction. This last strategy is the basis of ortho linked SBFs (substitution in position 4) ${ }^{68-71}$ which will be developed in this review. 4-substituted SBFs as host for PhOLEDs have started to appear in the literature less than 10 years ago and the SBF scaffold substituted in position 4 is undoubtedly a promising core for such applications. Through a structure properties relationship approach, the aim of the present review is to report the state of the art of this emerging family of molecules regarding synthesis, physico-chemical and photophysical properties and applications as host in PhOLEDs.

\section{General synthesis of 4-Substituted SBFs}

All the dyes investigated in this review have been synthesized from the 4-bromo-9,9'-spirobifluorene (4-Br-SBF) platform (Figure 2). This platform is undoubtedly the cornerstone of all the 4-substituted SBFs reported to date. Indeed, incorporation of a molecular fragment in position 4 of a SBF is more complicated than in position 2 as the direct electrophilic substitution of SBF does not occur on the C4 position of SBF but specifically on the C2 position. ${ }^{2}{ }^{29}$ Thus, the direct incorporation of a fragment in C4 via an electrophilic aromatic substitution is not possible.
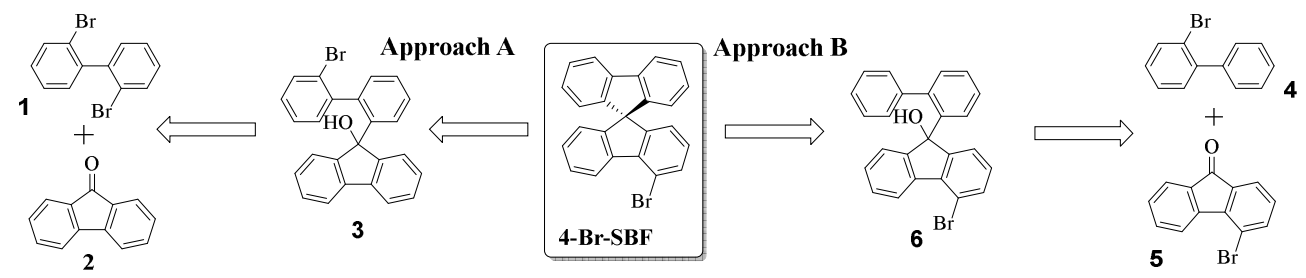

Figure 2. Retrosynthetic analyses of 4-Br-SBF (Approaches $A^{70}$ and $B^{71}$ )

First described in $1930,{ }^{72}$ SBF is obtained in a two-step route from 2-halogenobiphenyl (such as 2bromo-biphenyl 4) and 9-fluorenone 2 through a metal-halogen exchange reaction followed by an intramolecular cyclization of the resulting fluorenol to form the spiro carbon. The synthesis of the 4-BrSBF platform is based on the introduction of the bromine atom before this key cyclization step. Two 
different approaches depicted in Figures 3 and 4 have been reported and are based on the introduction of the bromine atom either on the nucleophile (biphenyl 1, Approach A-Figure 2) or on the electrophile (fluorenone 5, Approach B-Figure 2).

The first rational synthesis of 4-Br-SBF has been developed by the group of $\mathrm{Ma}$ in 2009 following the approach $A^{70}$ (Figure 2). In this approach (Figure 3), a mono lithium-halogen exchange of 2,2'dibromobiphenyl $\mathbf{1}$ is performed in the presence of $\mathrm{n}$-BuLi followed by the immediate trapping of the corresponding lithiated intermediate with 9-fluorenone $\mathbf{2}$. The intramolecular electrophilic ring closure of the corresponding fluorenol $\mathbf{3}$ (not isolated), in acidic media, further provides 4-Br-SBF. This efficient synthetic pathway allows obtaining 4-Br-SBF with $83 \%$ yield in two steps. This key platform or its pinacol analogue 4-(9,9'-spirobi[fluoren]-4-yl)-4,4,5,5-tetramethyl-1,3,2-dioxaborolane (4-Pin-SBF), synthesized with $\mathrm{n}$-BuLi and pinacol borane from 4-Br-SBF (Figure 3), will be then used to construct various 4-substituted SBFs through Pd catalysed reactions (see below).

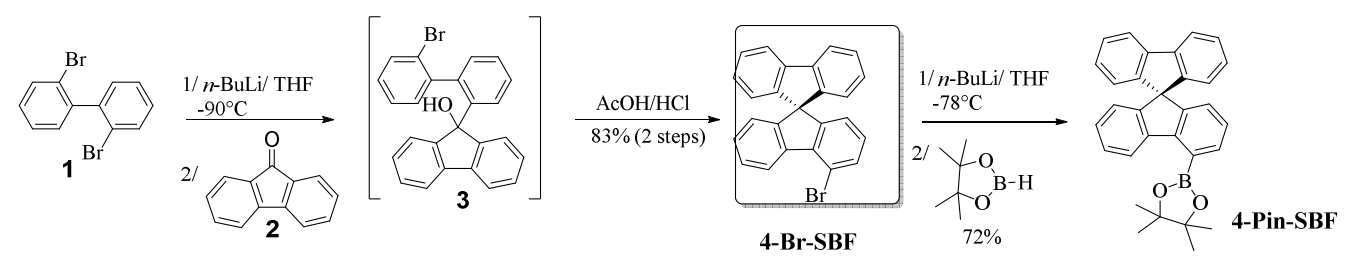

Figure 3. Synthesis of 4-Br-SBF - Approach $A^{70}$

The second approach towards 4-Br-SBF (Approach B ${ }^{71}$, Figure 2) reported in 2015 consists to fix the bromine atom on the fluorenone core (electrophile) prior to the final cyclisation. This route (Figure 4) involves the synthesis of a key building block: 4-bromo-9-fluorenone 5, which is obtained by a Miyaura-Suzuki cross-coupling between phenylboronic acid $\mathbf{7}$ possessing an ethylcarboxylate group in position 2 and 2-bromoiodobenzene 8 . The selective cross-coupling reaction proceeds with $65 \%$ yield leading to the biphenyl 9 possessing on one ring the ethylcarboxylate and on the other a bromine atom. The intramolecular electrophilic aromatic substitution in acidic media (methanesulfonic acid: $\mathrm{MsOH}$ ) leads to the formation of $\mathbf{5}$ with $95 \%$ yield. The coupling of $\mathbf{5}$ with 2-lithiated biphenyl further provides the fluorenol 6 not isolated and involved in an intramolecular ring closure to give 4-Br-SBF with high yield ( $75 \%$ over the last three steps). The overall yield of the approach $B$, ie $46 \%$, is lower than that of the approach A (83\%), ${ }^{70}$ but uses as key intermediate the versatile 4-bromo-fluorenone 5 . This molecule can be a useful building block to synthesize other families of OSCs constructed on the 4fluorene scaffold such as dicyanovinylene, ${ }^{73,}{ }^{74}$ spiroxanthene, ${ }^{75,}{ }^{76}$ spirothioxanthene, ${ }^{77}$ spirophenylacridine ${ }^{60,61}$ spiroindoloacridine ${ }^{63}$ and quinolinophenothiazine ${ }^{62}$ derivatives.

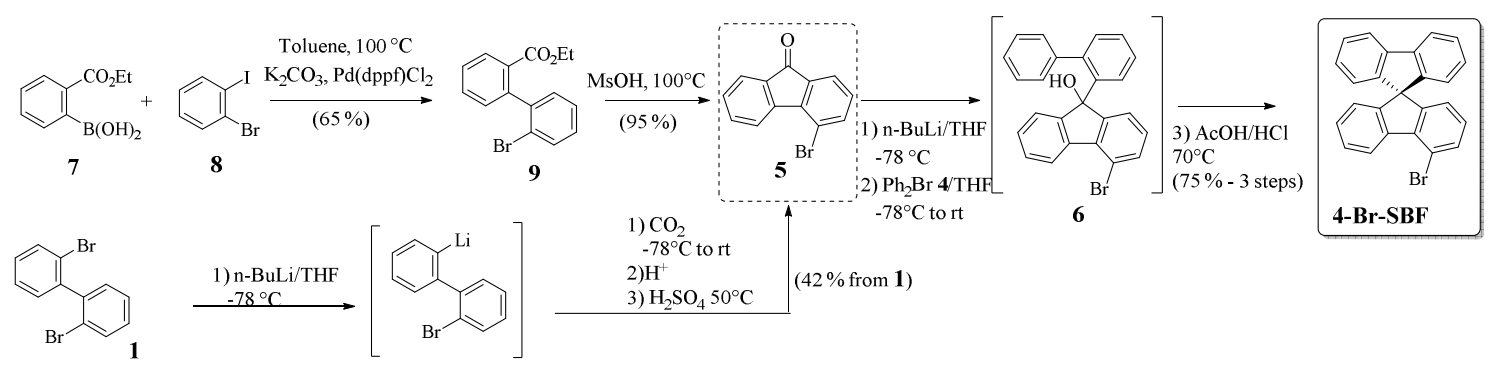

Figure 4. Synthesis of 4-Br-SBF -Approach B

Fluorenone 5 has also been synthesized by Ma et al. using a different route (Figure 4, bottom). ${ }^{69}$ Thus, 1 was treated with 1 equivalent of $\mathrm{n}$-BuLi and then reacted with carbon dioxide to form the corresponding carboxylic acid further involved in an electrophilic cyclisation to provide 5 with $42 \%$ yield.

In conclusion, all the dyes further reported herein have been synthesized from the key 4-Br-SBF or its pinacol analogue 4-Pin-SBF. These different cross-coupling reactions will be briefly developed in each part below. 


\section{Origin of the $\pi$-conjugation breaking}

4-substituted SBFs belong to the new generation of SBFs, whereas 2-substituted SBFs can be seen as the 'first generation' of SBFs. The development of OSCs based on the 4-substituted SBFs has started with the development of the PhOLED technology and the need of organic host materials with high $\mathrm{E}_{\mathrm{T}}$. Indeed, in order to obtain a very high $E_{T}$, the $\pi$-electrons delocalization within the OSC should absolutely be restricted. Determining the origin of the $\pi$-conjugation disruption found in 4-substituted SBFs is the first important question to address herein.
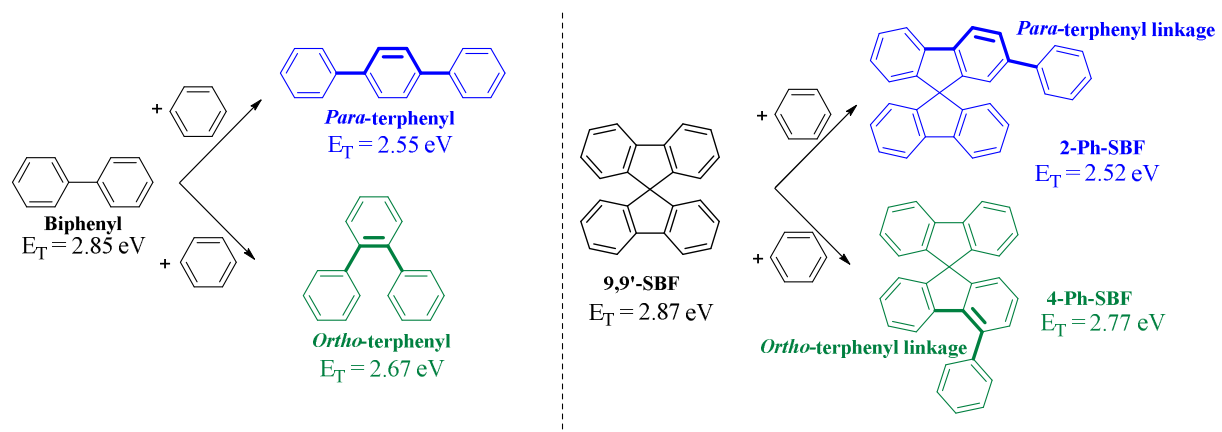

Figure 5. Biphenyl, para- and ortho-terphenyl (left) and 9,9'-SBF, 2-Ph-SBF and 4-Ph-SBF (right) and their $\mathrm{E}_{\mathrm{T}}$.

In a 4-substituted SBF, the pending substituent is in ortho position of the biphenyl linkage (Figure 5right) whereas in 2-SBF, the pending substituent is in para position. This feature is of great importance as very often an ortho linkage leads to a strong steric hindrance, which in turn can break the conjugation. ${ }^{3,36,68,78,79}$ This feature can be exemplified with the terphenyl molecules possessing either a para or an ortho linkage (figure 5, left). ${ }^{3,36}$ First, we need to mention that biphenyl has an $\mathrm{E}_{\mathrm{T}}$ of $2.85 \mathrm{eV}{ }^{80}$ Adding one phenyl unit either in ortho or in para position reduced this $\mathrm{E}_{\mathrm{T}}$ due to the $\pi$-conjugation extension, however not with the same amplitude. Indeed, in the para-terphenyl, the conjugation is maximized due to the para linkages and the $\mathrm{E}_{\mathrm{T}}$ is strongly decreased to $2.55 \mathrm{eV}$. In the ortho-terphenyl core, the ortho linkages lead to a strong steric hindrance, which maintains the $E_{T}$ at $2.67 \mathrm{eV}$, higher than that of the para-terphenyl (figure 5, left). ${ }^{3,}$
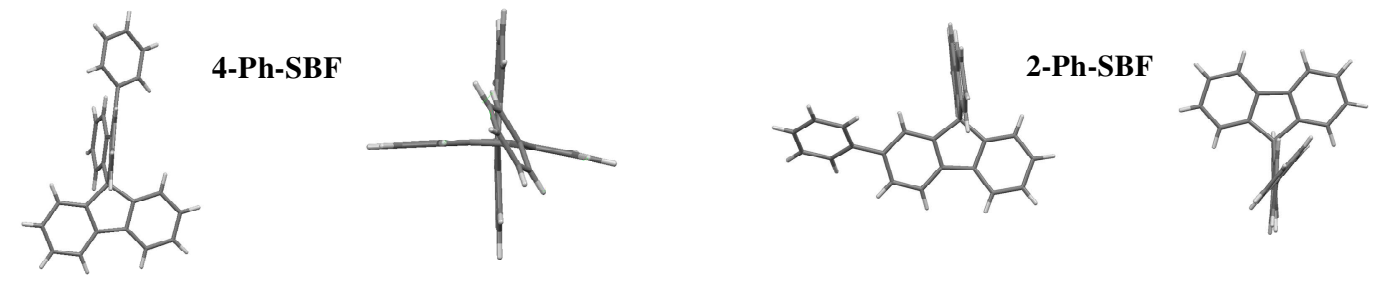

Figure 6. Molecular structure of 4-Ph-SBF (left) and of 2-Ph-SBF (right) (The asymmetric unit of both compounds contains two independent molecules, only one molecule is presented here for clarity) ${ }^{81,82}$

As 4- and 2-substituted SBFs are respectively built on an ortho- and para-terphenyl backbone, similar properties evolution is expected. From a structural point of view, the main difference between 4substituted-SBFs and 2-substituted-SBFs is found in the angle formed between the pendant substituent and its attached fluorene moiety. We will analyse this feature all along this review and particularly in this part through a representative example: the structural comparison of 4-phenylspirobifluorene (4-Ph-SBF) ${ }^{81}$ and its regioisomer 2-phenyl-spirobifluorene (2-Ph-SBF) (Figure 6). ${ }^{82}$ These two molecules are both constituted of a SBF core substituted by a phenyl ring either in position 4 for 4-Ph-SBF or in position 2 for 2-Ph-SBF. In 2-Ph-SBF, the dihedral angle between the mean plane of the pendant phenyl ring and that of its attached phenyl ring of the fluorene has been reported at $37.4^{\circ} .{ }^{82}$ This angle, characteristic of a non-encumbered phenyl/fluorene para linkage, ${ }^{83}$ maximises the conjugation between the two fragments. In its regioisomer, 4-Ph-SBF, the fluorene/phenyl dihedral angle is reported at $51.2^{\circ}$ in molecule 1 and at $56.6^{\circ}$ in molecule 2 (4-Ph-SBF indeed possesses an asymmetric unit containing two molecules 1 and 2, only the molecule 1 is presented in figure 6 for clarity purpose) being hence impressively larger than that of 2-Ph-SBF. This structural feature has been 
assigned by the authors to the steric interaction between the hydrogen atoms in ortho position of the pendant phenyl ring and those of the fluorenyl core ${ }^{81}$ and is at the origin of the $\pi$-conjugation breaking observed in all 4-substituted SBFs.

Another structural feature is detected by the authors for 4-Ph-SBF that is the intense deformation of the substituted fluorenyl core (this structural particularity will be also pointed for other 4-substituted SBFs as outlined below). Indeed, a dihedral angle as high as $12.7^{\circ}$ is measured between the phenyl units of the substituted-fluorenyl core (Figure 6 , left). Such structural deformation is more pronounced than that observed for the regioisomer 2-Ph-SBF (deformation of ca $7.1^{\circ}$ ) and for SBF $\left(1.2^{\circ}\right.$ and $\left.4.2^{\circ}\right) .{ }^{81}$,

${ }^{84}$ The deformation of the substituted fluorene in 4-Ph-SBF has been assigned to intermolecular packings, which can induce a folding of the fluorenyl core. Thus, the ortho linkage found in 4substituted SBFs has strong structural consequences, which will have important electronic repercussions. All the dyes, which will be described in the following of this review, present a large dihedral angle between the fluorene and its substituent in C4. However, we will see that this angle can be modulated depending of the nature of the substituent borne by the fluorene (see part 5).

\section{Pure hydrocarbons (PHC) based on a 4-substituted SBF scaffold}
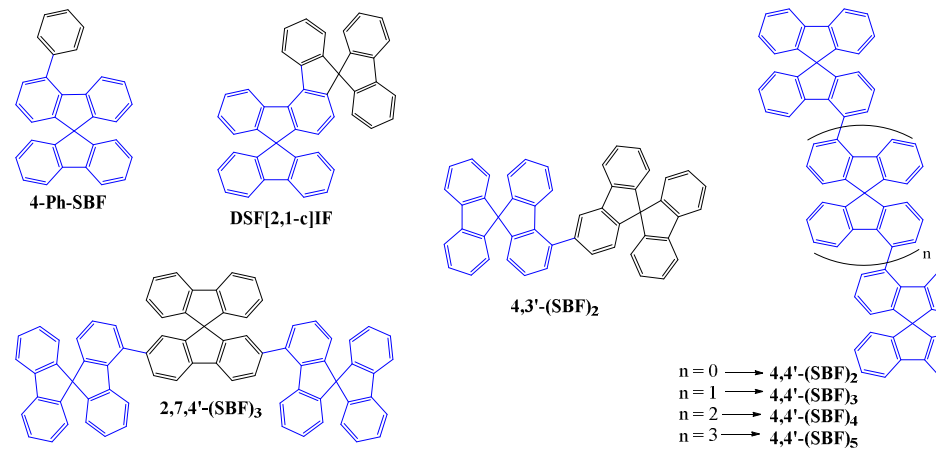

$4,3^{\prime}-(\mathrm{SBF})_{2}$

$\mathrm{n}=0 \longrightarrow 4,4^{\prime}-(\mathrm{SBF})_{2}$
$\mathrm{n}=1 \longrightarrow 4,4^{\prime}-(\mathrm{SBF})_{3}$

$\mathrm{n}=1 \longrightarrow 4,4^{\prime}-(\mathrm{SBF})_{3}$
$\mathrm{n}=2 \longrightarrow 4,4^{\prime}-(\mathrm{SBF})_{4}$

$\mathrm{n}=3 \longrightarrow 4,4^{\prime}-(\mathrm{SBF})_{5}$

Figure 7: Pure hydrocarbon (PHC) derivatives based on a 4-substituted SBF scaffold

In order to obtain high-efficiency PhOLEDs, a good charge balance is necessary in the host and many different building blocks have been used for this purpose such as indolocarbazole, ${ }^{85}$ phenylacridine, ${ }^{60}$, ${ }^{61,86}$ indoloacridine, ${ }^{63}$ phosphine oxide, ${ }^{40,53,56}$ pyridine, benzimidazole ${ }^{68}$ among others. However, it has been shown that the C-C bond is significantly stronger than the C-S, C-P or C-N bonds. ${ }^{87}$ This molecular stability of pure hydrocarbons (PHC) renders them highly attractive and designing such materials for PhOLED applications is an active research field worldwide. In this part, we will review the PHCs constructed on a 4-substituted SBF scaffold (Figure 7) and will compare their properties with those of some of their regioisomers substituted in position 2 (Figure 8).

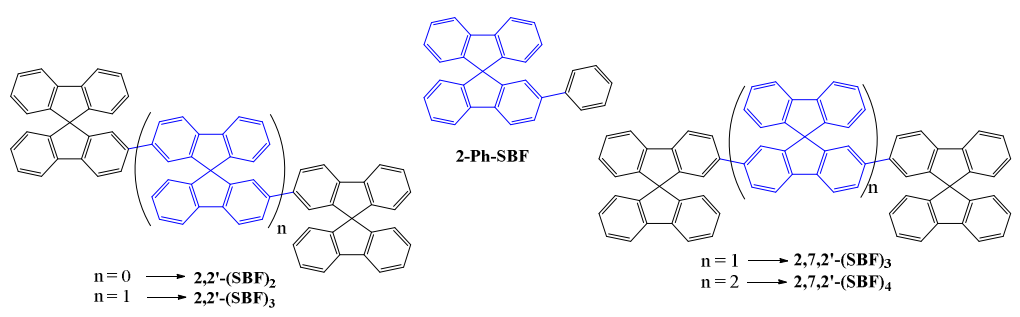

Figure 8: Pure hydrocarbon (PHC) derivatives based on a 2-substituted SBF scaffold

\section{Synthesis}

All the PHC molecules reported herein ${ }^{69-71,81,88-90}$ have been synthesized from Suzuki couplings involving 4-Br-SBF or its pinacol analogue 4-Pin-SBF as starting materials. The syntheses of the 2substituted SBFs, 2,7,2'-(SBF) $)_{3}, \mathbf{2 , 7 , 2}-(\mathrm{SBF})_{4}{ }^{90} \mathbf{2}^{2} \mathbf{2}^{\prime}-(\mathrm{SBF})_{3}, \mathbf{2}^{2} \mathbf{2}^{\prime}-(\mathrm{SBF})_{2}{ }^{89}$ and $\mathbf{2}-\mathrm{Ph}^{-\mathrm{SBF}^{71}}$ will not be described. 
Thus, 4-Ph-SBF has been synthesized by the coupling of 4-Br-SBF and phenylboronic acid through classical Suzuki conditions (Pd(dppf) $\left.\mathrm{Cl}_{2} / \mathrm{K}_{2} \mathrm{CO}_{3} / \mathrm{DMF}\right)$ with $91 \%$ yield, Figure 9. Similarly, oligo-SBFs 4,3'$(\mathrm{SBF})_{2}, \mathbf{2 , 7}, \mathbf{4}^{\prime}-(\mathrm{SBF})_{3}$ and $\mathbf{4 , 4}$ '-(SBF $)_{2}$ have been synthesized from the coupling of 4-Br-SBF with respectively spirobifluorene-3-boronic acid $\left(3-\mathrm{B}(\mathrm{OH})_{2}-\mathrm{SBF}\right), 2$,7-dibromo-spirobifluorene $\left(2,7-\mathrm{Br}_{2}-\mathrm{SBF}\right)$ and 4-Pin-SBF in good yields (81, 81 and $72 \%$ resp.).

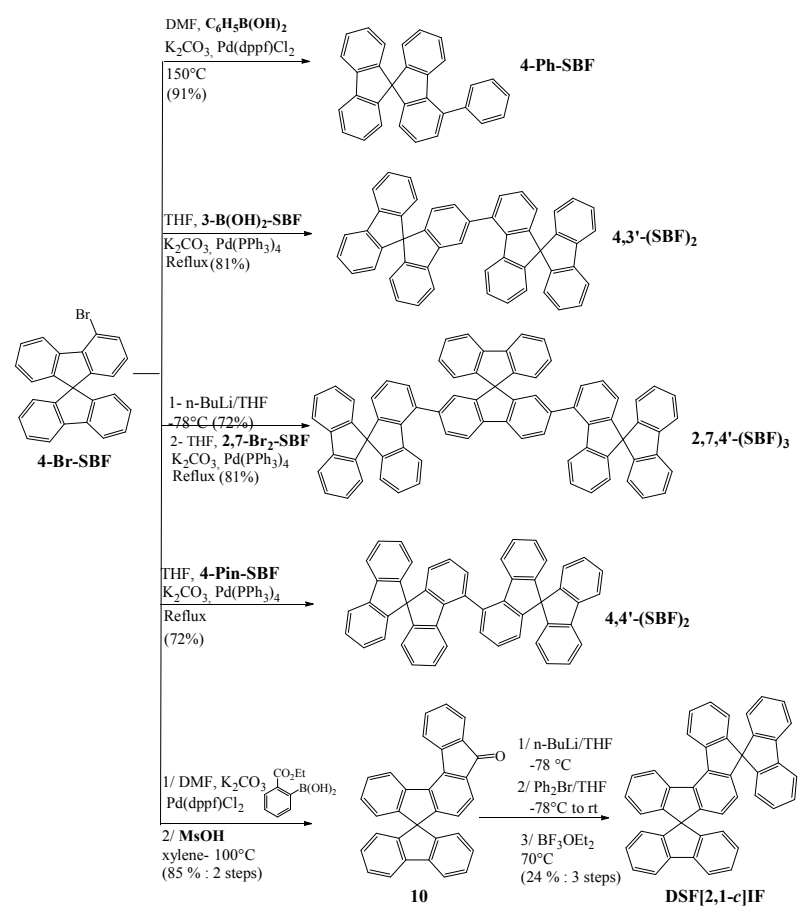

Figure 9. Synthesis of 4-Ph-SBF, 4,3'-(SBF) $2,2,7,44^{\prime}-(\mathrm{SBF})_{3}, 4,44^{\prime}-(\mathrm{SBF})_{2}, \mathrm{DSF}[\mathbf{2 , 1 - c ] I F}$ from 4-Br-SBF

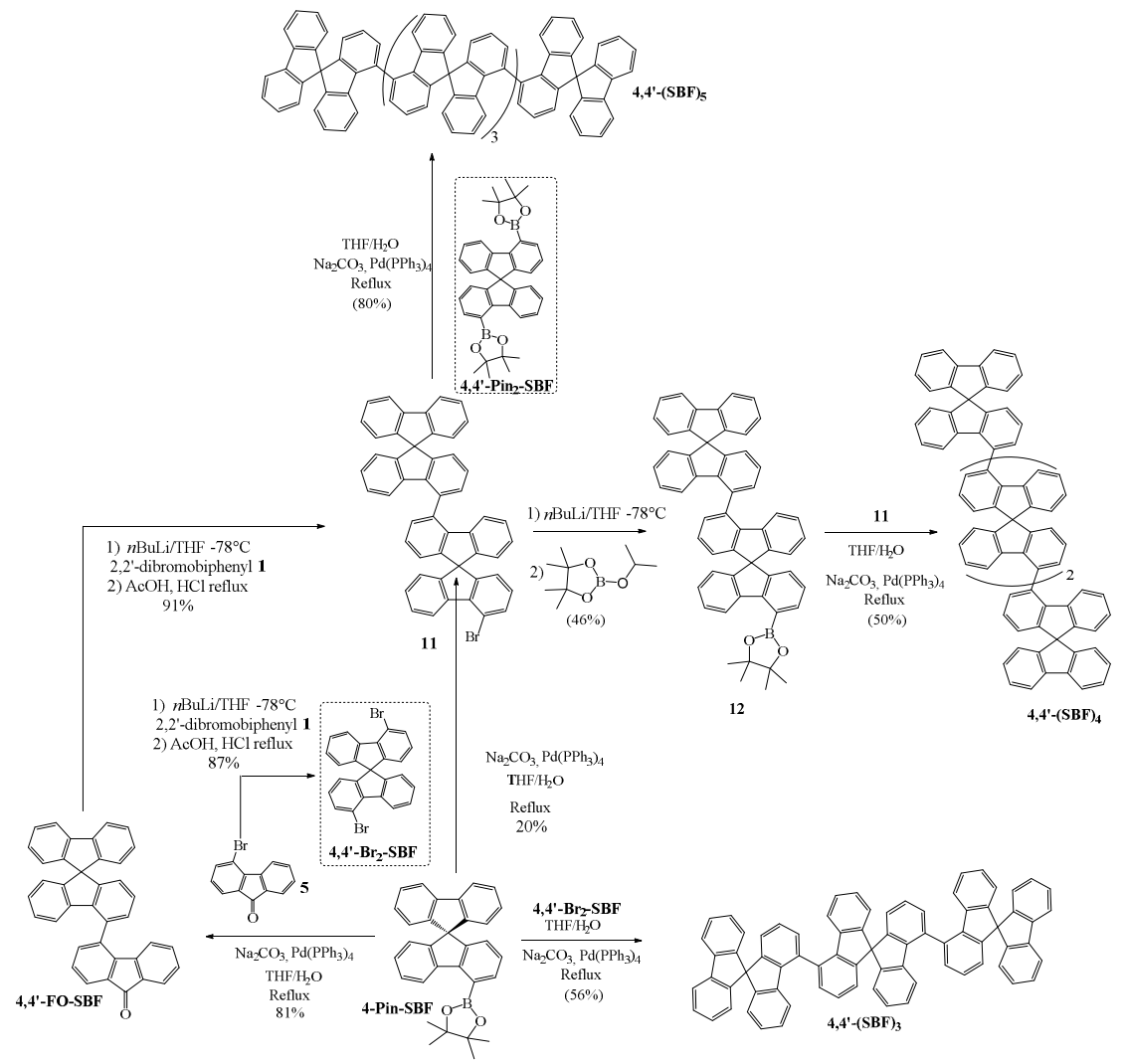

Figure 10. Synthesis of the SBF oligomers $4,4^{\prime}-(\mathrm{SBF})_{3}, \mathbf{4 , 4} \mathbf{4}^{\prime}-(\mathrm{SBF})_{4}$ and $\mathbf{4 , 4} \mathbf{4}^{\prime}-(\mathrm{SBF})_{5}$ 
Finally, DSF[2,1-c]IF can be seen as a 4-Ph-SBF fragment, whith the pendant phenyl ortho-bridged to the SBF unit in $\mathrm{C} 3$ by a second spirofluorene core. It has been synthesised in a multistep route starting from the coupling of 4-Br-SBF with 2-(ethoxycarbonyl)phenylboronic acid providing after intramolecular ring closure the spirofluorene-indeno[2,1-c]fluorenone 10. DSF[2,1-c]IF was then classically obtained by coupling the ketone 10 with 2-bromobiphenyl 4, followed by the intramolecular ring closure ( $24 \%$ yield over the three last steps). ${ }^{3}$

Access to longer oligospirobifluorenes, 4,4'-(SBF) $)_{3}, 4,4^{\prime}-(\mathrm{SBF})_{4}$ and $4,4^{\prime}-(\mathrm{SBF})_{5}$ first involved the synthesis of 4,4'-Br${ }_{2}-\mathbf{S B F}$ and its related pinacol 4,4'-Pin ${ }_{2}-\mathrm{SBF}$ (figure 10). 4,4'- $\mathbf{B r}_{2}-\mathbf{S B F}$ was synthesised by reaction of 5 with 1 equivalent of (2-bromobiphenyl-2-yl)lithium followed by an intramolecular cyclisation (87\% yield). 4,4'- $\mathbf{B r}_{2}-\mathbf{S B F}$ was then converted to its pinacol 4,4'-Pin ${ }_{2}-\mathbf{S B F}$ in classical conditions. The coupling of 4,4'- $\mathrm{Br}_{2}$-SBF with two equivalents of 4-Pin-SBF then leads to the SBF trimer $4,4^{\prime}-(\mathrm{SBF})_{3}$ in good yields (56\%). The same coupling of $4,4^{\prime}-\mathrm{Br}_{2}-\mathrm{SBF}$ with only one equivalent of 4-PinSBF leads to the brominated-SBF dimer $\mathbf{1 1}$ in a rather low yield $(20 \%)$ due to the simultaneous formation of 4,4'-(SBF) $)_{3}$. Another route to $\mathbf{1 1}$ is also reported in two steps: (i) coupling of 4-Pin-SBF with 5 leading to the 4-(4-fluorenone)-spirobifluorene 4,4'-FO-SBF and (ii) reaction of 4,4'-FO-SBF with 1 followed by an intramolecular ring-closure. This two steps route provides $\mathbf{1 1}$ with a yield of $74 \%$ (from 4-Br-SBF) being higher than the previously mentioned approach. Thus, the tetramer $\mathbf{4 , 4}-(\mathbf{S B F})_{4}$ can be synthesized by the coupling of the dimer 11 with its pinacol 12 (yield $=50 \%$ ). Finally, the pentamer 4,4'-(SBF) ${ }_{5}$ was afforded by treated one equivalents of 11 with one equivalent of 4,4'-Pin $\mathbf{2}^{-}$ SBF through Suzuki coupling ( $80 \%$ yield).

\section{Structural Properties}

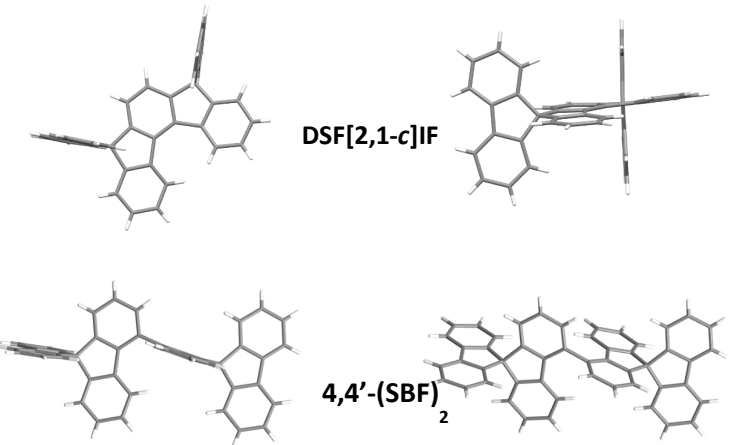

Figure 11. X-ray structures of DSF[2,1-c]IF (top) ${ }^{3}$ and $\mathbf{4 , 4} \mathbf{4}^{-}-(\mathrm{SBF})_{2}{\text { (bottom) }{ }^{70}}^{70}$

We have stressed above the importance of the dihedral angle between the pendant substituent and the fluorene. In the case of $4,4^{\prime}-(\mathrm{SBF})_{2}$, an angle as high as $88.3^{\circ}$ is reported (figure 11 -bottom) $)^{70}$ being impressively larger than that of 4-Ph-SBF $\left(c a 50^{\circ}\right) .{ }^{81}$ This angle has important consequences on the electronic properties which are described below. Unfortunately, as far as we know, no other X-ray data are reported for other PHC based on the 4-substituted SBF core with pendant groups. Dispiro[fluorene-9,5'-indeno[2,1-c]fluorene-8',9"-fluorene] (DSF[2,1-c]IF) appears as a particular example as there is no pendant group in C4 but instead a bridged spirofluorene (C4 and C3 substitution). DSF[2,1-c]IF is hence a bridged analogue of 4-Ph-SBF. Thus, in DSF[2,1-c]IF, the substituent in $\mathrm{C} 4$ is almost planar with a dihedral angle of $13^{\circ}$ between the two side phenyl rings of the dihydroindenofluorene core (figure 11-top). ${ }^{3}$ Due to this bridge rigidification and the resulting planar structure, the electronic properties appear to be different to those described for the other 4substituted SBFs (see below). This clearly shows the chief role played by the dihedral angle in such compounds.

\section{Electronic properties}


In order to describe the general behaviour of 4-substituted SBFs in absorption spectroscopy, the couple SBF/4-Ph-SBF has been choosen as a representative example. DSF[2,1-c] $\mathbf{I F}^{3}$ with its fused structure will be also used herein for comparison purpose. The UV-Vis absorption spectrum of 4-PhSBF (in cyclohexane) exhibits at low energy two thin absorption bands at 296 and $308 \mathrm{~nm}$, similar to those observed for SBF (figure 12, left) ${ }^{81,91}$ and for the other 4-substituted oligo-SBFs such as 4,4'$(\mathrm{SBF})_{2}, 4,4^{\prime}-(\mathrm{SBF})_{3}, 4,4^{\prime}-(\mathrm{SBF})_{4}$ or 4,4'-(SBF) $)_{5}{ }^{69},{ }^{70}$ However, for 4-Ph-SBF, the band at $308 \mathrm{~nm}$ clearly presents a longer wavelength tail leading to an optical energy gap $\left(\Delta \mathrm{E}^{\mathrm{opt}}\right)$ of $3.82 \mathrm{eV}$, more contracted by $0.15 \mathrm{eV}$ than that of SBF (3.97 eV). The absorption tail of 4-Ph-SBF is the consequence of the substitution in position 4. Indeed, although the $\pi$-conjugation of 4-Ph-SBF is strongly disrupted compared to that of its para-linked regioisomer 2-Ph-SBF $\left(\lambda_{\max }=319 \mathrm{~nm}, \Delta \mathrm{E}^{\mathrm{opt}}=3.70 \mathrm{eV}\right){ }^{82}$ this tail reflects nevertheless a certain degree of $\pi$-conjugation between the phenyl ring and the fluorene moiety. Thus, in 4-Ph-SBF, the $\pi$-conjugation is not completely broken but strongly disrupted. The gap contraction observed for 4-Ph-SBF is nevertheless more pronounced than that of highly twisted oligoSBFs 4,4'-(SBF) $)_{2}, 4,4^{\prime}-(\mathrm{SBF})_{3}, \mathbf{4}, \mathbf{4}^{\prime}-(\mathrm{SBF})_{4}$ or $\mathbf{4 , 4 ^ { \prime }}-(\mathrm{SBF})_{5}$ which possess a $\Delta \mathrm{E}^{\mathrm{opt}}$ of $3.93 \mathrm{eV}$, independent of the number of SBF units, ${ }^{69,70}$ being hence almost identical to that of SBF $(3.97 \mathrm{eV})$. This feature finds its origin in the very large fluorene/fluorene dihedral angle of $88.3^{\circ}$ reported for $4,4^{\prime}-(\mathrm{SBF})_{2}$ (Figure 11 , bottom), which leads to an almost complete $\pi$-conjugation interruption. ${ }^{70}$ Thus, the bulkiness induced by the presence of the substituent in $\mathrm{C} 4$ and hence the angle formed between this substituent and the fluorenyl unit has a marked effect on the $\pi$-conjugation intensity. DSF[2,1-c]IF confirms the key importance of this angle on the electronic properties of 4-substituted SBFs. Indeed, the absorption maximum of DSF[2,1-c]IF is reporded at $338 \mathrm{~nm}$, being strongly red shifted compared to those of 4-PhSBF and 4,4'-(SBF) $)_{2}$. Indeed, due to the bridge rigidification, a very small angle of only $13^{\circ}$ is reported for this molecule (Figure 11, top), and the $\pi$-conjugation is hence maximised. This feature clearly shows that the $\pi$-conjugation disruption observed in 4-substituted SBFs finds its origin in the large dihedral angle formed between the fluorene and the substituent and not in the electronic decoupling. ${ }^{4}$
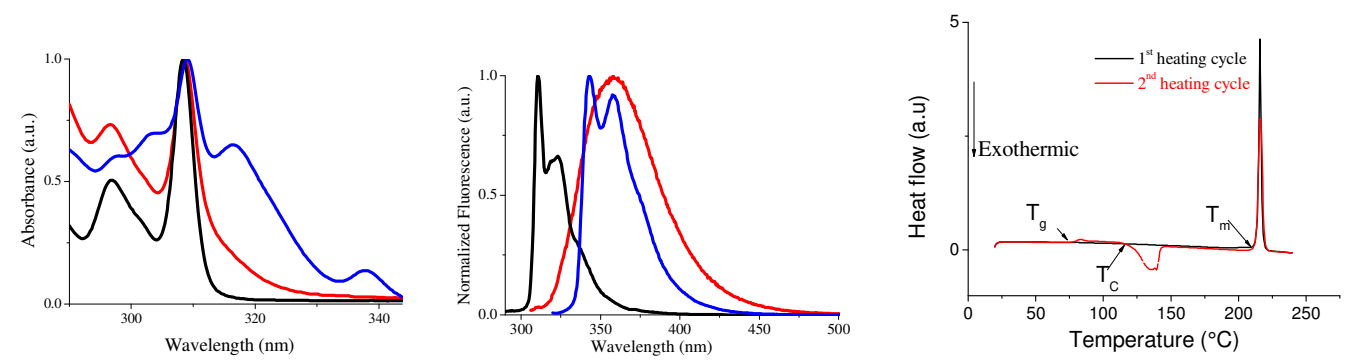

Figure 12. Absorption (left) and Emission (middle) spectra of 4-Ph-SBF (red line), DSF[2,1-c]IF (blue line) and SBF (back line) in cyclohexane, $\mathrm{C}=10^{-6} \mathrm{M}$, DSC curves of 4-Ph-SBF (right).

Despite very similar properties in the fundamental state, 4-Ph-SBF and SBF display remarkable but surprising differences in their excited states (figure 12, middle). ${ }^{81}$ Indeed, 4-Ph-SBF exhibits a structureless emission spectrum $\left(\lambda_{\max }=358 \mathrm{~nm}\right)$, noticeably different in shape and wavelength compared to that of $\mathbf{S B F},{ }^{81},{ }^{91}$ which presents a well-resolved spectrum $\left(\lambda_{\max }=310 / 323 \mathrm{~nm}\right)$ mirror image of its absorption spectrum. This large and unresolved band is found for all the dyes exclusively built on the 4-substituted SBF scaffold such as 4,4'-(SBF) $)_{2}\left(\lambda_{\max }=373 \mathrm{~nm}\right), \mathbf{4 , 4} \mathbf{4}^{\prime}-(\mathrm{SBF})_{3}, \mathbf{4 , 4} \mathbf{4}^{\prime}-(\mathrm{SBF})_{4}, \mathbf{4 , 4} \mathbf{4}^{\prime}-$ $(\mathrm{SBF})_{5}\left(\lambda_{\max }=374 \mathrm{~nm}\right){ }^{69}$ and $4,3^{\prime}-(\mathrm{SBF})_{2}\left(\lambda_{\max }=370 \mathrm{~nm}\right){ }^{88}$ This band is also found for other SBF

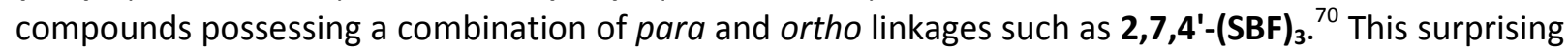
loss of resolution of the emission spectrum is also observed for the other examples of 4-substituted SBFs described in the following of this review (except 4-PhCbz-SBF (4-N-phenyl-carbazole-9,9'spirobi[fluorene]), which is a particular example precisely described in part 6). Indeed, this feature appears hence to be a unique characteristic of 4-substituted-SBF derivatives as 2-substituted-SBF analogues always present well resolved emission bands assigned to the double bond character of the $\mathrm{C}-\mathrm{C}$ bond linking the pendant substituent and the fluorenyl core in the excited state. ${ }^{8,9,83,92,93}$ Thus, $\mathbf{2 , 2}-(\mathbf{S B F})_{3}$ and $\mathbf{2 , 2} \mathbf{2}^{\prime}-(\mathbf{S B F})_{2}$ exclusively built on para linkages present a well resolved emission spectrum, 
drastically different to those of their 4-substituted analogues, namely $4,4^{\prime}-(\mathrm{SBF})_{2}$ and $4,4^{\prime}-(\mathrm{SBF})_{3}$. The same conclusion can be drawn for 2-Ph-SBF and 4-Ph-SBF. ${ }^{82}$ If it seems clear nowadays that the position of the substitution ( $C 2$ vs $\mathrm{C} 4$ ) is at the origin of this spectacular effect, no complete answer has been provided in the literature yet. ${ }^{71,81,82,94}$ However, some recent findings on 4-PhCbz-SBF (see structure in Figure 23) seem to shed light on this peculiar behaviour, which will be discussed in part 6. ${ }^{95}$ DSF[2,1-c]IF highlights the importance of the planarization on the emission properties. ${ }^{3}$ Indeed, and oppositely to the other 4-substituted-SBFs above described, DSF[2,1-c]IF presents a well-resolved emission spectrum with two thin bands at 343 and $358 \mathrm{~nm}$ (Figure 12, middle), confirming the cancelation of 'the 4-substituent effect'. This is due to the rigid and almost flat dihydroindeno[2,1c]fluorene core, which only allows very weak molecular motions.

It is always difficult to accurately compare the quantum yields of different molecules as the experimental conditions (solvent, reference etc) need to be identical. The quantum yield $\left(\Phi_{\text {sol }}\right)$ of 4-PhSBF is reported at 0.4 being identical to that of SBF and more than twice inferior to that of its regioisomer 2-Ph-SBF, $0.87 .^{71}$ The higher quantum yield of 2-Ph-SBF vs 4-Ph-SBF is explained by the authors by a combination of higher radiative rate constant $\mathrm{k}_{\mathrm{r}}\left(\mathrm{k}_{\mathrm{r}}\right.$ of $5.6 \times 10^{8}$ and $1.0 \times 10^{8} \mathrm{~s}^{-1}$ resp.) and smaller non radiative rate constant $\mathrm{k}_{\mathrm{nr}}\left(8.3 \times 10^{7}\right.$ and $1.4 \times 10^{8} \mathrm{~s}^{-1}$ resp.). The SBF oligomers $4,4^{-}-(\mathrm{SBF})_{3}$, 4,4'-(SBF) $)_{4}$ and $4,4^{\prime}-(\mathrm{SBF})_{5}$ all present similar $\Phi_{\text {sol }}$ of $0.63,0.58$ and 0.6 respectively.

To insure efficient host-guest energy transfers in the Emitting layer (EML) of a PhOLED ${ }^{96,97}$ and to avoid back energy transfers from the guest to the host, the $\mathrm{E}_{\mathrm{T}}$ of the host should be higher than that of the guest. The determination of the $E_{T}$ of an organic host is hence an important feature in this research field. As organic materials are very often not emissive from their excited triplet state $T_{1}$ at room temperature, the $E_{T}$ is usually evaluated by the first phosphorescent peak of the emission spectrum recorded at $77 \mathrm{~K}$. We have seen above, the strong impact of the SBF substitution in position 4 on the absorption and emission spectra at room temperature but what are the repercussions at $77 \mathrm{~K}$ and hence on the $\mathrm{E}_{\mathrm{T}}$ ?

First, the $E_{T}$ of $S B F$ has been reported at $2.87 \mathrm{eV}$ being slightly lower than that of its building block fluorene $\left(E_{T}=2.92 \mathrm{eV}\right){ }^{81}$ The slight conjugation between the two fluorene units in SBF (called spiroconjugation $)^{91,98-102}$ decreases the $\mathrm{E}_{\mathrm{T}}$ of $\mathrm{SBF}$ by $c a 0.05 \mathrm{eV}$ compare to fluorene. ${ }^{81,91}$ All the PHC derivatives exclusively built on ortho linkages possess a similar $E_{T}$, measured at $2.77 \mathrm{eV}$ for 4-Ph-SBF and close to

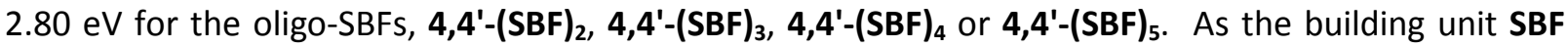
presents an $E_{T}$ of $2.87 \mathrm{eV}$, a decrease of ca $0.05 / 0.1 \mathrm{eV}$ is reported for the molecules above mentioned. This highlights that (i) the $\pi$-conjugation is not completely broken and that (i) the nature and the number of substituents do not strongly impact the $E_{\mathrm{T}}$. For comparison, 2,2'-(SBF $)_{3}$ and $\mathbf{2 , 7}, \mathbf{2}^{\prime}-(\mathbf{S B F})_{3}$, both built on para linkages possess a $\mathrm{E}_{\mathrm{T}}$ of $2.28 \mathrm{eV}^{89}$ impressively smaller than those of the ortho linked SBFs above described. Indeed, due to the para linkages of 2-substituted SBFs, there is an electronic delocalization on the two connected fluorenes and the $E_{T}$ is hence very low. Thus, the steric congestion induced by the ortho linkage of 4-substituted SBFs leads to significant $E_{T}$ increase of ca 0.5 $\mathrm{eV}$ compared to the 2-substituted analogues. This feature highlights the strong impact of the

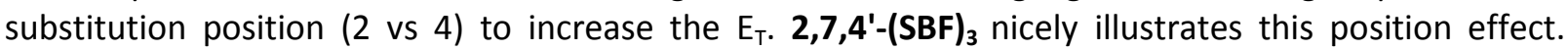
Indeed, this $\mathrm{SBF}$ trimer possesses an intermediate $\mathrm{E}_{\mathrm{T}}$ of $2.55 \mathrm{eV}$, being smaller than the fully ortho linked SBF trimer $\mathbf{4 , 4} \mathbf{4}^{\prime}-(\mathrm{SBF})_{3}$ but higher than the fully para linked one $\mathbf{2 , 2}-(\mathbf{S B F})_{\mathbf{3}}$. This is the consequence of the combination (i) of the para linkages of the 2,7-substituted SBF, which decreases the $E_{T}$ due to the extension of the conjugation and (ii) of the ortho linkages which leads to a sterically hindered environment. Similar observations can be made for the SBF dimers, which $E_{T}$ decreases from 2.81 to 2.76 and $2.3 \mathrm{eV}$ for $\mathbf{4 , 4} \mathbf{4}^{\prime}-(\mathrm{SBF})_{2}$ to $\mathbf{4 , 3} \mathbf{3}^{\prime}-(\mathrm{SBF})_{2}$ and $\mathbf{2 , 2} \mathbf{2}^{\prime}-(\mathrm{SBF})_{2}$. Interestingy, $\mathbf{4 , 3} \mathbf{3}^{\prime}-(\mathrm{SBF})_{2}$ described by Liao et al. ${ }^{88}$ is a SBF dimer possessing a different position of substitution on each SBF: a meta and an ortho linkage. The partial electronic decoupling induced by the meta substitution coupled to the steric hindrance induced by the ortho substitution leads to a high $\mathrm{E}_{\mathrm{T}}$ of $2.76 \mathrm{eV}$. Finally, DSF[2,1-c]IF, due to its extended central backbone, possesses an $E_{T}$ of $2.63 \mathrm{eV}^{3}$ being lower than those described above for the 4-substituted oligo-SBFs. Indeed, in DSF[2,1-c]IF, due to the ring bridging, the dihedral angle is small $\left(13^{\circ}\right)$ maximising hence the conjugation and in turn decreasing the $\mathrm{E}_{\mathrm{T}}$. 


\section{Thermal properties}

The thermal properties of an OSC are key features before any integration into an electronic device. Indeed, it is known that the temperature of an OLED increases upon working due to Joule effect and can reach temperature as high as $90^{\circ} \mathrm{C} .^{103}$ The stability of the constituted materials is hence of great importance to notably avoid the decomposition of the material during the device working. Two parameters play a key role: the decomposition temperature $\left(T_{d}\right)$ obtained by Thermogravimetric Analysis (TGA) and the glass transition temperature $\left(T_{g}\right)$ obtained by Differential Scanning Calorimetry (DSC). The $T_{d}$ is defined as the temperature at which the sample has lost the first $5 \%$ of its mass. ${ }^{2}{ }^{104}$ This temperature can also be seen in some cases as the sublimation temperature. Indeed, the sublimation of the material at high temperature may also lead to a total mass loss. Spiro compounds usually possess very high $T_{d}$ due to their bulky shape. ${ }^{2,104}$ 4-Ph-SBF presents a $T_{d}$ of $254^{\circ} \mathrm{C}$, slightly higher than that of its regioisomer 2-Ph-SBF and that of its building block SBF (238 and $234^{\circ} \mathrm{C} \mathrm{resp}$.). Switching from phenyl to SBF leads to a strong enhancement of the $T_{d}$ reporded at $360^{\circ} \mathrm{C}$ for $4,4^{\prime}-$ $(\mathrm{SBF})_{2}$, and at $367^{\circ} \mathrm{C}$ for its regioisomer $2,2^{\prime}-(\mathrm{SBF})_{2}$. Increasing the size of the molecule by connecting more SBF units also leads to a considerable increase of the $T_{d}\left(464^{\circ} \mathrm{C}\right.$ for $\mathbf{2 , 2}-(\mathrm{SBF})_{3}$ and $535^{\circ} \mathrm{C}$ for $\left.2,7,4^{\prime}-(\mathrm{SBF})_{3}\right)$. DSF $[2,1-c]$ IF also presents a high $\mathrm{T}_{d}$ of $347^{\circ} \mathrm{C}$, highlighting the strong impact of the bridge rigidification on the $T_{d}$.

Generally spiro compounds are also characterized by a high $\mathrm{T}_{\mathrm{g}}$, this is even one of their most appealing property. ${ }^{2,104,105}$ A characteristic example of DSC curve is presented for 4-Ph-SBF (Figure 12, right). 4Ph-SBF presents on the first heating, a sharp endothermic peak at $216^{\circ} \mathrm{C}$ associated to its melting. When the isotropic liquid was cooled down, no recristallization occurs and the cooling leads then to an amorphous solid. When the amorphous glass was heated again, a $T_{\mathrm{g}}$ was detected at $76^{\circ} \mathrm{C}$ (from peak onset). On further heating above the $\mathrm{T}_{\mathrm{g}}$, an exothermic peak caused by crystallization was observed at $139^{\circ} \mathrm{C}$ followed by the sharp endothermic fusion peak at $216^{\circ} \mathrm{C}$. This thermal behaviour is typical of organic glasses. ${ }^{2,} 106$ Thus, 4-Ph-SBF possesses a $\mathrm{T}_{\mathrm{g}}$ almost identical to that of its isomer 2-Ph-SBF $\left(T_{g}=78^{\circ} \mathrm{C}\right)$. Switching from phenyl in 4-Ph-SBF/2-Ph-SBF to SBF in $\mathbf{4 , 4}-(\mathrm{SBF})_{\mathbf{2}} / \mathbf{2}, \mathbf{2}^{\prime}-(\mathrm{SBF})_{2}$, leads to a significant $\mathrm{T}_{\mathrm{g}}$ increase respectively reported at 170 and $174^{\circ} \mathrm{C}$. Thus, the substituent borne by the SBF has a strong impact on its $\mathrm{T}_{\mathrm{g}}$ but the position of substitution (4 vs 2$)$ not. This is also highlighted for the other SBF dimers. Indeed, 4,4'-(SBF) ${ }_{2}, \mathbf{4}^{\prime} \mathbf{3}^{\prime}-(\mathrm{SBF})_{2}, \mathbf{2 , 2} \mathbf{2}^{\prime}-(\mathrm{SBF})_{2}$ all possess a $\mathrm{T}_{\mathrm{g}}$ at $170^{\circ} \mathrm{C} / 180^{\circ} \mathrm{C}$ being hence weakly dependent on the substitution. However, the incorporation of extra SBF fragments in 4,4'-(SBF) $)_{3}, 4,4^{\prime}-(\mathrm{SBF})_{4}$ and $4,4^{\prime}-(\mathrm{SBF})_{5}$ has a significant impact as it leads to a further $\mathrm{T}_{\mathrm{g}}$ increase, reported at 244,280 and $326^{\circ} \mathrm{C}$ resp.. Thus, as the number of SBF units increases, the $T_{g}$ increases as well. Thus, we have shown above that the electronic properties and notably the $E_{T}$ is identical for the four oligomers (ca $2.8 \mathrm{eV}$ ), whereas the $T_{\mathrm{g}}$ is strongly increased by $156^{\circ} \mathrm{C}$ from $4,4^{\prime}-(\mathrm{SBF})_{2}$ to $4,4^{\prime}-(\mathrm{SBF})_{5}$. This is one of the key advantages of the spiro bridge: keeping an electronic property and enhancing the physical properties.

Table 1. Selected electronic and physical data for PHC compounds presented in part 4

\begin{tabular}{|c|c|c|c|c|c|c|c|c|c|}
\hline & $\lambda_{\mathrm{abs}}(\mathrm{nm})$ & $\lambda_{\text {fluo }}(\mathrm{nm})$ & $E_{\mathrm{T}}(\mathrm{eV})$ & $\Phi_{\text {sol }}$ & $\mathrm{HOMO}^{\mathrm{a}}$ & LUMO & $\Delta E_{\mathrm{opt}}{ }^{e}$ & $\mathrm{~T}_{\mathrm{g}}$ & $T_{d}$ \\
\hline 4-Ph-SBF ${ }^{81}$ & 308 (+ sh) & 358 & 2.77 & 0.4 & $-5.95^{a}$ & $-1.95^{\mathrm{a}}$ & 3.82 & 76 & 254 \\
\hline 2-Ph-SBF ${ }^{71}$ & 319 & 335,351 & 2.56 & 0.84 & $-5.88^{a}$ & $-2.10^{\mathrm{a}}$ & 3.70 & 78 & 238 \\
\hline SBF $^{81}$ & 308 & 310,323 & 2.87 & 0.40 & $-5.94^{a}$ & $-1.89^{a}$ & 3.97 & no & 234 \\
\hline $4,4^{\prime}-(\mathrm{SBF})_{2}{ }^{70}$ & 309 & 373 & 2.81 & - & - & - & - & 170 & 360 \\
\hline $4,4^{\prime}-(\mathrm{SBF})_{3}{ }^{69}$ & 308 & 374 & 2.80 & 0.63 & $-6.08^{a}$ & $-2.15^{c}$ & 3.93 & 244 & - \\
\hline $4,4^{\prime}-(\mathrm{SBF})_{4}{ }^{69}$ & 308 & 374 & 2.80 & 0.58 & $-6.08^{a}$ & $-2.15^{c}$ & 3.93 & 280 & - \\
\hline $4,4^{\prime}-(\mathrm{SBF})_{5}{ }^{69}$ & 308 & 374 & 2.80 & 0.60 & $-6.08^{a}$ & $-2.15^{c}$ & 3.93 & 326 & - \\
\hline $4,3^{\prime}-(\mathrm{SBF})_{2}{ }^{88}$ & 318 & 370 & 2.76 & - & $-5.76^{b}$ & $-2.11^{c}$ & 3.65 & 177 & 407 \\
\hline$D S F[2,1-c] I F^{3}$ & 338 & 343,358 & 2.63 & 0.5 & -5.87 & -2.00 & 3.60 & no & 347 \\
\hline $2,7,4^{\prime}-(\mathrm{SBF})_{3}{ }^{70}$ & $309 / 325$ & 390 & 2.55 & - & - & - & - & 232 & 535 \\
\hline $2,2^{\prime}-(\mathrm{SBF})_{2}{ }^{89}$ & 333 & $367 / 387$ & 2.30 & $0.66^{d}$ & - & - & - & 174 & 367 \\
\hline $2,2^{\prime}-(\mathrm{SBF})_{3}{ }^{89}$ & 333 & $367 / 387$ & 2.28 & $0.56^{d}$ & - & - & - & 228 & 464 \\
\hline
\end{tabular}




$$
\begin{aligned}
& \begin{array}{llllllllll}
\mathbf{2 , 7 , 2}-(\mathrm{SBF})_{3}{ }^{90} & 350 & - & - & - & - & - & - & 237 & -
\end{array}
\end{aligned}
$$

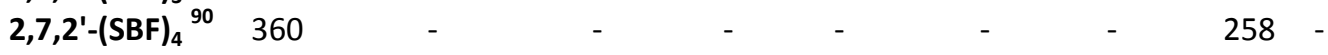

${ }^{\text {a. }}$ From $\mathrm{CV},{ }^{\text {b. }}$ from UPS, ${ }^{\text {c. }}$ from $\Delta E^{\text {opt }}$ and HOMO, ${ }^{\text {d. }}$ as thin film with an integrated sphere, ${ }^{\text {e. }}$ from the absorption spectrum $\lambda_{\text {onset, }}-{ }^{-:}$not reported in literature, no: not observed

\section{Phosphorescent OLEDs}

Performances of red, green or blue PhOLEDs using the 4-substituted SBFs as hosts are presented below. The red emitting Iridium complexes used below are bis(2,4-diphenylquinolyl$\left.\mathrm{N}, \mathrm{C2} 2^{\prime}\right)$ iridium(acetylacetonate) $\quad\left((\mathrm{ppq})_{2} \mathrm{Ir}(\mathrm{acac})\right) \quad\left(\mathrm{E}_{\mathrm{T}}: \quad 2.01 \mathrm{eV}\right) \quad$ or $\quad$ bis[2-(20-benzo[4,5a]thienyl)pyridinato- $\mathrm{N}, \mathrm{C} 30]$ iridium(acetylacetonate) $\left((\mathrm{Btp})_{2} \mathrm{Ir}(\mathrm{acac})\right)\left(\mathrm{E}_{\mathrm{T}}: 2 \mathrm{eV}\right){ }^{89}$ the green emitting one is tris[2-phenylpyridinato- $\left.\mathrm{C}^{2}, N\right]$ iridium(III) $\left(\operatorname{Ir}(\mathrm{ppy})_{3}\right)\left(\mathrm{E}_{\mathrm{T}}: 2.42 \mathrm{eV}\right)$, and the sky blue emitting one is bis[2-(4,6-difluorophenyl)pyridinato- $\left.\mathrm{C}^{2}, N\right]$ (picolinato)iridium(III) (FIrpic) $\left(\mathrm{E}_{\mathrm{T}}: 2.62 \mathrm{eV}\right) .{ }^{107}$

Table 2. Selected EL data of red, green and blue devices using PHC compounds presented in part 4

\begin{tabular}{|c|c|c|c|c|c|c|}
\hline $\begin{array}{l}\text { Host } \\
E_{T}\end{array}$ & $\begin{array}{l}\text { Dopant } \\
\text { doping level }\end{array}$ & $V_{\text {on }}(V)$ & E.Q.E (\%) & $C E(c d / A)$ & PE (Im/W) & Ref \\
\hline \multicolumn{7}{|c|}{ Red Devices } \\
\hline $\begin{array}{l}2,2^{\prime}-(\mathrm{SBF})_{3}{ }^{\mathrm{a}} \\
2.28 \mathrm{eV} \\
2,7,4^{\prime}-(\mathrm{SBF})_{3}{ }^{\mathrm{b}} \\
2.55 \mathrm{eV}\end{array}$ & $\begin{array}{l}\text { Btp }_{2} \operatorname{Ir}(\mathrm{acac}) \\
8 \mathrm{wt} \% \\
(\mathrm{ppq})_{2} \operatorname{Ir}(\mathrm{acac}) \\
6 \text { wt } \%\end{array}$ & $2.5 / 3.0$ & $\begin{array}{l}8.6 \\
@ 0.3 \mathrm{~mA} / \mathrm{cm}^{2} \\
10.5 \\
\text { (max value) }\end{array}$ & $\begin{array}{l}8.4 \\
\text { (max value) }\end{array}$ & $\begin{array}{l}4 \\
\text { (max value) } \\
4.1 \\
\text { (max value) }\end{array}$ & 70 \\
\hline \multicolumn{7}{|c|}{ Green Devices } \\
\hline $2,7,4^{\prime}-(\mathrm{SBF})_{3}{ }^{b}$ & $\operatorname{Ir}(p p y)_{3}$ & 4 & 12.6 & 48.2 & 26.8 & 70 \\
\hline $2.55 \mathrm{eV}$ & 8 wt \% & & (max value) & (max value) & (max value) & \\
\hline $4,4^{\prime}-(\mathrm{SBF})_{3}{ }^{\mathrm{C}}$ & $\operatorname{Ir}(p p y)_{3}$ & - & 17.3 & 66 & 46 & 69 \\
\hline $2.80 \mathrm{eV}$ & 11 wt \% & & (max value) & (max value) & (max value) & \\
\hline SBF $^{d}$ & $\operatorname{Ir}(\mathrm{ppy})_{3}$ & 3.1 & 8.5 & 33.4 & 20.5 & 81 \\
\hline $2.87 \mathrm{eV}$ & 9 wt \% & $@ 1 \mathrm{~cd} / \mathrm{m}^{2}$ & (max value) & (max value) & (max value) & \\
\hline 4-Ph-SBF ${ }^{d}$ & $\operatorname{Ir}(\mathrm{ppy})_{3}$ & 3.5 & 10.4 & 48.1 & 36 & 81 \\
\hline $2.77 \mathrm{eV}$ & 9 wt $\%$ & $@ 1 \mathrm{~cd} / \mathrm{m}^{2}$ & (max value) & (max value) & (max value) & \\
\hline $\operatorname{DSF}[2,1-c] I F^{d}$ & $\operatorname{Ir}(p p y)_{3}$ & 3.0 & 13.3 & 49.0 & 26.6 & 3 \\
\hline $2.63 \mathrm{eV}$ & 10 wt $\%$ & $@ 1 \mathrm{~cd} / \mathrm{m}^{2}$ & (max value) & (max value) & (max value) & \\
\hline
\end{tabular}

\begin{tabular}{|c|c|c|c|c|c|c|}
\hline \multicolumn{7}{|c|}{ Sky-blue Devices } \\
\hline $4,4^{\prime}-(\mathrm{SBF})_{3}{ }^{\mathrm{C}}$ & FIrpic & - & 11.6 & 25 & 17 & 69 \\
\hline $2.80 \mathrm{eV}$ & 8 wt \% & & (max value) & (max value) & (max value) & \\
\hline $4,3^{\prime}-(S B F)_{2}$ & FIrpic & 3.0 & 22 & 44.5 & 36.5 & 88 \\
\hline $2.76 \mathrm{eV}$ & 8 wt \% & & (max value) & (max value) & (max value) & \\
\hline SBF $^{d}$ & FIrpic & 3.3 & 6.6 & 20.6 & - & 81 \\
\hline $2.87 \mathrm{eV}$ & 19 wt \% & @ $1 \mathrm{~cd} / \mathrm{m}^{2}$ & (max value) & (max value) & & \\
\hline 4-Ph-SBF ${ }^{d}$ & FIrpic & 4.0 & 5.7 & 18.4 & - & 81 \\
\hline $2.77 \mathrm{eV}$ & 19 wt \% & @ $1 \mathrm{~cd} / \mathrm{m}^{2}$ & (max value) & (max value) & & \\
\hline
\end{tabular}

- : not reportedDevice structure ${ }^{a}:$ ITO/PEDOT-PSS(30 nm)/TCTA $(30 \mathrm{~nm}) /$ Host-Guest(30 nm)/BCP(10 nm)/Alq $3(60 \mathrm{~nm}) / \mathrm{LiF}(0.5 \mathrm{~nm}) / \mathrm{Al}$,

${ }^{\mathrm{b}}: \mathrm{ITO} / \mathrm{MoO}_{3}(10 \mathrm{~nm}) / \mathrm{NPB}(40 \mathrm{~nm}) /$ Host-Guest$(30 \mathrm{~nm}) / \mathrm{BCP}(10 \mathrm{~nm}) / \mathrm{Alq}_{3}(30 \mathrm{~nm}) / \mathrm{LiF}(1 \mathrm{~nm}) / \operatorname{Al}(100 \mathrm{~nm})$

c: ITO/MoO $3(10 \mathrm{~nm}) / \mathrm{NPB}(80 \mathrm{~nm}) / \mathrm{TCTA}(5 \mathrm{~nm}) /$ Host-Guest $(20 \mathrm{~nm}) / \mathrm{TPBi}(30 \mathrm{~nm}) / \mathrm{LiF}(1 \mathrm{~nm}) / \mathrm{Al}(120 \mathrm{~nm})$

${ }^{d}$ : ITO/CuPc(10 nm)/NPB(40 nm)/TCTA(10 nm)/ Host-Guest $(20 \mathrm{~nm}) / \operatorname{TPBi}(40 \mathrm{~nm}) / \operatorname{LiF}(1.2 \mathrm{~nm}) / \operatorname{Al}(100 \mathrm{~nm})$

The first example has been reported with the trimer $2, \mathbf{2}^{\prime}-(\mathrm{SBF})_{3}{ }^{89}$ Due to its low $\mathrm{E}_{\mathrm{T}}$ of $2.28 \mathrm{eV}$, this molecule has been only incorporated in a red device with the following architecture ITO/PEDOT$\mathrm{PSS}(30 \mathrm{~nm}) / \mathrm{TCTA}(30 \mathrm{~nm}) / \mathbf{2}, \mathbf{2}^{\prime}-(\mathrm{SBF})_{3}:(\mathrm{Btp})_{2} \mathrm{Ir}(\mathrm{acac})(30 \mathrm{~nm}) / \mathrm{BCP}(10 \mathrm{~nm}) / \mathrm{Alq}_{3}(60 \mathrm{~nm}) / \mathrm{LiF}(0.5 \mathrm{~nm}) / \mathrm{Al}$. This device, with the red phosphor (Btp) ${ }_{2} \operatorname{Ir}(\mathrm{acac})$ in $8 \mathrm{wt} \%$, presents a maximal External Quantum Efficiency (EQE) of $8.6 \%$ and a maximal Power Efficiency (PE) of $4 \mathrm{~lm} / \mathrm{W}$. As above mentioned, switching from

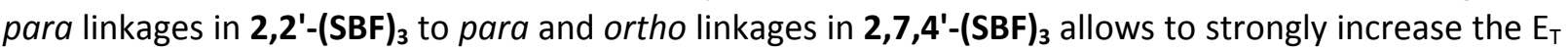
(from 2.28 to $2.55 \mathrm{eV}$, Table 1). Thus, 2,7,4'-(SBF) ${ }_{3}$ was used as host not only in red emitting devices 
(dopant $(\mathrm{ppq})_{2} \operatorname{Ir}(\mathrm{acac})$ ) but also in green emitting ones (dopant $\left.\operatorname{Ir}(\mathrm{ppy})_{3}\right)$ with the following

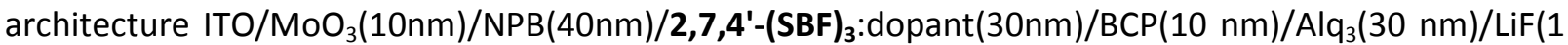
$\mathrm{nm}) / \mathrm{Al}(100 \mathrm{~nm}) .{ }^{70}$ With the green dopant $\operatorname{Ir}(\mathrm{ppy})_{3} 8 \mathrm{wt} \%$, the device displays a Current Efficiency (CE) of $48.2 \mathrm{~cd} / \mathrm{A}$, a maximum PE of $26.8 \mathrm{~lm} / \mathrm{W}$ and an EQE of $12.6 \%$. The performance is lower with the red dopant (ppq) $)_{2} \mathrm{r}(\mathrm{acac})$ in $6 \mathrm{wt} \%$, with a CE of $8.4 \mathrm{~cd} / \mathrm{A}$, a PE of $4.1 \mathrm{~lm} / \mathrm{W}$ and a maximum EQE of $10.5 \%$.

The trimer 4,4'-(SBF) ${ }_{3}$ has been incorporated in both green and blue PhOLEDs. ${ }^{69}$ The structure was ITO/ $\mathrm{MoO}_{3}(10 \mathrm{~nm}) / \mathrm{NPB}(80 \mathrm{~nm}) / \mathrm{TCTA}(5 \mathrm{~nm}) / 4,4^{\prime}-(\mathrm{SBF})_{3}$ :dopant(20nm)/TPBi(30nm)/LiF(1nm)/Al(120nm). The green device $\left(\operatorname{Ir}(\mathrm{ppy})_{3} 11 \mathrm{wt} \%\right)$ displays a max EQE of $17.3 \%$, a CE of $66 \mathrm{~cd} / \mathrm{A}$ and a PE of $46 \mathrm{Im} / \mathrm{W}$ and the sky blue device (FIrpic 8 wt \%) displays a max EQE of 11.6\%, a CE of $25 \mathrm{~cd} / \mathrm{A}$ and a PE of 17 $\mathrm{Im} / \mathrm{W}$.

In this research field, it is always difficult to accuretaly compare the efficiency of a host within a device. Indeed, the device structure (and not only the host) has a strong importance in the performance. Thus and in order to accurately compare the performance of the hosts, the device architecture should be strictly identical. In the literature, the device performances are presented in many different ways (maximum values or at 1 or $10 \mathrm{~mA} / \mathrm{cm}^{2}$ principally) rendering their comparison very difficult.

Interestingly, as 4-Ph-SBF, SBF and DSF[2,1-c] IF have been incorporated as host in PhOLEDs possessing an identical architecture, the different device performances can be hence only imputed to the host. The device configuration was: ITO/CuPc(10 nm)/NPB $(40 \mathrm{~nm}) / \operatorname{TCTA}(10 \mathrm{~nm}) / \operatorname{Host}: \operatorname{Ir}(\mathrm{ppy})_{3}(20 \mathrm{~nm})$ or Host: Flrpic(20 nm)/TPBi(40 nm)/LiF(1.2 nm)/Al(100 nm) for green or blue devices respectively. The green device with 4-Ph-SBF:Ir(ppy $)_{3}$ in $9 \mathrm{wt} \%$ as EML has a low threshold voltage $\mathrm{V}_{\text {on }}$ of $3.5 \mathrm{~V}$, with maximum CE and PE of $48.1 \mathrm{~cd} / \mathrm{A}$ and $36 \mathrm{~lm} / \mathrm{W}$ resp., equivalent to an EQE of $10.4 \%{ }^{81} \mathrm{SBF}$ in identical conditions presents lower performance ( $C E=33.4 \mathrm{~cd} / \mathrm{A}, \mathrm{PE}=20.5 \mathrm{Im} / \mathrm{W}$ and $\mathrm{EQE}=8.5 \%)$ with nevertheless a slightly lower $\mathrm{V}_{\text {on }}$ of $3.1 \mathrm{~V} .^{81}$ Thus, the incorporation in $\mathrm{C} 4$ of a phenyl ring in 4-Ph-SBF allows increasing the EQE of green devices, highlighting the efficiency of this design. Device with DSF[2,1-c]IF:Ir(ppy $)_{3}$ in $10 \mathrm{wt} \%$ as EML presents the highest performance in the series with CE $=49.0$ $\mathrm{cd} / \mathrm{A}, \mathrm{PE}=26.6 \mathrm{Im} / \mathrm{W}, \mathrm{EQE}=13.3 \%$ and $\mathrm{V}_{\mathrm{on}}=3 \mathrm{~V}$. $^{3}$ Thus, the performance follows the trend: DSF[2,1c] IF $>4-\mathrm{Ph}-\mathrm{SBF}>\mathrm{SBF}$, indicating that the C4-substitution and the bridge rigidification both have a key role in the PhOLED performance.

Blue PhOLEDs appear to follow a different trend, highlighting the difficulty to design universal hosts. Indeed, with SBF as host (FIrpic: $19 \mathrm{wt} \%$ ), the device presents a CE of $20.6 \mathrm{~cd} / \mathrm{A}$, an EQE of $6.6 \%$ with a $\mathrm{V}_{\text {on }}$ of $3.3 \mathrm{~V}$ whereas with 4-Ph-SBF as host (FIrpic $19 \mathrm{wt} \%$ ), the device efficiency is slightly lower (EQE= $5.7 \%$ and $C E=18.4 \mathrm{~cd} / \mathrm{A}$ ). ${ }^{81}$ Due to its $\mathrm{E}_{\mathrm{T}}$ of $2.63 \mathrm{eV}$, almost identical to that of FIrpic, DSF[2,1-c]lF has not been incorporated in a blue device. ${ }^{3}$

Finally, the best performance for such PHC derivatives has been reported by Liao, Jiang and their coworkers with the ortho/meta dimer 4,3'-(SBF) ${ }_{2}{ }^{88}$ The device configuration was : ITO/HAT-CN $(10 \mathrm{~nm}) /$ $\operatorname{TAPC}(40 \mathrm{~nm}) / 4,3^{\prime}-(\mathrm{SBF})_{2}$ :FIrpic(8wt\%)(20nm)/TmPyPB $(45 \mathrm{~nm}) / \mathrm{Liq}(2 \mathrm{~nm}) / \mathrm{Al}(120 \mathrm{~nm})$. With such device, the authors report a very high maximum EQE of $22 \%$ with corresponding CE of $44.5 \mathrm{~cd} / \mathrm{A}$ and PE of $36.5 \mathrm{~lm} / \mathrm{W}$ and $a V_{\text {on }}$ of $3.0 \mathrm{~V}$. The authors explain this high performance by a combination of two main parameters. First, the MLCT absorption of Flrpic is largely overlapped with the emission of $4,3^{\prime}-(\mathrm{SBF})_{2}$ implying effective energy transfers from $4,3^{\prime}-(\mathbf{S B F})_{2}$ to Flrpic and second, the ambipolar character of $4, \mathbf{3}^{\prime}-(\mathrm{SBF})_{2}$, which is a key feature for charge transport. 


\section{4-Substituted SBF incorporating electron accepting units.}

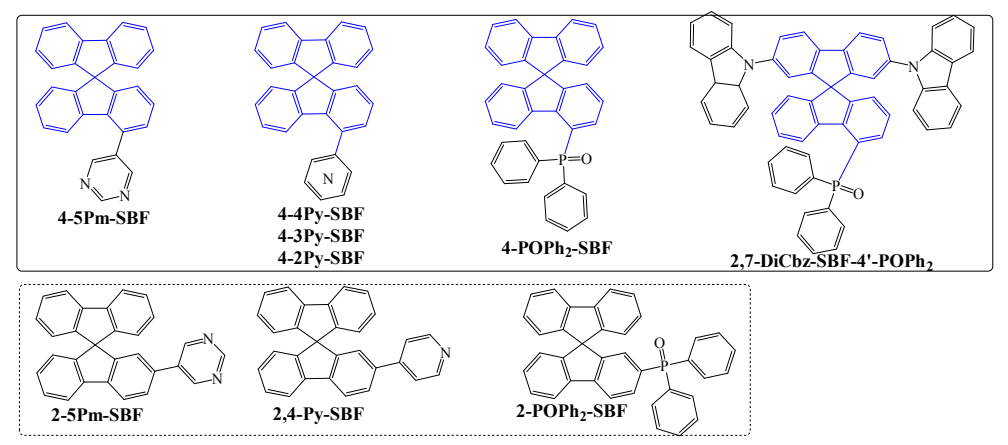

Figure 13: 4-(Top) and 2-(bottom) substituted SBFs incorporating electron-withdrawing fragments

Numbers of electron withdrawing functionalities have been introduced on the SBF scaffold in order to make the electronic properties of the resulting dyes fitting with a specific application. ${ }^{2}$ For that purpose, electron-deficient heterocycles such as $1,3,4$-oxadiazoles, ${ }^{108,66,}{ }^{109}$ pyridine ${ }^{110}$ quinoline, ${ }^{111}$ quinoxaline ${ }^{112}$ pyrimidine, ${ }^{113,114}$ and pyridopyrazine ${ }^{115}$ have been introduced on the SBF core but most of the time in 2, 2' and/or 7, 7' positions. As 4-substituted SBFs remain weakly studied to date, only few examples incorporating electron-accepting fragments have been reported as host in PhOLEDs.

Diphenyl-9,9'-spirobi[9H-fluoren]-4-yl-phosphine oxide (4-POPh ${ }_{2}$-SBF) first reported by Lee and coworkers in 2010 is built on a SBF backbone possessing in position 4 a phosphine oxide group. ${ }^{116}$ Our group has reported in 2015 a structurally related compound, namely 2,7-DiCbz-SBF-4'-POPh $\mathbf{2}\left(9,9^{\prime}-\left(4^{\prime}\right.\right.$ diphenyl-phosphine oxide-9,9'-spirobi[9H-fluorene]-2,7-diyl)bis-9H-carbazole). ${ }^{53}$ This molecule is similar to 4-POPh ${ }_{2}-\mathbf{S B F}$ as it possesses a 4-phosphine oxide-fluorene but the spirolinked fluorene is flanked with two $\mathrm{N}$-carbazoles units in positions $2^{\prime}$ and $7{ }^{\prime}$. The four other examples incorporate in $\mathrm{C} 4$ either a 5-pyrimidine ring (4-5Pm-SBF) ${ }^{82}$ or pyridine isomers (4-4Py-SBF, 4-3Py-SBF and 4-2Py-SBF). ${ }^{71}$ In a structure properties relationship approach, 2-substituted analogues incorporating either a 4pyridine (2-4Py-SBF), a 5-pyrimidine (2-5Pm-SBF) or a phosphine oxide (2-POPh $\mathbf{P}_{2}-\mathrm{SBF}$ ) have been also reported herein in order to shed light on the impact of the substituents position on the SBF scaffold.

Synthesis

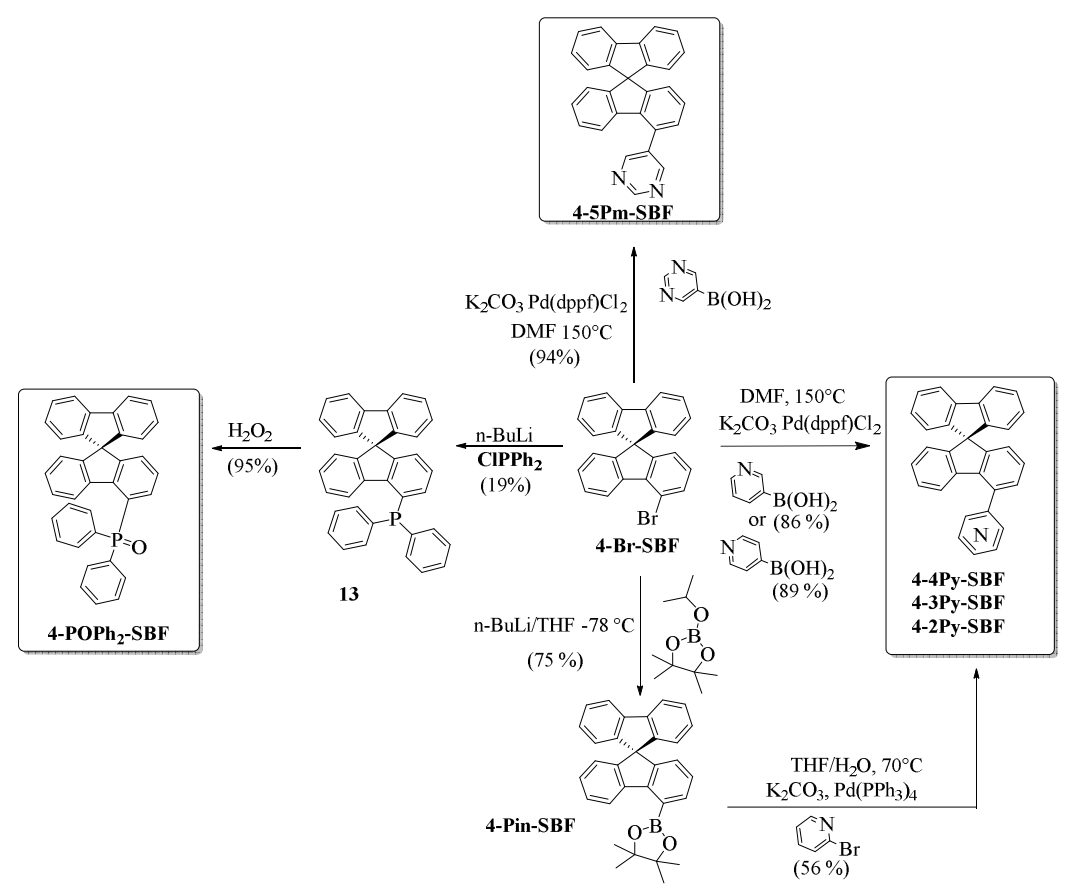

Figure 14. Synthesis of 4-4Py-SBF, ${ }^{71}$ 4-3Py-SBF, ${ }^{71}$ 4-2Py-SBF, ${ }^{71}$ 4-5 $\mathrm{PmSBF}^{82}$ and $4-\mathrm{POPh}_{2} \mathrm{SBF}^{116}$ 
The synthesis of these 4-substituted SBFs implies, as above mentioned, the key building block 4-BrSBF. Thus, as presented figure 14, Suzuki cross-couplings (Pd(dppf) $\mathrm{Cl}_{2} / \mathrm{K}_{2} \mathrm{CO}_{3} / \mathrm{DMF}$ ) between 4-Br-SBF and either 4- or 3-pyridine-phenyl boronic acid provide 4-4Py-SBF and 4-3Py-SBF with excellent yields of 89 and $86 \%$ resp. ${ }^{71}$ However, the instability of 2-pyridine-phenyl boronic acid does not allow its coupling with 4-Br-SBF and the synthesis of 4-2Py-SBF has been performed via a modified approach involving the cross-coupling of 4-Pin-SBF and 2-bromopyridine (overall yield $42 \%$ from $4-\mathrm{Br}$-SBF). ${ }^{71}$ Similarly, Suzuki cross-coupling between 4-Br-SBF and 5-pyrimidine boronic acid provides 4-5Pm-SBF with $94 \%$ yield. ${ }^{82}$ The model compounds $\mathbf{2 - 4 P y - S B F}{ }^{71}$ and $\mathbf{2 - 5 P m - S B F}{ }^{82}$ (figure 13, bottom) were obtained through similar pathways from the 2-bromo-9,9'-spirobifluorene (yield : $82 \%$ and $77 \%$ resp.). 4-POPh ${ }_{2}-\mathrm{SBF}$ was synthetized through the treatment of 4-Br-SBF with $\mathrm{n}-\mathrm{BuLi}$, followed by the trapping of the resulting lithiated intermediate with chlorodiphenylphosphine $\left(\mathrm{ClPPh}_{2}\right)$ (yield $\left.19 \%\right){ }^{116}$ The corresponding 4-diphenylphosphine-SBF 13 obtained was further oxidized $\left(\mathrm{H}_{2} \mathrm{O}_{2}\right)$ to provide 4-POPh $\mathbf{P}_{\mathbf{2}} \mathbf{S B F}$ with $95 \%$ yield. The 2 -substituted isomer $\mathbf{2 - P O P h}{ }_{2}-\mathbf{S B F}$ was synthetized using an identical approach. ${ }^{110}$

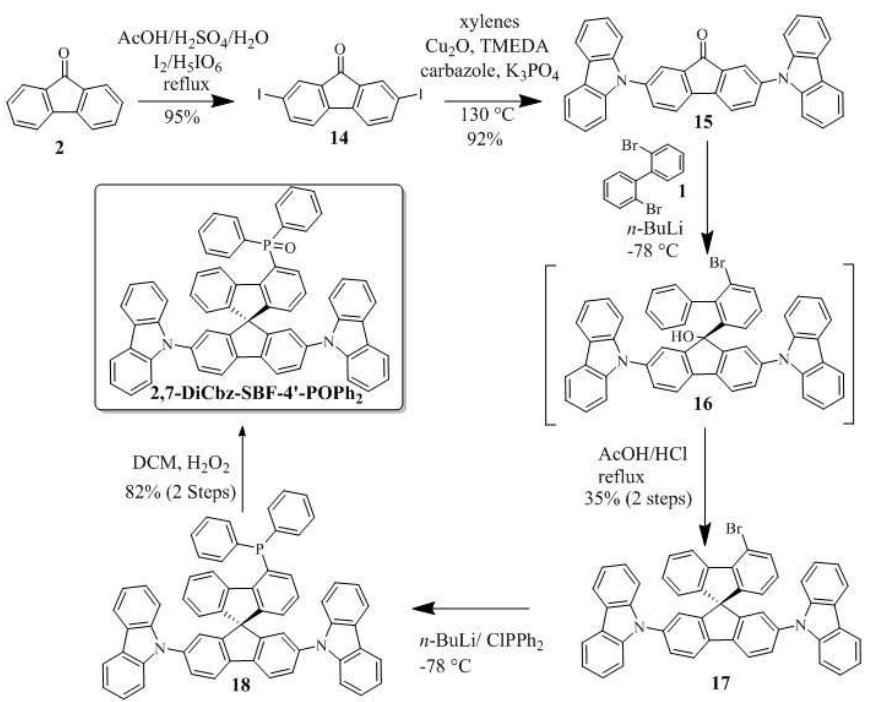

Figure 15. Synthesis of 2,7-DiCbz-SBF-4'-POPh ${ }_{2}^{53}$

As the molecular structure of 2,7-DiCbz-SBF-4'-POPh ${ }_{\mathbf{2}}$ is more elaborated, it has been synthesized following a different route involving the coupling of the 2,7-dicarbazole-fluorenone 15 with 2,2'bromobiphenyl 1 (Figure 15)..$^{53}$ The resulting fluorenol $\mathbf{1 6}$ is then involved in an intramolecular ring closure to provide 17 (35\% yield, 2 steps). Incorporation of the phosphine oxide was then classically performed through the following sequence: (i) lithium-halogen exchange on 17 (ii) trapping of the lithiated intermediate with $\mathrm{CIPPh}_{\mathbf{2}}$ to provide the diphenylphosphine derivative $\mathbf{1 8}$ and (iii) oxidation of

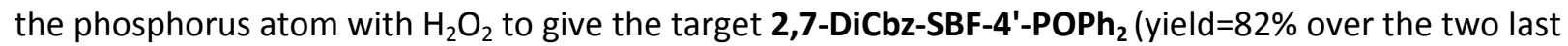
steps). The overall yield of this approach is rather high (25\%) and does not use any Pd catalyst.

\section{Structural properties}
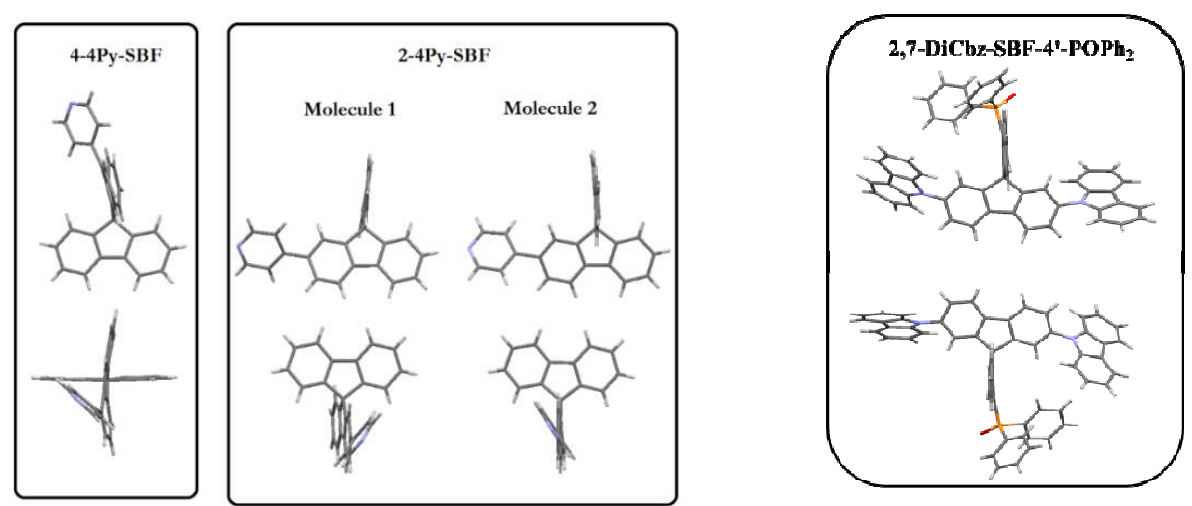
Figure 16. X-ray structures of 4-4Py-SBF (left), ${ }^{71}$ 2-4Py-SBF (middle) ${ }^{71}$ and 2,7-DiCbz-SBF-4'-POPh ${ }_{\mathbf{2}}\left(\right.$ right $^{53}$

As mentioned in part 3, the $\pi$-conjugation breaking observed in 4-substituted SBFs is induced by the large dihedral angle between the fluorene and the pendant substituent. Figure 16 reports the X-ray structures of 4-4Py-SBF, ${ }^{71}$ 2-4Py-SBF ${ }^{71}$ and 2,7-DiCbz-SBF-4'-POPh ${ }_{2}{ }^{53}$ In 4-4Py-SBF, the pyridyl/fluorene dihedral angle is reported at $42.2^{\circ}$, being slightly higher than that of its $\mathrm{C} 2$ isomer 2-4Py-SBF $\left(37.5^{\circ}\right.$ and $32.8^{\circ}$ as two molecules are present in the asymmetric unit). The angular difference between the 2 isomers (less than $9.4^{\circ}$ ) is hence smaller than that reported above between 2-Ph-SBF and 4-Ph-SBF (around $\left.13.8^{\circ}\right)^{81}$ translating the influence of the substituent (pyridine $v s$ phenyl) on this chief structural parameter which controls the electronic properties. Indeed, we will see below that this angular variation leads to a more extended $\pi$-conjugation between the pyridine and the fluorene in 4-4Py-SBF than between the phenyl and the fluorene in 4-Ph-SBF. An intense deformation of the substituted fluorene core $\left(16.8^{\circ}\right)$ is also observed in 4-4Py-SBF which is more pronounced than that reported for 4Ph-SBF $\left(12.7^{\circ}\right)^{81}$ and for 2-4Py-SBF $\left(3.2^{\circ}\right.$ and $5.0^{\circ}$ for the two molecules). ${ }^{71}$ The comparison of these 2 couples 4-4Py-SBF/2-4Py-SBF and 4-Ph-SBF/2Ph-SBF indicates that the fragment attached in $\mathrm{C} 4$ has a strong influence on the structural parameters and hence on the $\pi$-conjugation intensity with the fluorene.

Oppositely to the other 4-substituted SBFs described above, in which the conjugation is only broken by a steric congestion, the conjugation between the phosphine oxide and the fluorene is also broken by the phosphorus atom in 2,7-DiCbz-SBF-4'-POPh ${ }_{2}$.

\section{Electronic properties}

As a representative example, the UV-Visible absorption spectra of the pyridine and pyrimidinesubstituted SBFs are presented in figure 17-left (4-Ph-SBF and 2-substituted-SBFs have also been plotted for comparison). SBFs substituted in C4 with either pyrimidine or pyridine show similar absorption spectra with two main bands at ca 297 and $308 \mathrm{~nm}$ and a tail around $320 \mathrm{~nm}$. This tail, which translates the $\pi$-conjugation extension between the fluorene and the pyridine or the pyrimidine unit, presents different intensities. Thus, in the pyridine series, the authors report that the tail intensity depends on the position of the nitrogen atom. This feature indicates that more intense $\pi$ conjugation occurs between fluorene and pyridine units following the sequence 4-2Py-SBF > 4-4Py-SBF > 4-3Py-SBF. In the case of 4-5Pm-SBF, the tail presents an almost identical intensity than that 42Py-SBF. The PHC analogue 4-Ph-SBF presents a less intense tail (Figure 17 left, black line), compared to pyridine-substituted SBFs. This feature has been correlated to the larger angle formed between the fluorene and the phenyl in C4 in 4-Ph-SBF (higher than $51.2^{\circ}$ ) than between the fluorene and the pyridine in $\mathrm{C} 4$ in $4 \mathrm{Py}-\mathrm{SBF}\left(42.2^{\circ}\right)$, Figure 16. Compared to 4-Ph-SBF $\left(\triangle \mathrm{E}^{\mathrm{opt}}: 3.82 \mathrm{eV}\right)$, 4-3Py-SBF, 4-2PySBF, 4-4Py-SBF and 4-5Pm-SBF possess a slightly narrower optical gap $\Delta \mathrm{E}^{\mathrm{opt}}$ ie $3.81,3.80$ and $3.75 \mathrm{eV}$ and $3.72 \mathrm{eV}$ resp. (Table 3). The authors assign this gap contraction to the decrease of the LUMO energy levels induced by the electron withdrawing pyridine or pyrimidine ring (see electrochemistry below). The 2-substituted SBFs, due to their extended conjugation, display a shorter $\Delta \mathrm{E}^{\mathrm{opt}}$ (3.70 eV for 2-4Py-SBF and $3.66 \mathrm{eV}$ for 2-5Pm-SBF) compared to their 4-substituted analogues.

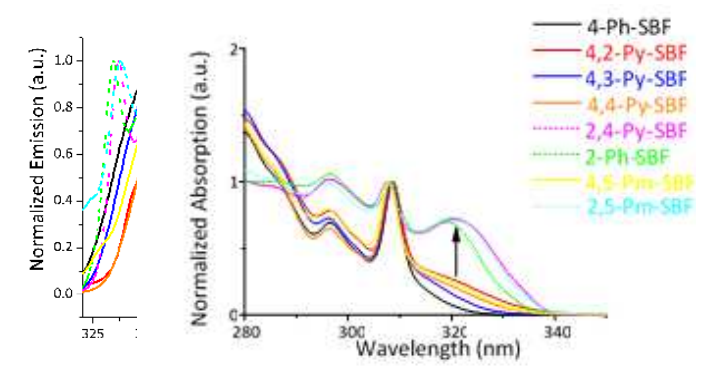

Figure 17. Left: UV-vis absorption and right: emission spectra of SBF derivatives (in cyclohexane). 
The electrochemical investigations have shed light on the impact of electron-withdrawing groups in position 4 of a SBF core (cyclic voltammetry samples are provided in Figure 18). ${ }^{71}$ The first oxidation of 4-4Py-SBF and 4-5Pm-SBF (Figure 18 right) is reported at nearly the same potential than that of 4-PhSBF $(1.69 \pm 0.1 \mathrm{~V})$. Thus, the incorporation of the pyridine or pyrimidine units at C4 of the SBF core has almost no influence on the HOMO energy levels. Indeed, the HOMOs are reported to lye at $-5.88 \mathrm{eV}$ for all the pyridine isomers 4-4Py-SBF, 4-3Py-SBF and $\mathbf{4 - 2 P y - S B F}{ }^{71}$ and at $-5.97 \mathrm{eV}$ for $\mathbf{4}-\mathbf{5 P m}-\mathbf{S B F}{ }^{82}$ compared to $-5.95 \mathrm{eV}$ for 4-Ph-SBF. ${ }^{81}$ On the contrary, the electrochemical reduction of 4-4Py-SBF and 4-5Pm-SBF (Figure 18 left) is reported at less negative potentials ( -2.48 and $-2.37 \mathrm{~V}$ resp., in THF) than the reduction of 4-Ph-SBF (-2.64 V, in DMF). This leads to LUMO levels lying at $-2.11 \mathrm{eV}$ for 4-4Py-SBF,

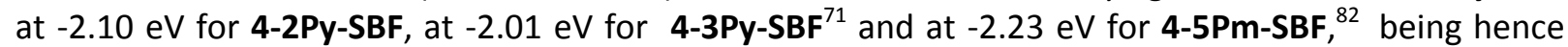
deeper compare to that of 4-Ph-SBF (LUMO: $-1.95 \mathrm{eV}$ ). ${ }^{81}$ The decrease of the LUMO energy level induced by the pyridyl ring is slightly less pronounced than that of the pyrimidine ring translating the different electron-withdrawing force of these two heterocycles, the latter being stronger than the former. Thus, incorporation of electron-withdrawing pyridine and pyrimidine in C4 of the SBF core has almost no influence on the HOMO energy levels but a significant impact on the LUMO energy levels. This is an important feature in the electrochemistry of 4-substituted SBFs.
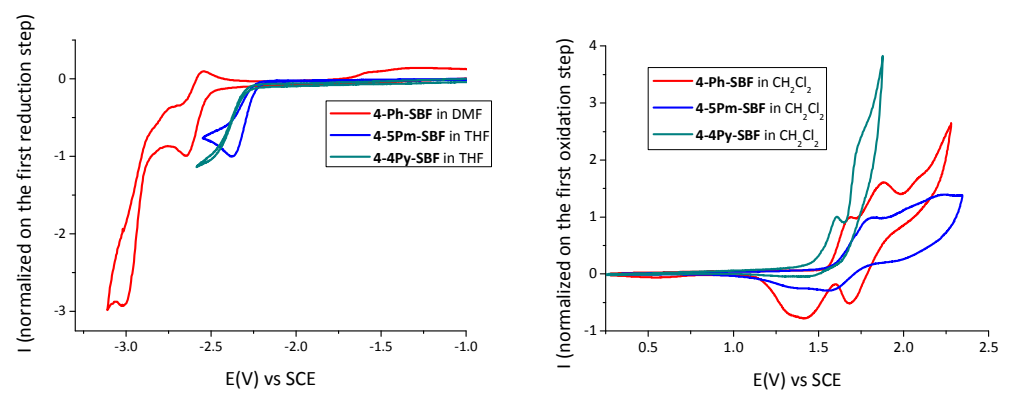

Figure 18. Cyclic voltammetry in reduction (left, recorded in DMF or THF + $0.1 \mathrm{M} \mathrm{Bu}_{4} \mathrm{NPF}_{6}$ ) and in oxidation (right, recorded in $\mathrm{CH}_{2} \mathrm{Cl}_{2}+0.2 \mathrm{M} \mathrm{Bu}_{4} \mathrm{NPF}_{6}$ ) of 4-Ph-SBF (red line), 4-5Pm-SBF (blue line) and 4-4Py-SBF (green line). The current is normalized at the first oxidation or reduction step. (Pt disk electrode $\emptyset 1 \mathrm{~mm}, 100 \mathrm{mV} / \mathrm{s}$ ).

4-substituted SBFs, as already indicated in part 4, present structureless and large emission spectra centred herein at $370 \mathrm{~nm}$ for 4-2Py-SBF, $363 \mathrm{~nm}$ for 4-3Py-SBF, $365 \mathrm{~nm}$ for 4-5Pm-SBF and $369.5 \mathrm{~nm}$ for 4-4Py-SBF, red shifted compared to the emission of 4-Ph-SBF (358 nm) (figure 17, right). ${ }^{71,81}$ The presence of a pyridyl or pyrimidine unit instead of the phenyl ring induces a bathochromic shift of the emission. The authors have also pointed out that the emission maxima follow the same sequence than that described above in absorption for the intensity of the tail at ca $320 \mathrm{~nm}$, indicating that it is directly linked to the intensity of the $\pi$-conjugation.

4-2Py-SBF with a $\Phi_{\text {sol }}$ of $c a 0.17$ and lifetime of 3.88 ns appears clearly less emissive than 4-3Py-SBF, 44Py-SBF and 4-Ph-SBF with $\Phi_{\text {sol }}$ of $0.40,0.40$ and 0.42 and lifetimes of $3.89,3.80$ and $4.20 \mathrm{~ns}$ respectively (Table 3). 2-substituted SBFs, 2-4Py-SBF and 2-Ph-SBF, show relatively higher $\Phi_{\text {sol }}(0.55$ and 0.87$)$ and much shorter lifetimes (1.03 ns and $1.56 \mathrm{~ns})$. Oppositely to pyridine-substituted SBFs, pyrimidine-substituted SBFs shows a quenching of fluorescence with very low $\Phi_{\text {sol }}$ of 0.04 and 0.02 and lifetimes of $0.61 \mathrm{~ns}$ and $0.44 \mathrm{~ns}$ for $4-5 \mathrm{Pm}-\mathrm{SBF}$ and $2-5 \mathrm{Pm}-\mathrm{SBF}$, respectively. ${ }^{82}$ The cause of this quenching is assigned by the authors to the presence of the aromatic NCHN fragment in the 5pyrimidine unit, which has a strong impact on the deactivation rates of the excited state. Indeed, they report for pyrimidine substituted derivatives 4-5Pm-SBF and 2-5Pm-SBF a lower radiative rate constant $\mathrm{k}_{\mathrm{r}}\left(6.6 \times 10^{7}\right.$ and $4.6 \times 10^{7} \mathrm{~s}^{-1}$ resp. $)$ and a much higher non-radiative rate constant $\mathrm{k}_{\mathrm{nr}}\left(1.6 \times 10^{9}\right.$ and $2.2 \times 10^{9} \mathrm{~s}^{-1}$ resp.) compared to phenyl-substituted derivatives 4-Ph-SBF and 2-Ph-SBF $\left(\mathrm{k}_{\mathrm{r}}\right.$ of $1.0 \times 10^{8}$ and $5.6 \times 10^{8} \mathrm{~s}^{-1}$ resp. and $\mathrm{k}_{\mathrm{nr}}$ of $1.4 \times 10^{8}$ and $8.3 \times 10^{7} \mathrm{~s}^{-1}$ resp.).

4-POPh ${ }_{2}-\mathbf{S B F}$ and its isomer $\mathbf{2}-\mathbf{P O P h}_{2}-\mathbf{S B F}$ are herein particular cases. Indeed the tetrahedral geometry of the phosphorus atom insures an efficient conjugation break between the fluorene and the diphenylphosphine oxide unit. UV-vis absorption spectra display two absorption bands at 308/322 nm for 4- 
$\mathbf{P O P h}_{2}-\mathbf{S B F}^{116}$ and at 308/316 nm for 2-POPh ${ }_{2}-\mathrm{SBF}^{116}$ The band at $308 \mathrm{~nm}$, previously observed for other SBF based compounds, corresponds to $\pi-\pi^{*}$ transitions involving the fluorene. ${ }^{91}$ The authors do not provide any explanation regarding the nature of the second absorption band red shifted by $6 \mathrm{~nm}$

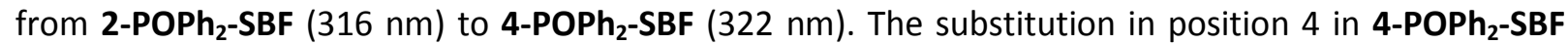
and in position 2 in 2-POPh ${ }_{2}$-SBF provides (i) very similar HOMO energy levels (-6.57 vs $-6.55 \mathrm{eV}$ resp.) and (ii) different LUMO energy levels (-2.82 vs $-2.73 \mathrm{eV}$ resp.). The emission spectra of both molecules are almost the same with a large and unresolved band recorded with a maximum at $339 \mathrm{~nm}$ and 346

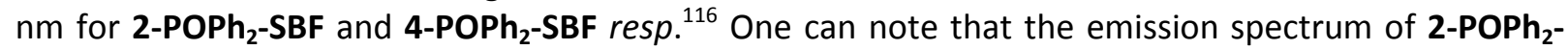
SBF is surprisingly not resolved.

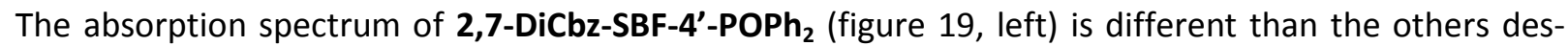
cribed in this review due to its substitution on both fluorenes..$^{53}$ Indeed, due to the presence of the two carbazole units, 2,7-DiCbz-SBF-4'-POPh ${ }_{2}$ possesses an identical spectrum than that of its constituting building block 2,7-bis-carbazol-9-yl-9,9'SBF (Spiro-2CBP) ${ }^{117}\left(\lambda_{\max }=349 \mathrm{~nm}, \Delta \mathrm{E}^{\text {opt }}=3.41 \mathrm{eV}\right)$. The absorption bands at low energy have been assigned by the authors to transitions implying the carbazole/ fluorene/carbazole fragment. The phosphine oxide in position 4' has hence a limited influence on the optical properties.

The HOMO energy level of 2,7-DiCbz-SBF-4'-POPh ${ }_{2}$ is evaluated at $-5.51 \mathrm{eV}$ by electrochemistry (Figure 19 , right), ${ }^{53}$ largely higher than that of SBF $(-5.94 \mathrm{eV})^{81}$ due to the substitution with the two carbazole fragments in $\mathrm{C} 2 / \mathrm{C} 7$. The first electron transfer is indeed assigned by the authors to the 'carbazole/fluorene/carbazole' fragment. The cyclic voltammetry of 4-POPh${ }_{2}-\mathbf{S B F}$ in the same experimental conditions leads to an HOMO level of $-6.00 \mathrm{eV} .^{53}$ Thus, the HOMO level of 4-POPh $\mathbf{H}_{2}-\mathrm{SBF}$ is very deep, even slightly deeper than that of SBF $(-5.94 \mathrm{eV})$, indicating the slight influence of the phosphine oxide on the fluorene oxidation. Through cathodic explorations, the cyclic voltammetries of 2,7-DiCbzSBF-4'-POPh ${ }_{2}$ and of 4-POPh ${ }_{2}$-SBF are reported similar leading to the same LUMO energy levels, -2.10 $\mathrm{eV}$. The electrochemical gaps $\left(\Delta \mathrm{E}^{\mathrm{el}}\right)$ have been evaluated at ca $3.41 \mathrm{eV}$ for $\mathbf{2 , 7}-\mathbf{D i C b z}-\mathbf{S B F}-\mathbf{4}^{\prime}-\mathbf{P O P h}_{\mathbf{2}}$ and at ca $3.90 \mathrm{eV}$ for $\mathbf{4}-\mathbf{P O P h}_{\mathbf{2}}$-SBF. Thus, in 2,7-DiCbz-SBF-4'-POPh${ }_{2}$, the authors state that the main electronic properties are driven by the carbazole/fluorene/carbazole moiety and that the withdrawing effect of the phosphine oxide is weak. This is the consequence of the $\pi$-conjugation disruption caused by this sterically hindered linkage and by the tetrahedral geometry of the phosphorus atom. As $\Delta \mathrm{E}^{\mathrm{el}}$ of SBF is of $4.05 \mathrm{eV}$, the C4-substitution of $\mathbf{4}-\mathbf{P O P h}_{2}-\mathbf{S B F}$ reduces the gap by only $0.15 \mathrm{eV}$ (mainly by decreasing the LUMO level) highlighting the interest of this position to keep a wide gap.
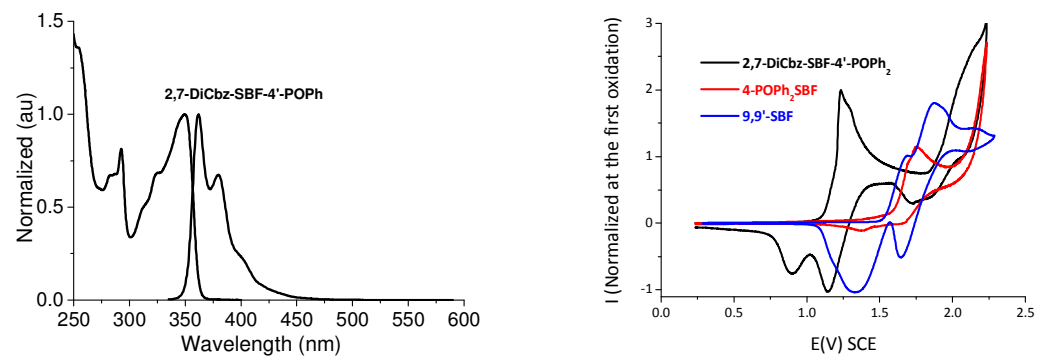

Figure 19. Left: UV-vis absorption and emission spectra of 2,7-DiCbz-SBF-4'-POPh voltammetry (Pt disk electrode $\emptyset 1 \mathrm{~mm}, 100 \mathrm{mV} / \mathrm{s}, \mathrm{CH}_{2} \mathrm{Cl}_{2} 0.2 \mathrm{M} \mathrm{Bu}_{4} \mathrm{NPF}_{6}$ ) in oxidation of 9,9'-SBF (blue line), 4$\mathrm{POPh}_{2}$-SBF (red line) and 2,7-DiCbz-SBF-4'-POPh (black line).

2,7-DiCbz-SBF-4'-POPh ${ }_{2}$ exhibits a well-defined emission spectrum (cyclohexane, $\lambda_{\max }=362 / 380 \mathrm{~nm}$, Figure 19, left). This behaviour is different to the other 4-substituted SBFs due to the presence of the two carbazole fragments. In addition, 2,7-DiCbz-SBF-4'-POPh $\mathbf{H}_{\mathbf{2}}$ is a very efficient violet-blue fluorophore with a high $\Phi_{\text {sol }}$ of 0.78 in solution (quinine sulphate as reference) indicating few non-radiative pathway from $S_{1}$ to $S_{0}$, and further few intersystem crossing (ISC) from $S_{1}$ to $T_{1}$ as described below.

The $E_{T}$ of all these dyes have been evaluated from the emission spectra at 77K. 4-3Py-SBF and 2-4PySBF respectively possess the highest and lowest $\mathrm{E}_{\mathrm{T}}$ in the pyridine series (2.79 eV and $2.58 \mathrm{eV}$ resp.) 
assigned to the different substitution position ( $C 4$ vs $\mathrm{C2}$ ). It should be mentioned that 4-2Py-SBF $\left(E_{T}=2.74 \mathrm{eV}\right)$ possesses the most intense phosphorescence whereas 2-4Py-SBF $\left(E_{T}=2.58 \mathrm{eV}\right)$ possesses the less intense one, translating different efficiencies in term of ISC between $\mathrm{S}_{1}$ and $\mathrm{T}_{1}{ }^{71}$ Interestingly, the authors correlated these features to the quantum yields $\Phi_{\text {sol }}, 2-4 \mathrm{Py}-\mathrm{SBF}$ possessing the highest $\Phi_{\text {sol }}$ $(55 \%)$ and the lowest $E_{T}(2.58 \mathrm{eV})$ and 4-2Py-SBF possessing the lowest $\Phi_{\text {sol }}(17 \%)$ and the highest $E_{T}$ $(2.79 \mathrm{eV}){ }^{71}$ In the pyrimidine series, there is the same amplitude of ca $0.17 \mathrm{eV}$ between the 4substituted isomer $\left(E_{T}=2.75 \mathrm{eV}\right.$ for $\left.\mathbf{4 - 5 P m}-\mathbf{S B F}\right)$ and its 2-substituted isomer $\left(\mathrm{E}_{\mathrm{T}}=2.58 \mathrm{eV}\right.$ for 2-5-Pm$\mathrm{SBF})$.

Table 3. Selected electronic and physical data of 2- and 4-SBFs incorporating electron-widrawing groups (4-PhSBF and 2-Ph-SBF are also presented for comparison purpose).

\begin{tabular}{|c|c|c|c|c|c|c|c|c|c|c|}
\hline & $\begin{array}{l}\text { 4-Ph- } \\
\mathrm{SBF}^{81}\end{array}$ & $\begin{array}{l}\text { 2-Ph- } \\
\text { SBF }^{81}\end{array}$ & $\begin{array}{l}4-2 P y- \\
S_{B F}{ }^{71}\end{array}$ & $\begin{array}{l}\text { 4-3Py- } \\
\text { SBF }^{71}\end{array}$ & $\begin{array}{l}\text { 4-4Py- } \\
\text { SBF }^{71}\end{array}$ & $\begin{array}{l}\text { 2-4Py-SBF } \\
71\end{array}$ & $\begin{array}{l}\text { 4-5Pm- } \\
\mathrm{SBF}^{82}\end{array}$ & $2-5 \mathrm{Pm}-\mathrm{SBF}^{82}$ & $\begin{array}{l}\text { 2,7-DiCbz- } \\
\text { SBF-4'- } \\
\text { POPh }_{2}{ }^{53} \\
\end{array}$ & $\begin{array}{l}\text { 4-POPh } \\
\mathrm{SBF}^{116,53}\end{array}$ \\
\hline$\lambda_{\text {max rabs }}(n m)$ & $\begin{array}{l}297 \\
308^{a}\end{array}$ & $\begin{array}{l}297 \\
308 \\
319^{a}\end{array}$ & $\begin{array}{l}297 \\
308^{a}\end{array}$ & $\begin{array}{l}297 \\
308^{\mathrm{a}}\end{array}$ & $\begin{array}{l}297 \\
308^{a}\end{array}$ & $\begin{array}{l}297 \\
308 \\
321^{a}\end{array}$ & $\begin{array}{l}297 \\
308, \\
318^{\mathrm{a}}\end{array}$ & $\begin{array}{l}296,308, \\
320^{\mathrm{a}}\end{array}$ & $292,349^{a}$ & $\begin{array}{l}308, \\
322^{116,53}\end{array}$ \\
\hline$\Delta \mathrm{E}^{\mathrm{opt}}$ & $3.82^{a}$ & $3.70^{a}$ & $3.80^{\mathrm{a}}$ & $3.81^{a}$ & $3.75^{\mathrm{a}}$ & $3.70^{\mathrm{a}}$ & $3.72^{\mathrm{a}}$ & $3.66^{a}$ & $3.41^{\mathrm{a}}$ & $3.75^{116,53}$ \\
\hline $\begin{array}{l}\lambda_{\text {max, fluo }} \\
\text { solution (nm) }\end{array}$ & $358^{a}$ & $\begin{array}{l}335 \\
351^{\text {a }}\end{array}$ & $370^{a}$ & $363^{a}$ & $369^{a}$ & $\begin{array}{l}337,354 \\
370^{\mathrm{a}}\end{array}$ & $\begin{array}{l}298 \\
311^{\mathrm{a}}\end{array}$ & $338,355^{\mathrm{a}}$ & $362,380^{\mathrm{a}}$ & 346 \\
\hline $\begin{array}{l}\lambda_{\text {max, fluo, }} \text { thin } \\
\text { film }(\mathrm{nm})^{\mathrm{b}}\end{array}$ & 363 & $\begin{array}{l}343 \\
359\end{array}$ & 366 & 365 & 377 & 375,425 & 365 & 355,366 & - & $353^{116}$ \\
\hline $\begin{array}{l}\lambda_{\text {max, phosphor }} \\
(77 \mathrm{~K})(\mathrm{nm})\end{array}$ & $447^{d}$ & $483^{d}$ & $448^{d}$ & $444^{d}$ & $451^{d}$ & $480^{d}$ & $372^{e}$ & $480^{e}$ & 469 & - \\
\hline $\mathrm{E}_{\mathrm{T}}(\mathrm{eV})$ & $2.77^{d}$ & $2.56^{d}$ & $2.76^{d}$ & $2.79^{d}$ & $2.74^{d}$ & $2.58^{d}$ & $2.75^{\mathrm{e}}$ & $2.58^{\mathrm{e}}$ & 2.64 & $2.78^{116}$ \\
\hline$\Phi_{\text {sol }}(\%)^{c}$ & 42 & 87 & 17 & 40 & 40 & 55 & 0.04 & 0.02 & 0.87 & - \\
\hline $\begin{array}{l}\text { Fluorescence } \\
\text { lifetime (ns) }^{\text {a }}\end{array}$ & 4.2 & 1.56 & 3.88 & 3.89 & 3.80 & 1.03 & 0.61 & 0.44 & 4.6 & - \\
\hline $\begin{array}{l}\text { Radiative rate } \\
\text { constant } \\
\left(\mathrm{k}_{\mathrm{r}}\right)\left(10^{8} \mathrm{~s}\right)\end{array}$ & 1.00 & 5.58 & 0.44 & 1.03 & 1.05 & 5.34 & 0.66 & 0.46 & 6.4 & - \\
\hline $\begin{array}{l}\text { Non-radiative } \\
\text { rate constant } \\
\left(\mathrm{k}_{\mathrm{nr}}\right)\left(10^{8} \mathrm{~s}\right)\end{array}$ & 1.38 & 0.83 & 2.14 & 1.54 & 1.58 & 4.37 & 16 & 22 & 1.8 & - \\
\hline $\mathrm{HOMO}^{f}$ & -5.95 & -5.88 & -5.88 & -5.90 & -5.88 & -5.78 & -5.97 & -5.96 & -5.51 & $\begin{array}{l}-6.57^{116} \\
-6.00^{53}\end{array}$ \\
\hline LUMO $^{f}$ & -1.95 & -2.10 & -2.12 & -2.01 & -2.11 & -2.26 & -2.23 & -2.30 & -2.10 & $\begin{array}{l}-2.82^{116} \\
-2.10^{53}\end{array}$ \\
\hline$T_{d}^{g}$ & 254 & 238 & 242 & 220 & 217 & 181 & 277 & 242 & 426 & $297^{53}$ \\
\hline & 76 & 78 & 81 & 81 & 84 & 92 & 85 & 94 & 193 & $127^{116}$ \\
\hline
\end{tabular}

Thus, compared to the $E_{T}$ of SBF $(2.87 \mathrm{eV}),{ }^{81}$ the substitution by the 3-pyridyl ring $\left(\mathrm{E}_{\mathrm{T}}: 2.79 \mathrm{eV}\right)$ less affects the $E_{T}$ than the substitution by the 5-pyrimidyl ring $\left(E_{T}: 2.75 \mathrm{eV}\right)^{82}$ or by the 4- or 2-pyridyl rings $\left(E_{\mathrm{T}}: 2.74\right.$ or $2.76 \mathrm{eV}$, resp.), Table 3. The case of 4-POPh ${ }_{2}-\mathbf{S B F}$ is somewhat particular as the phosphorus insures a $\pi$-conjugation breaking and the $E_{\mathrm{T}}$ is reported by Lee et al. at $2.78 \mathrm{eV} .{ }^{116}$ Due to its high $\Phi_{\text {sol }}$ of 0.78 in solution, the ISC is not preferred in 2,7-DiCbz-SBF-4'-POPh ${ }_{2}$ and the phosphorescence contribution is very weak. The opposite was observed above for the pyridine substituted SBFs: low quantum yield and high phosphorescence contribution. ${ }^{71}$ Thus, 2,7-DiCbz-SBF-4'-POPh ${ }_{2}$ presents an $E_{T}$ of $2.64 \mathrm{eV}$. The triple substitution of the SBF core in $\mathrm{C} 2 / \mathrm{C} 7$ and $\mathrm{C}^{\prime}$ and the spatial separation of the substituents via the spiro bridge only leads to an $\mathrm{E}_{\mathrm{T}}$ decrease of $0.23 \mathrm{eV}$ compared to non-substituted SBF $\left(E_{T}=2.87 \mathrm{eV}\right)$, remaining high enough to be used as host for green PhOLEDs but not for blue ones.

Thermal properties

$\mathrm{T}_{d}$ of 4-substituted-pyridine SBFs, 4-4Py-SBF, 4-3Py-SBF and 4-2Py-SBF, lie in a small range between $217^{\circ} \mathrm{C}$ and $242^{\circ} \mathrm{C}$, the 2-pyridyl ring leading to the more stable molecule. ${ }^{71}$ The $T_{d}$ are however lower 
than that of 4-Ph-SBF $\left(254^{\circ} \mathrm{C}\right)$. Similarly, $\mathrm{T}_{\mathrm{d}}$ of 2-4Py-SBF is evaluated at $181^{\circ} \mathrm{C}$ lower than that of 2-PhSBF $\left(238^{\circ} \mathrm{C}\right)$. The substitution of the SBF core by a pyridyl unit instead of a phenyl unit leads then to less thermally stable compounds. Pyrimidine has the opposite effect with 4-5Pm-SBF possessing a higher $\mathrm{T}_{d}\left(277^{\circ} \mathrm{C}\right)$ than that of 4-Ph-SBF, showing the interest of the incorporation of a pyrimidine unit in C4.

Thus, the substitution position has an influence on the $T_{d}$, with an increase of $T_{d}$ of $16^{\circ} \mathrm{C}$ from 2-Ph-SBF to 4-Ph-SBF, of $35^{\circ} \mathrm{C}$ from 2-5Pm-SBF to 4-5Pm-SBF and of $36^{\circ} \mathrm{C}$ from 2-4Py-SBF to 4-4Py-SBF. This $T_{d}$

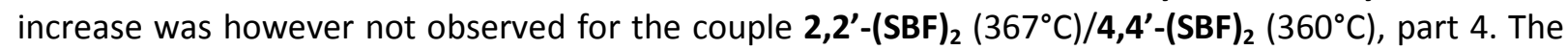
pyridyl substituent nevertheless has a positive influence on the $T_{g}$. Indeed, $T_{g}$ of 4-4Py-SBF, 4-3Py-SBF and 4-2Py-SBF, lye between 81 and $84^{\circ} \mathrm{C}$, being higher than that of 4-Ph-SBF ${ }^{81}\left(76^{\circ} \mathrm{C}\right)$. The $\mathrm{T}_{\mathrm{g}}$ of $2-4 \mathrm{Py}-$ SBF $\left(92^{\circ} \mathrm{C}\right)$ is also higher than that of $2-\mathbf{P h}^{-S_{B F}}{ }^{82}\left(78^{\circ} \mathrm{C}\right)$. Thus, independently of the substitution $(\mathrm{C} 2$ or C4), pyridyl-substituted compounds always possess slightly higher $\mathrm{T}_{\mathrm{g}}$ than their phenyl analogues. The same conclusion is drawn for pyrimidine-substituted $\mathrm{SBFs}$, which $\mathrm{T}_{\mathrm{g}}$ is higher than that of their phenyl substituted parent $\left(\mathrm{T}_{\mathrm{g}}\right.$ of $4-5 \mathrm{Pm}-\mathrm{SBF} 85^{\circ} \mathrm{C}$ vs $\mathrm{T}_{\mathrm{g}}$ of 4-Ph-SBF $76^{\circ} \mathrm{C}$ and $\mathrm{T}_{\mathrm{g}}$ of 2-5Pm-SBF $94^{\circ} \mathrm{C}$ vs $\mathrm{T}_{\mathrm{g}}$ of 2-PhSBF $78^{\circ} \mathrm{C}$ ). The authors state that these higher $T_{g}$ are the consequence of stronger intermolecular interactions due to $\mathrm{CH}^{\prime \prime} \mathrm{N}$ hydrogen bonding interactions. ${ }^{71}$

$\mathrm{T}_{d}$ of 4-POPh${ }_{2}-\mathrm{SBF}$ is reported at $297^{\circ} \mathrm{C}^{53}$ being higher than those exposed above, meaning that the introduction of phosphine oxide on C4 increases the $T_{d}$. The $T_{d}$ of 2,7-DiCbz-SBF-4'-POPh ${ }_{2}{ }^{53}$ occurs at the very high temperature of $426{ }^{\circ} \mathrm{C}$ significantly higher than those exposed above. This is caused by the increase of molecular weight and by the twisted structure of this molecule. In DSC, $\mathrm{T}_{\mathrm{g}}$ of 2,7-DiCbzSBF-4'-POPh ${ }_{2}$ is reported at the very high temperature of $193^{\circ} \mathrm{C}$, strongly higher than those reported for 4-POPh ${ }_{2}$-SBF $\left(127^{\circ} \mathrm{C}\right)^{116}$ and for the other 4-substituted SBFs exposed above. ${ }^{69,} 71,118$ This means that the substitution on the two fluorenes is highly beneficial to increase the $T_{\mathrm{g}}$. The $\mathrm{T}_{\mathrm{g}}$ of 4-POPh $\mathbf{P}_{\mathbf{2}}-\mathrm{SBF}$ is nevertheless significantly higher than that of its regioisomer $2-\mathbf{P O P h}_{2}-\mathbf{S B F}\left(96^{\circ} \mathrm{C}\right)^{116}$ indicating that the phosphine oxide position has an important influence on the thermal properties. This result is nevertheless different to those above exposed in the 4-Ph-SBF/2-Ph-SBF or in the 4-4Py-SBF/2-4PySBF or in the 4-5Pm-SBF/2-5Pm-SBF series for which the $T_{g}$ decreases when the substituent moves from the 4 to the 2-position, highlighting the difficulty to draw clear trends.

\section{Phosphorescent OLEDs}

The PhOLED structure using pyridyl- or pyrimidine-substituted SBFs as host is the same than that reported for 4-Ph-SBF and the performance of the devices can be hence directly compared (ITO/CuPc(10nm)/ NPB(40nm)/TCTA(10nm)/Host:dopant(20nm)/TPBi(40nm)/LiF(1.2nm)/Al(100nm)). All the green devices using pyrimidine or pyridine based materials as host, present better performances (12.7<EQE< 15.7\%) than those reported for SBF (8.5\%) and 4-Ph-SBF (10.4\%) table 2).

Table 4. Performance of green $\left(\operatorname{Ir}(\mathrm{ppy})_{3}\right)$ devices. $^{\mathrm{a}}$

\begin{tabular}{|c|c|c|c|c|}
\hline & $\begin{array}{l}V_{\text {on }}(V) \\
@ 1 \mathrm{~cd} / \mathrm{m}^{2}\end{array}$ & $\begin{array}{l}\text { E.Q.E (\%) } \\
\text { @ } 10 \mathrm{~mA} / \mathrm{cm}^{2} \\
\end{array}$ & $\begin{array}{l}\text { CE (cd/A) } \\
@ 1 / 10 \mathrm{~mA} / \mathrm{cm}^{2}\end{array}$ & $\begin{array}{l}\mathrm{PE} \\
@ 1 / 10 \mathrm{~mA} / \mathrm{cm}^{2} \\
\text { @ } 1 / \mathrm{l})\end{array}$ \\
\hline 4-5-Pm-SBF & 3.7 & 13.8 & $56.6 / 50.5$ & $25.9 / 17.9$ \\
\hline 4-4-Py-SBF & 3.4 & 15.7 & $63.4 / 56.8$ & $33.9 / 23.1$ \\
\hline 4-3-Py-SBF & 3.6 & 14.9 & $57.3 / 55.5$ & $32.3 / 24.5$ \\
\hline 4-2-Py-SBF & 3.9 & 12.7 & $59.0 / 47.3$ & $31.0 / 20.0$ \\
\hline 2-4-Py-SBF & 3.3 & 14.3 & $56.3 / 51.9$ & $31.8 / 22.3$ \\
\hline 2-5Pm-SBF & 3.1 & 14.2 & $56.7 / 51.4$ & $32.6 / 22.6$ \\
\hline 2-Ph-SBF & 3.9 & 9.5 & $39.6 / 35.2$ & $21.5 / 15.3$ \\
\hline 2,7-DiCbz-SBF-4'-POPh ${ }_{2}{ }^{b}$ & 2.4 & $6.2\left(13.2^{c}\right)$ & $45.8^{\mathrm{c}} / 21.5$ & $49.6^{c} / 12.4$ \\
\hline 4-POPh ${ }_{2}-\mathrm{SBF}^{\mathrm{b}}$ & 3.3 & $8.1\left(13.3^{c}\right)$ & $50.2^{c} / 30.5$ & $29.8^{c} / 9.6$ \\
\hline
\end{tabular}


Thus, the device using 4-5Pm-SBF as host has a $\mathrm{V}_{\text {on }}$ of $3.7 \mathrm{~V}$ and presents a $\mathrm{CE}$ of $50.5 \mathrm{~cd} / \mathrm{A}$, a PE of $17.9 \mathrm{~lm} / \mathrm{W}$, and an EQE of $13.8 \%$ (at $10 \mathrm{~A} / \mathrm{cm}^{2}$ ), strongly higher than that of PHC SBF and 4-Ph-SBF (Table 2).

The green devices using pyridyl-substituted SBFs as host all present similar performances and the best ones are reported for 4-4Py-SBF. This device emits light at 3.4 V and presents a CE of $56.8 \mathrm{~cd} / \mathrm{A}$, a PE of $23.1 \mathrm{Im} / \mathrm{W}$ and an EQE of $15.7 \%$ (at $10 \mathrm{~A} / \mathrm{cm}^{2}$ ). PhOLEDs using 4-3Py-SBF and 4-4Py-SBF as host present better performance than that using 4-5Pm-SBF, with $\mathrm{V}_{\text {on }}$ lowered by 0.1-0.3 $\mathrm{V}$ and EQE increased by $1-2 \%$, highlighting that pyridine is more efficient than pyrimidine in such design. However, as the LUMO is more decreased by the introduction of pyrimidine, this parameter cannot be the only involved in the different performance. It should be mentioned that these values are all recorded at $10 \mathrm{~mA} / \mathrm{cm}^{2}$ (values at $1 \mathrm{~mA} / \mathrm{cm}^{2}$ are also provided in Table 4) by the authors and are not maximum values as often reported.

For comparison, the 2-substituted compounds 2-4Py-SBF and 2-5Pm-SBF have also been reported as host in identical devices. The EQE (at $10 \mathrm{~mA} / \mathrm{cm}^{2}$ ) of the device using 2-4Py-SBF is reported at $14.3 \%$ almost identical to that using 2-5Pm-SBF $(14.2 \%)^{82}$ but strongly higher than that reported for 2-Ph-SBF (9.5\%). There is also a decrease of the $\mathrm{V}_{\text {on }}$ from $3.9 \mathrm{~V}$ for 2-Ph-SBF to $3.3 \mathrm{~V}$ for 2-4Py-SBF and to $3.1 \mathrm{~V}$ for 2-5Pm-SBF. The EQE of 2-4Py-SBF is nevertheless lower than that of 4-4Py-SBF (14.3\% vs 15.7\%).

2,7-DiCbz-SBF-4'-POPh ${ }_{2}$ has been incorporated as host in a very simple single-layer green PhOLED $\left(\operatorname{Ir}(\mathrm{ppy})_{3}\right)$ with no transporting neither blocking layers. Indeed, simplifying the device architecture to reach single-layer PhOLEDs is an important research field which would be beneficial to decrease the whole cost of PhOLEDs. The architecture is the following : ITO/PEDOT:PSS (40 nm)/Host: $\operatorname{lr}(\mathrm{ppy})_{3}(10 \%)$ $(100 \mathrm{~nm}) / \mathrm{LiF}(1.2 \mathrm{~nm}) / \mathrm{Al}(100 \mathrm{~nm})$. This single-layer PhOLED displays high maximal EQE of $13.2 \%$, maximum CE of $45.8 \mathrm{~cd} / \mathrm{A}$ and maximum $\mathrm{PE}$ as high as $49.6 \mathrm{Im} / \mathrm{W}$ (at $0.01 \mathrm{~mA} / \mathrm{cm}^{2}$, Table 4). ${ }^{53}$ The $\mathrm{V}_{\text {on }}$ is very low $(2.4 \mathrm{~V})$, translating an excellent charge injection within the EML. In order to shed light on the effect of the phosphine oxide on the device performance, the authors also have investigated benchmark devices using 4-POPh $\mathbf{P}_{2}-\mathbf{S B F}$ as host in a similar device architecture. Single-layer PhOLED using 4-POPh $\mathbf{h}_{\mathbf{2}}$-SBF as host displays an EQE as high as that of 2,7-DiCbz-SBF-4'-POPh ${ }_{2}$-based PhOLED, ie $13.3 \%$, this performance indicating the strong influence of the phosphine oxide fragment in the PhOLED performance. However, due to the deeper HOMO level of 4-POPh ${ }_{2}-\mathbf{S B F}(-6.00 \mathrm{eV})$, the green single-layer PhOLED displays a higher $\mathrm{V}_{\text {on }}$ of $3.3 \mathrm{~V}$, ca $\mathbf{1 V}$ higher than that using 2,7-DiCbz-SBF-4'-POPh as host (HOMO level:-5.53 eV) due to a better charge injection in the latter than in the former. The performance of 2,7-DiCbz-SBF-4'-POPh ${ }_{2}$ was among the highest reported for green single-layer PhOLEDs. ${ }^{53}$

The electron and hole mobility of a host influence the performance of a device and especially of a single-layer device. The authors have evaluated the charge carriers properties of 2,7-DiCbz-SBF-4'$\mathbf{P O P h}_{\mathbf{2}}$ by the Space Charge Limited Current method. ${ }^{53}$ There is around one order of magnitude between the hole mobility $\left(\mu_{\mathrm{h}}: 8.5 \times 10^{-7} \mathrm{~cm}^{2} / \mathrm{V} . \mathrm{s}\right)$ and the electron mobility $\left(\mu_{\mathrm{e}}: 4.2 \times 10^{-8} \mathrm{~cm}^{2} / \mathrm{V} . \mathrm{s}\right)$ which is an important feature for a well balance within the OLED. ${ }^{53}$ This feature is correlated by the authors to the high performance of the 2,7-DiCbz-SBF-4'-POPh ${ }_{2}$ green single layer device. The determination of the electron mobilities of 4-POPh $\mathbf{P}_{\mathbf{2}}-\mathbf{S B F}$ and $\mathbf{2}-\mathbf{P O P \mathbf { P } _ { 2 }}-\mathbf{S B F}$ using electron only devices is also reported in literature. ${ }^{116} \mu_{\mathrm{e}}$ values of $7 \times 10^{-4} \mathrm{~cm}^{2} /$ V.s for $4-\mathrm{POPh}_{2}-\mathrm{SBF}$ and $5 \times 10^{-4} \mathrm{~cm}^{2} / \mathrm{V}$.s for 2-POPh${ }_{2}-\mathbf{S B F}$ indicate a slight modulation induced by the position of the phosphine oxide fragment on the SBF cores.

Table 5. Performance of blue (FIrpic) devices.

\begin{tabular}{|c|c|c|c|c|}
\hline & $\begin{array}{l}V_{\text {on }} \quad(V) \\
@ 1 \mathrm{~cd} / \mathrm{m}^{2}\end{array}$ & $\begin{array}{l}\text { E.Q.E }(\%) \\
@ 10 \mathrm{~mA} / \mathrm{cm}^{2}\end{array}$ & $\begin{array}{l}\text { CE (cd/A) } \\
@ 1 / 10 \mathrm{~mA} / \mathrm{cm}^{2}\end{array}$ & $\begin{array}{lr}\mathrm{PE} & (\mathrm{Im} / \mathrm{W}) \\
@ 1 / 10 \mathrm{~mA} / \mathrm{cm}^{2}\end{array}$ \\
\hline $\mathrm{SBF}^{\mathrm{a}}$ & 4.0 & 6.5 & 20.1/18.7 & $10.8 / 7.9$ \\
\hline 4-Ph-SBF ${ }^{\mathrm{a}}$ & 4.7 & 6.0 & $18.4 / 16.7$ & $8.5 / 6.1$ \\
\hline 4-5Pm-SBF & 4.1 & 5.0 & $15.2 / 14.5$ & 7.9/5.7 \\
\hline 4-4Py-SBF ${ }^{\mathrm{a}}$ & 4.3 & 5.1 & $16.1 / 14.6$ & $8.3 / 5.9$ \\
\hline 4-3Py-SBF ${ }^{a}$ & 4.7 & 4.9 & $16.2 / 14.2$ & $7.5 / 5.1$ \\
\hline
\end{tabular}




\begin{tabular}{|c|c|c|c|c|}
\hline 4-2Py-SBF & 5.0 & 3.9 & $10.9 / 10.4$ & $4.8 / 3.6$ \\
\hline 2-4Py-SBF ${ }^{\mathrm{a}}$ & 4.8 & 0.2 & $0.7 / 0.6$ & $0.4 / 0.3$ \\
\hline 4-POPh ${ }_{2}-\mathrm{SBF}^{\mathrm{b}}$ & - & $17.5^{\mathrm{c}}$ & $35.6^{c}$ & $24.7^{c}$ \\
\hline 4-POPh ${ }_{2}-\mathrm{SBF}^{\mathrm{d}}$ & & $17.2^{\mathrm{e}}$ & $35.3^{\mathrm{e}}$ & $26.0^{\mathrm{e}}$ \\
\hline
\end{tabular}

${ }^{a}$ Device structure: ITO/CuPc(10 nm)/NPB(40 nm)/TCTA(10 nm)/FIrpic:host(20 wt\%, $\left.20 \mathrm{~nm}\right) / \operatorname{TPBi}(40 \mathrm{~nm}) / \mathrm{LiF}(1.2 \mathrm{~nm}) / \mathrm{Al}(100 \mathrm{~nm})$.

${ }^{b}$ Device structure: ITO/PEDOT:PSS(60 nm)/NPB(20 nm)/mCP(10 nm)/FIrpic:4-POPh $-S B F(c a 10 / 11 \mathrm{wt} \%, 30 \mathrm{~nm}) / 4-P O P h_{2}-S B F(25 \mathrm{~nm}) / \mathrm{LiF}(1$ $\mathrm{nm}) / \mathrm{Al}(100 \mathrm{~nm})$

${ }^{\mathrm{C}} \mathrm{EQE}, \mathrm{CE}$ or PE @300 cd/m².

${ }^{\mathrm{d}}$ Device structure:ITO/PEDOT:PSS(60nm)/NPB(20nm)/mCP(10nm)/FIrpic:4-POPh ${ }_{2}-\mathrm{SBF}(10 \%, 30 \mathrm{~nm}) / \mathrm{BCP}(5 \mathrm{~nm}) / \mathrm{Alq}{ }_{3}(20 \mathrm{~nm}) / \mathrm{LiF}(1 \mathrm{~nm}) / \mathrm{Al}$ $(100 \mathrm{~nm})$

${ }^{\mathrm{e}} \mathrm{EQE}, \mathrm{CE}$ or PE @200 cd/m².

The 4-substituted SBFs incorporating electrowithdrawing fragments have also been used as host for the sky blue emitter Flrpic (Table 5). The moderate performances of the resulting PhOLEDs based on the three pyridines are in the same range with however slightly better performances for 4-3Py-SBF and 4-4Py-SBF, indicating that 3-pyridine and 4-pyridine rings are the most efficient pyridyl regioisomers for PhOLEDs (in both green and blue). At $10 \mathrm{~mA} / \mathrm{cm}^{2}$, an EQE of $5.1 \%$ and a $V_{\text {on }}$ of $4.3 \mathrm{~V}$ are reported for 4-4Py-SBF and an EQE of 4.9\% and a $V_{\text {on }}$ of $4.7 \mathrm{~V}$ are reported for 4-3Py-SBF. The blue devices using 42Py-SBF as host display lower performance than that using the precedent isomers (EQE $=3.9 \% / \mathrm{V}_{\text {on }}$ $=5.0 \mathrm{~V}$ ) following the same trend observed for the green devices. The blue devices using 4-5Pm-SBF${ }^{82}$ $\left(\mathrm{V}_{\mathrm{on}}=4.1 \mathrm{~V} / \mathrm{EQE}=5 \%\right)$ present similar performances than those reporded for 4-4Py-SBF.

4-POPh ${ }_{2}$-SBF was also incorporated as host for FIrpic in a multilayer PhOLED with two different architectures:ITO/PEDOT:PSS(60nm)/NPB(20nm)/mCP(10nm)/4-POPh ${ }_{2}$-SBF:FIrpic(10\%)(30nm)/BCP $(5 \mathrm{~nm}) / \mathrm{Alq}_{3}(20 \mathrm{~nm}) / \mathrm{LiF}(1 \mathrm{~nm}) / \mathrm{Al}(100 \mathrm{~nm})$ and ITO/PEDOT:PSS $(60 \mathrm{~nm}) / \mathrm{NPB}(20 \mathrm{~nm}) / \mathrm{mCP}(10 \mathrm{~nm}) / 4-$ POPh $_{2}$-SBF:FIrpic (10\%)(30nm)/4-POPh ${ }_{2}-\mathrm{SBF}(25 \mathrm{~nm}) / \mathrm{LiF}(1 \mathrm{~nm}) / \mathrm{Al}(100 \mathrm{~nm}) .{ }^{116}$ In the first architecture, 4$\mathrm{POPh}_{2}-\mathrm{SBF}$ is only used as host for Flrpic and in the second, it has a double role, host for FIrpic and electron transporting layer. With the first architecture, the 4-POPh $-\mathbf{S B F}$-based PhOLED displays a high maximum EQE of $17.2 \%$, maximum CE and PE of $35.3 \mathrm{~cd} / \mathrm{A}$ and $26.0 \mathrm{~lm} / \mathrm{W}$. This performance is better than that reported for its isomer 2-POPh ${ }_{2}-\mathbf{S B F}$ in an identical device configuration (EQE: $15.6 \%$ ). ${ }^{116}$

Using the second device architecture, in which 4-POPh${ }_{2}-\mathbf{S B F}$ is used both as host in the EML and as electron transport layer, higher performances were obtained (EQE of 17.5\%, CE of $35.6 \mathrm{~cd} / \mathrm{A}$ and PE of $24.7 \mathrm{Im} / \mathrm{W}$ ). Thus, phosphine oxide based materials display strongly higher performance than that of pyridine or pyrimidine based materials, highlighting the remarkable influence of this core.

\section{4-substituted SBF incorporating electron-donating units.}

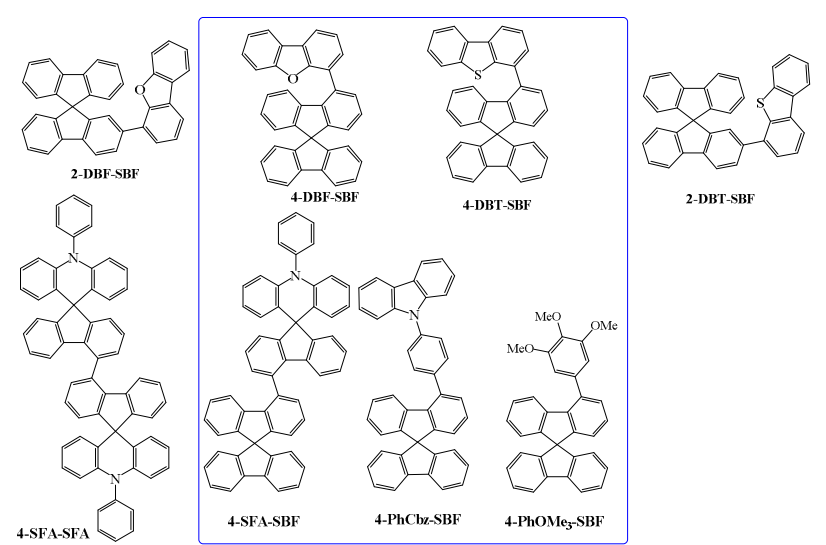

Figure 20: Electron rich molecules based on a 4-substituted SBF scaffold (and their 2-substituted analogues)

To the best of our knowledge, only five examples of 4-substituted SBFs incorporating electrondonating fragments have been reported as host in PhOLEDs (figure 20). 4-DBF-SBF (4- $(9,9$ '-spirobi[ $9 \mathrm{H}$ fluoren]-2-yl)-dibenzofuran) reported by Lee et al. in 2012 is built on a SBF backbone possessing in C4 a 
dibenzofuran fragment. ${ }^{118}$ In 2013, the same group has reported the incorporation of a dibenzothienyl core in C4 of a SBF unit leading to 4-DBT-SBF (4-(9,9'-spirobi[9H-fluoren]-4-yl)-dibenzothiophene). ${ }^{119}$ The group of $\mathrm{Ma}$ has reported in 2014 the incorporation in $\mathrm{C4}$ of a spiro-fluorene-phenylacridine 4SFA-SBF (10-phenyl-4'-(9,9'-spirobi[9H-fluoren]-4-yl)-spiro[acridine-9(10H),9'-[9H]fluorene]) ${ }^{120}$ and following a similar design, also has reported a dimer of spiro-fluorene-phenylacridine linked by their $\mathrm{C} 4$ in 4-SFA-SFA $(10,10$ '-diphenyl-4',4"-bispiro[acridine-9(10H),9'-[9H]fluorene]). Our group has reported in 2017 two other dyes incorporating electron-rich fragments in $\mathrm{C4}$ either a trimethoxybenzene in 4$\mathrm{PhOMe}_{3}$-SBF (4-(3,4,5-trimethoxyphenyl)-9,9'-spirobi[fluorene]) or a phenyl N-carbazole in 4-PhCbzSBF). ${ }^{95}$ This last example appears particularly singular as it possesses different properties than those reported in this review. 


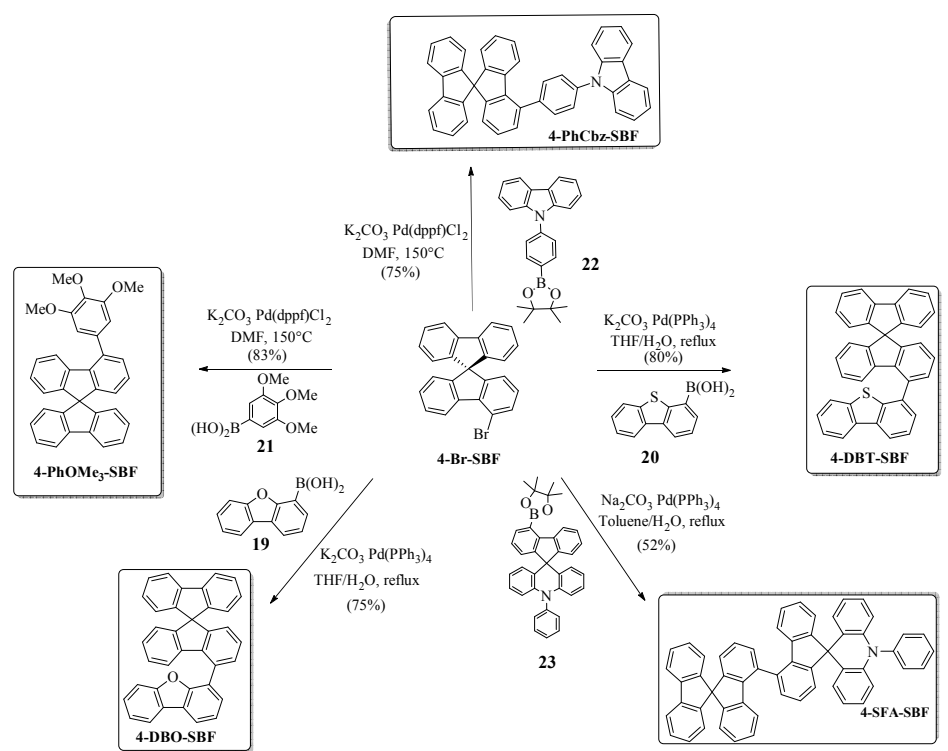

Figure 21. Synthesis of 4-DBF-SBF, ${ }^{118}$ 4-DBT-SBF, ${ }^{119} 4$-PhOMe ${ }_{3}-\mathrm{SBF}^{95}{ }^{95}$-PhCbz-SBF ${ }^{95}$ and 4-SFA-SBF ${ }^{120}$

As depicted figure 21, 4-DBF-SBF and 4-DBT-SBF have been synthesized by the group of Liao from Suzuki coupling of 4-Br-SBF with respectively 4-(dibenzofuranyl)boronic acid 19 (Yield=75\%) or 4dibenzothienylboronic acid 20 (yield=80\%). Similarly, 4-PhOMe $-\mathbf{S B F}$ and 4-PhCbz-SBF were also synthesized with high yields $(83$ and $75 \%$ respectively) from 4-Br-SBF and 3,4,5trimethoxyphenylboronic acid $\mathbf{2 1}$ or 9H-carbazole-9-(4-phenyl) boronic acid pinacol ester $\mathbf{2 2}$ respectively. The 4-SFA-SBF has also been synthesized in a similar manner, through the coupling of 4$\mathrm{Br}$-SBF with the spirofluorene phenylacridine derivative $\mathbf{2 3}$ (yield=52\%).

\section{Structural Properties}

No X-ray data have been reported neither for 4-DBF-SBF ${ }^{118}$ nor for 4-DBT-SBF. ${ }^{119}$ However, for the 2substituted derivatives, 2-DBF-SBF and 2-DBT-SBF, angles as high as $53.5^{\circ}$ between the two linked phenyl units have been reported by the authors from X-Ray data. These large dihedral angles of 2substituted SBFs suggest that the 4-substituted SBFs should even possess larger angles. Molecular modelling of 4-DBF-SBF and 4-DBT-SBF confirms this feature revealing large dihedral angles of $63.9^{\circ}$ and $76.1^{\circ}$, suggesting an intense $\pi$-conjugation breaking between the fluorene and either the dibenzofuran or the dibenzothiophene. Moreover, molecular modelling performed for 4-SFA-SBF and 4-SFA-SFA reveals a larger angle close to $90^{\circ}$ between the two ortho connected fluorene cores. ${ }^{120}$
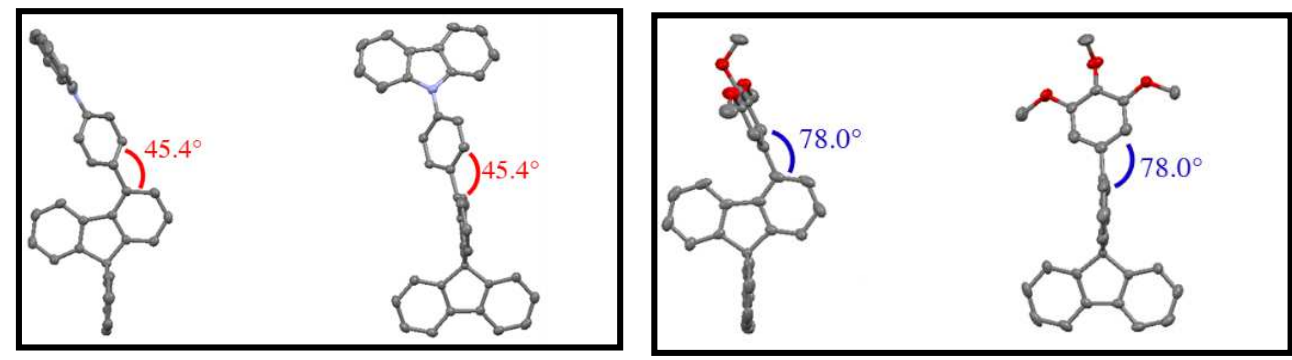

Figure 22. Molecular structures of 4-PhCbz-SBF (left) and of 4-PhOMe ${ }_{3}$-SBF (right) from X-Ray data. ${ }^{95}$

The only available $X$-ray data of 4-substituted SBFs incorporating electron rich fragments are those recently reported for 4-PhCbz-SBF and 4-PhOMe ${ }_{3}$-SBF (Figure 22).$^{95}$ Thus, the angle between the mean plane of the fluorene and that of its C4-substituent is reported at $45.4^{\circ}$ for $4-\mathrm{PhCbz}-\mathrm{SBF}$ and at $78^{\circ}$ for 4-Ph(OMe) ${ }_{3}$-SBF. Despite a larger substituent attached, 4-PhCbz-SBF displays a smaller angle than that 
of 4-Ph(OMe) ${ }_{3}$-SBF. The authors conclude that the substitution pattern, i.e. meta/para vs para, of the pendant phenyl has a stronger impact on the angle than the bulkiness of the substituent itself. Compared to unsubstituted 4-Ph-SBF, ${ }^{81}$ the fluorene/phenyl angle is slightly smaller for 4-PhCbz-SBF and much larger for 4-Ph(OMe) ${ }_{3}-\mathrm{SBF}$, translating different $\pi$-conjugation breaking. Regarding the deformation of the substituted fluorene, two different cases are reported. First, for 4-PhCbz-SBF, a strong deformation of the substituted fluorene core, $11.2^{\circ}$, is reported (similar to that of 4-Ph-SBF, $\left.12.7^{\circ}\right) .{ }^{81}$ However, it is difficult to rationalize these fluorene foldings since a very small angle of $2.7^{\circ}$ is reported for 4-Ph(OMe) ${ }_{3}$-SBF. ${ }^{95}$

\section{Electronic properties}

The electronic properties of the couples 4-DBF-SBF/2-DBF-SBF and 4-DBT-SBF/2-DBT-SBF are similar and in accordance with those exposed above, highlighting the limited influence of the sulphur and oxygen atom on the electronic properties. $\Delta \mathrm{E}^{\text {opt }}$ are reported at $3.52 / 3.83 \mathrm{eV}$ for 2-DBF-SBF/4-DBF$\mathbf{S B F}^{118}$ and 3.5/3.7 eV for 2-DBT-SBF/4-DBT-SBF. ${ }^{119}$ The dibenzofuran leads hence to a less extended conjugation compared to dibenzothiophene and hence to a slightly wider $\Delta \mathrm{E}_{\mathrm{opt}}$. 4-SFA-SBF and 4-SFASFA also present a main band at $308 \mathrm{~nm}$ (fluorene/fluorene transition) giving a wide $\Delta \mathrm{E}^{\text {opt }}$ of $3.93 \mathrm{eV}$ for both compounds. ${ }^{120}$ In fluorescence spectroscopy, the classical unresolved band is reported for 4DBF-SBF, this band being red shifted by $19 \mathrm{~nm}$ compared to that of 2-DBF-SBF (369 vs $350 \mathrm{~nm}$ ). 4-SFASBF and 4-SFA-SFA display a similar behaviour with a large band at 380 and $387 \mathrm{~nm}$ respectively. However, the couple 4-DBT-SBF/2-DBT-SBF does not follow this classical trend as 4-DBT-SBF displays a blue shifted band (355 nm) compared to that of 2-DBT-SBF (366 nm). Thus, if the band of 4-DBT-SBF can be seen as classical, that of 2-DBT-SBF appears surprising. This peculiar feature, surely due to the presence of the dibenzothiophene and/or to its anchoring position on the fluorene core is not detailed by the authors.
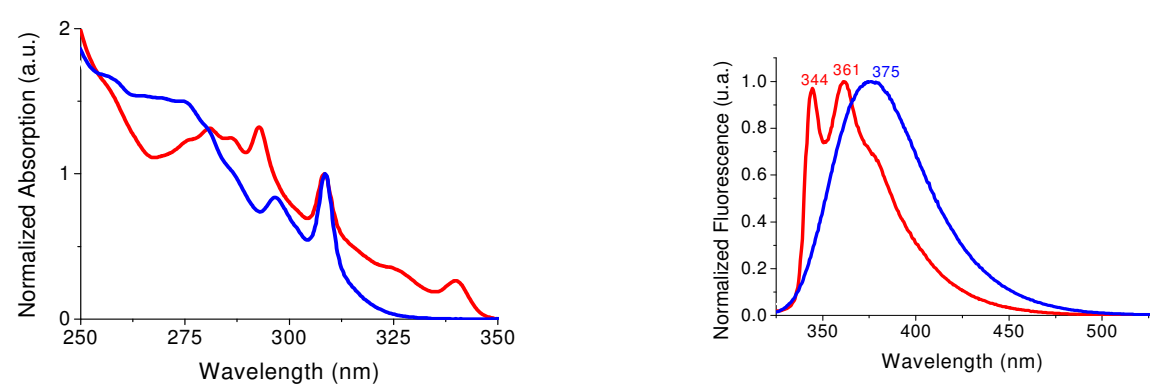

Figure 23. Normalized Absorption (left) and emission (right, $\lambda_{\text {exc }}: 309 \mathrm{~nm}$ ) spectra of 4-PhCbz-SBF (red lines) and of 4-Ph(OMe) ${ }_{3}$-SBF (blues lines) recorded in cyclohexane, $\mathrm{C}: 10^{-6} \mathrm{M}$

As presented figure 23 , both 4-Ph(OMe $)_{3}$-SBF and 4-PhCbz-SBF present the same absorption band $\left(\lambda_{\max }=309 \mathrm{~nm}\right)$ similar to that of SBF and 4-Ph-SBF (transitions occurring on the SBF core). For 4-Ph(OMe) ${ }_{3}$-SBF, the contribution at $309 \mathrm{~nm}$ presents the 'classical' wavelength tail exposed all along this review, leading to a $\Delta \mathrm{E}^{\mathrm{opt}}$ of $3.82 \mathrm{eV}$ (Figure 23-left). As above mentioned with pyridine isomers, this tail possess different intensities translating different coupling intensities between the fluorene and is subsituent. ${ }^{71}$ Herein, the intensity of the tail is almost identical between 4-Ph-SBF and 4-Ph(OMe $)_{3}$-SBF showing that the trimethoxy units only have a weak influence on the absorption. This conjugation effect cannot be explored in the case of 4-PhCbz-SBF because of the presence of an additional band at $340 \mathrm{~nm}$, assigned by the authors to transitions exclusively implying the $\mathrm{N}$-phenyl carbazole fragment ( $\Delta \mathrm{E}^{\text {opt }}$ 4-PhCbz-SBF: $\left.3.58 \mathrm{eV}\right) .^{95}$

As observed for other 4-substituted SBFs (see above), the fluorescence spectrum of 4-Ph(OMe) ${ }_{3}-\mathrm{SBF}$ is structureless ( $\lambda=375 \mathrm{~nm}$, Figure 23-right). The authors noted that the fluorescence spectrum of 4$\mathrm{Ph}(\mathrm{OMe})_{3}$-SBF displays the same shape than that of 4-Ph-SBF but shifted by $17 \mathrm{~nm}(\lambda=359 \mathrm{~nm})$. Thus, both molecules possess a very large Stokes shift, which is one of the characteristics of the uncommon fluorescence of 4-substituted SBFs. ${ }^{69,70,81,88,116,118,119}$ The authors provide in this work ${ }^{95}$ the beginning of an answer. Indeed, the large Stokes shift can found its origin in the significant differences between 
the geometries of the ground (SO) and first singlet excited (S1) states observed for both 4-Ph(OMe $)_{3^{-}}$ SBF and 4-Ph-SBF through theoretical calculations. The geometry difference between S0 and S1 is also more pronounced for 4-Ph(OMe) ${ }_{3}$-SBF than for 4-Ph-SBF explaining the difference observed in term of Stokes shift. Thus, due to a low rigidity, which allows important rearrangements at the excited state, these two molecules and more generally the 4-substituted SBFs possess large and unresolved fluorescence spectra.

4-PhCbz-SBF appears as a unique example in the 4-substituted SBFs family reported to date as it has not only a well resolved emission spectrum $\left(\lambda_{\max }=345,361 \mathrm{~nm}\right.$, Figure 23-right, $)$ but also a small Stokes shift $(5 \mathrm{~nm})$. The authors correlate this feature with the very similar geometries of SO and S1 obtained by molecular modelling. ${ }^{95}$ This is a significant difference with 4-Ph(OMe) ${ }_{3}$-SBF and 4-Ph-SBF above mentioned and all the other 4-substituted SBFs. Thus, the presence of the carbazole has a key role in the peculiar fluorescence of 4-PhCbz-SBF by avoiding molecular rearrangements between SO and S1. The high rigidity of 4-PhCbz-SBF could also explain the well resolved fluorescence compared to other 4-substituted SBFs. This is the first rationalization of the peculiar fluorescence of this family of dyes. ${ }^{95}$

Table 6. Selected electronical and physical data for 4-DBF-SBF/2-DBF-SBF ${ }^{118}$ 4-DBT-SBF/2-DBT-SBF, ${ }^{119}$ 4-PhOMe ${ }_{3}$ $\mathrm{SBF}^{95}{ }^{9-\mathrm{PhCbz}-\mathrm{SBF}}{ }^{95}$ and 4-SFA-SBF/4-SFA-SFA ${ }^{120}$

\begin{tabular}{|c|c|c|c|c|c|c|c|c|}
\hline & $\begin{array}{l}\text { 2-DBF- } \\
\text { SBF }^{118}\end{array}$ & $\begin{array}{l}\text { 4-DBF- } \\
\mathrm{SBF}^{118}\end{array}$ & $\begin{array}{l}\text { 2-DBT- } \\
\text { SBF }^{119}\end{array}$ & $\begin{array}{l}\text { 4-DBT- } \\
\text { SBF }^{119}\end{array}$ & $\begin{array}{l}\text { 4-PhOMe } \\
\mathrm{SBF}^{95}\end{array}$ & $\begin{array}{l}\text { 4-PhCbz- } \\
\text { SBF }^{95}\end{array}$ & $\begin{array}{l}\text { 4-SFA- } \\
\text { SBF }^{120}\end{array}$ & $\begin{array}{l}\text { 4-SFA- } \\
\text { SFA }^{120}\end{array}$ \\
\hline$\lambda_{\text {maxıabs }}(\mathrm{nm})$ & $\begin{array}{l}288, \\
308,326^{\text {a }}\end{array}$ & $279,308^{a}$ & $\begin{array}{l}290,308, \\
318^{\mathrm{a}}\end{array}$ & $286,309^{\mathrm{a}}$ & $297,309^{g}$ & $\begin{array}{l}293,309, \\
340^{g}\end{array}$ & $308^{a}$ & $308^{a}$ \\
\hline $\begin{array}{l}\lambda_{\text {max fluo }} \\
\text { solution }(\mathrm{nm})\end{array}$ & $350 / 366^{a}$ & $369^{a}$ & $366^{\mathrm{a}}$ & $355^{\mathrm{a}}$ & $375^{g}$ & $345 / 361^{g}$ & $380^{i}$ & $387^{i}$ \\
\hline $\begin{array}{l}\lambda_{\text {max, phospho }} \\
(77 \mathrm{~K})(\mathrm{nm})^{\mathrm{b}}\end{array}$ & 490 & 440 & 488 & 441 & 437 & 442 & 437 & 437 \\
\hline $\mathrm{E}_{\mathrm{T}}^{\mathrm{b}, \mathrm{c}}(\mathrm{eV})$ & 2.53 & 2.82 & 2.49 & 2.82 & 2.84 & 2.81 & 2.83 & 2.83 \\
\hline $\begin{array}{l}\Delta \mathrm{E}^{\mathrm{opt}}(\mathrm{eV}) \text { in } \\
\text { solution }\end{array}$ & 3.52 & 3.83 & 3.5 & 3.7 & 3.82 & 3.58 & 3.93 & 3.93 \\
\hline $\begin{array}{l}\Delta \mathrm{E}^{\mathrm{opt}}(\mathrm{eV}) \text { in } \\
\text { film }\end{array}$ & 3.54 & 3.79 & 3.4 & 3.6 & - & - & - & - \\
\hline $\mathrm{T}_{\mathrm{g}}\left({ }^{\circ} \mathrm{C}\right)$ & 115 & 124 & 122 & 131 & 90 & 127 & 188 & 189 \\
\hline $\mathrm{T}_{\mathrm{d}}\left({ }^{\circ} \mathrm{C}\right)$ & 302 & 305 & 318 & 317 & 340 & 410 & 402 & 408 \\
\hline HOMO $(\mathrm{eV})$ & $-5.83^{e}$ & $-6.00^{e}$ & $-6.1^{d}$ & $-6.3^{d}$ & $-5.62^{\mathrm{e}}$ & $-5.52^{\mathrm{e}}$ & $-5.33^{e}$ & $-5.31^{e}$ \\
\hline LUMO (eV) & $-2.31^{e}$ & $-2.17^{\mathrm{e}}$ & $-2.7^{f}$ & $-2.7^{f}$ & $-1.91^{\mathrm{e}}$ & $-1.97^{\mathrm{e}}$ & $-1.83^{h}$ & $-1.81^{h}$ \\
\hline
\end{tabular}

The $E_{T}$ of all the molecules presented in this part lye in the same short range. Thus, the $E_{T}$ of 4$\mathbf{P h}(\mathrm{OMe})_{3}$-SBF and 4-PhCbz-SBF are reported at 2.84 and $2.81 \mathrm{eV}$ respectively, those of 4-DBF-SBF and 4-DBT-SBF at $2.82 \mathrm{eV}^{118}$ and those of 4-SFA-SBF and 4-SFA-SFA at $2.83 \mathrm{eV}^{120}$

The HOMO/LUMO energy levels are always difficult to compare as not obtained in similar experimental conditions. Thus, the HOMO of 2-DBF-SBF measured by electrochemistry is lying at $-5.83 \mathrm{eV}$, being $0.17 \mathrm{eV}$ higher than that of 4-DBF-SBF $(-6.00 \mathrm{eV}) .{ }^{118}$ If one compare with that of 4-Ph-SBF $(-5.95 \mathrm{eV})$ and that of 2-Ph-SBF $(-5.88 \mathrm{eV})$, one can note that the trend is identical and translates the $\pi$-conjugation interruption in 4-DBF-SBF. The fact that the HOMO energy level of 4-DBF-SBF is lower than that of 4-Ph-SBF (and that of SBF, $-5.94 \mathrm{eV}$ ) may be related to the different experimental conditions. The LUMOs are respectively recorded at $-2.31 \mathrm{eV}$ and $-2.17 \mathrm{eV}$ for 2-DBF-SBF and 4-DBF-SBF translating a similar effect. The HOMOs of 2-DBT-SBF and 4-DBT-SBF have been evaluated by Ultraviolet Photoelectron Spectroscopy (UPS) at $-6.1 \mathrm{eV}$ and $-6.3 \mathrm{eV}^{119}$ and the values are hence different to those exposed above. However, a similar trend is found. The HOMO levels of 4-PhCbz-SBF and 4-Ph(OMe $)_{3^{-}}$ SBF, determined by cyclic voltammetry, respectively lye at $-5.52 \mathrm{eV}$ and at $-5.62 \mathrm{eV}$. These HOMO energy levels are very close to those of their corresponding electron donating fragment, N-PhCbz (- 
$5.59 \mathrm{eV})$ and $\mathrm{Ph}(\mathrm{OMe})_{3}(-5.67 \mathrm{eV})$, confirming the significant impact of these building blocks on the HOMO energies. ${ }^{95}$ However, the $\mathrm{C} 4$ substituted fluorene has a non-negligible influence on the HOMO energy levels as the conjugation is not completely broken. The HOMO energy levels of both 4-PhCbz-SBF and 4-Ph(OMe) ${ }_{3}$-SBF lye ca $0.3 / 0.45 \mathrm{eV}$ higher than that of 4-Ph-SBF (and those of 4-DBFSBF and 4-DBT-SBF), due the electron-rich character of the carbazole or the methoxy groups. Thus, the authors state that due to the conjugation disruption at the C4 position of SBF, the HOMOs are mainly governed by the electron-rich building blocks with nevertheless an influence of the SBF core.

Finally, in the case of 4-SFA-SBF and 4-SFA-SFA, the electron-rich phenylacridine also controls the HOMO levels reported through cyclic voltammetry at $-5.31 \mathrm{eV}$ and $-5.33 \mathrm{eV}$ respectively. ${ }^{70}$ These HOMO levels are very similar to those reported for other spiro compounds incorporating a phenylacridine core. ${ }^{59-61}$

\section{Thermal Properties}

The $T_{\mathrm{g}}$ is slightly increased from 2-DBF-SBF to 4-DBF-SBF (115 vs $124^{\circ} \mathrm{C}$ ) and from 2-DBT-SBF to 4-DBTSBF $\left(122\right.$ vs $\left.131^{\circ} \mathrm{C}\right)$, highlighting a substitution effect, which is nevertheless rather weak. On the other hand, this position effect has almost no impact on the $T_{d}$ but the nature of the substituent has, the dibenzothiophene fragment leading to higher $\mathrm{T}_{d}$ than dibenzofuran. 4-Ph(OMe) ${ }_{3}-\mathrm{SBF}$ and 4-PhCbz-SBF respectively present $T_{g} / T_{d}$ of $90 / 340^{\circ} \mathrm{C}$ and $127 / 410^{\circ} \mathrm{C}$. Thus, the presence of the carbazole core not only significantly modifies the electronic properties but also strongly enhances the physical properties of the resulting material. 4-PhCbz-SBF displays the highest $\mathrm{T}_{d}$ in this series $\left(410^{\circ} \mathrm{C}\right)$. 4-SFA-SBF and 4SFA-SFA also have excellent thermal properties with $T_{g} / T_{d}$ reported at $188 / 402^{\circ} \mathrm{C}$ and at $189 / 408^{\circ} \mathrm{C}$ respectively. It should be stressed that 4-SFA-SBF and the PHC dimer 4,4'-(SBF) $\mathbf{2}_{\mathbf{2}}$ (Figure 7) ${ }^{70}$ only differs by the presence of a spiroconnected phenylacridine in the former instead of a spiro connected fluorene in the latter. As $4,4^{\prime}-(\mathrm{SBF})_{2}$ possesses a $T_{d}$ of $360^{\circ} \mathrm{C}$ and a $T_{g}$ of $170^{\circ} \mathrm{C}$, one can conclude that switching from fluorene to phenylacridine leads to an enhancement of the thermal properties.

\section{Phosphorescent OLEDs}

Table 7. Selected PhOLEDs data for 4-DBF-SBF/2-DBF-SBF ${ }^{118}$ 4-DBT-SBF/2-DBT-SBF, ${ }^{119}$ 4-PhOMe ${ }_{3}$-SBF, ${ }^{95}$ 4PhCbz-SBF, ${ }^{95}$ and 4-SFA-SBF/4-SFA-SFA ${ }^{120}$

\begin{tabular}{|c|c|c|c|c|c|c|c|c|}
\hline & $\begin{array}{l}\text { 2-DBF- } \\
\text { SBF }^{b}\end{array}$ & $\begin{array}{l}\text { 4-DBF- } \\
\text { SBF }^{\text {b or c }}\end{array}$ & $\begin{array}{l}\text { 2-DBT- } \\
\text { SBF }^{\text {b }}\end{array}$ & $\begin{array}{l}\text { 4-DBT- } \\
\text { SBF }^{\text {b or c }}\end{array}$ & $\begin{array}{c}\text { 4-PhOMe } \mathrm{PH}_{3} \\
\mathrm{SBF}^{\text {a or d }}\end{array}$ & $\begin{array}{l}\text { 4-PhCbz- } \\
\text { SBF }^{\text {a or d }}\end{array}$ & $\begin{array}{l}\text { 4-SFA- } \\
\text { SBF }^{\mathrm{e}}\end{array}$ & $\begin{array}{l}\text { 4-SFA- } \\
\text { SFA }\end{array}$ \\
\hline & \multicolumn{8}{|c|}{ Green Devices with dopant $\operatorname{Ir}(p p y)_{3}{ }^{a}$ or $\operatorname{Ir}(p p y)_{2} a c a c^{b}$} \\
\hline $\mathrm{EQE}(\%)^{f}$ & 20.2 & 21.2 & 15 & 16.3 & 20.2 & 17.5 & - & - \\
\hline$C E(c d / A)^{f}$ & 59.3 & 64.4 & 56.9 & 62 & 78 & 67.9 & - & - \\
\hline$P E(L m / W)^{f}$ & 46.1 & 49.7 & 33.8 & 45.9 & 48.1 & 45.4 & - & - \\
\hline \multirow[t]{2}{*}{$\mathrm{V}_{\text {on }}(\mathrm{V})$} & 4.9 & 4.9 & 5.3 & 5.3 & 4.15 & 3.7 & - & - \\
\hline & \multicolumn{8}{|c|}{ Blue Devices with dopant FIrpic } \\
\hline $\operatorname{EQE}(\%)^{f}$ & - & 7.5 & - & 10.3 & 9.6 & 6.7 & 14 & 19.1 \\
\hline$C E(c d / A)^{f}$ & - & 22.2 & - & 23.5 & 24.2 & 18 & 29.4 & 41 \\
\hline$P E(L m / W)^{f}$ & - & 16.4 & - & 16.6 & 13.9 & 11 & 30.4 & 42 \\
\hline $\mathrm{V}_{\text {on }}(\mathrm{V})$ & - & 5.6 & - & 6.7 & 4.2 & 3.75 & 2.9 & 2.8 \\
\hline
\end{tabular}

${ }^{a}$ ITO/CuPc $(10 \mathrm{~nm}) /$ NPB $(40 \mathrm{~nm}) /$ TCTA $(10 \mathrm{~nm}) /$ host:Ir(ppy) $)_{3}(9 \%)(20 \mathrm{~nm}) / \mathrm{TPBi}(40 \mathrm{~nm}) / \mathrm{LiF}(1.2 \mathrm{~nm}) / \mathrm{Al}(100 \mathrm{~nm})$

${ }^{\mathrm{b}}$ ITO/MoO $(10 \mathrm{~nm}) / \mathrm{NPB}(35 \mathrm{~nm}) /$ TCTA $(10 \mathrm{~nm}) /$ host: Ir $(\text { ppy) })_{2}$ acac $(8 \mathrm{wt} \%, 15 \mathrm{~nm}) / \mathrm{TPBi}(65 \mathrm{~nm}) / \mathrm{Liq}(20 \mathrm{~nm}) / \mathrm{Al}(100 \mathrm{~nm})$

ITO/ $\mathrm{MoO}_{3}(10 \mathrm{~nm}) / \mathrm{NPB}(80 \mathrm{~nm} / \mathrm{TCTA}(5 \mathrm{~nm}) /$ host:Flrpic $(8 \% \mathrm{wt} \%, 20 \mathrm{~nm}) /$ TPBi $(40 \mathrm{~nm}) / \mathrm{Liq}(2 \mathrm{~nm}) / \mathrm{Al}(100 \mathrm{~nm})$

${ }^{d}$ ITO/CuPc $(10 \mathrm{~nm}) / \mathrm{NPB}(40 \mathrm{~nm}) /$ TCTA $(10 \mathrm{~nm}) /$ host:FIrpic $(20 \mathrm{wt} \%, 10 \mathrm{~nm}) / \mathrm{TPBi}(40 \mathrm{~nm}) / \mathrm{LiF}(1.2 \mathrm{~nm}) / \mathrm{Al}(100 \mathrm{~nm})$

ITO/MoO $(10 \mathrm{~nm}) / \mathrm{TAPC}(60 \mathrm{~nm}) /$ host:FIrpic $(10 \mathrm{wt} \%, 15 \mathrm{~nm}) / \mathrm{TmpyPBi}(35 \mathrm{~nm}) / \mathrm{LiF}(1 \mathrm{~nm}) / \mathrm{Al}(120 \mathrm{~nm})$

'maximum values

PhOLEDs using bis[2-(2-pyridinyl- $N$ )phenyl-C](2,4-pentanedionato- $\left.\mathrm{O}^{2}, \mathrm{O}^{4}\right)$ iridium(III) (Ir(ppy) ${ }_{2}$ acac) as green phosphor were fabricated with 2-DBT-SBF/4-DBT-SBF and 2-DBF-SBF/4-DBF-SBF. ${ }^{118}$ As the device architectures are identical, the performances can be compared. The architecture is the following ITO/ $\quad \mathrm{MoO}_{3}(10 \mathrm{~nm}) / \mathrm{NPB}(35 \mathrm{~nm}) / \mathrm{TCTA}(10 \mathrm{~nm}) /$ host:Ir(ppy) ${ }_{2}$ acac $(8 \mathrm{wt} \%, 15 \mathrm{~nm})$ /TPBi(65nm)/Liq(2nm)/AI (100 nm). 4-DBT-SBF displays a higher performance than that of 2-DBT-SBF with an EQE of $16.3 \%$ vs $15 \%$, CE of 62 vs $56.9 \mathrm{~cd} / \mathrm{A}$ and PE of 45.9 vs $33.8 \mathrm{Lm} / \mathrm{W}$. A similar result was 
obtained with the couple 2-DBF-SBF/4-DBF-SBF. ${ }^{118}$ Indeed, the device using 4-DBF-SBF as host shows higher performances (EQE of 21.2\%, a CE of $64.4 \mathrm{~cd} / \mathrm{A}$ and a PE of $49.7 \mathrm{Lm} / \mathrm{W}$ ) than those reported for 2-DBF-SBF (EQE of 20.2\%, a CE of $59.3 \mathrm{~cd} / \mathrm{A}$ and a PE of $46.1 \mathrm{Lm} / \mathrm{W}$ ). These performances indicate (i) that 4-substituted SBFs are more efficient than 2-substituted SBFs and (ii) that dibenzofuran is strongly more efficient than dibenzothiophene to host Ir(ppy) ${ }_{2}$ acac (EQE of $21.2 \%$ vs $16.3 \%$ ). With an identical device configuration (but different layer thicknesses, table 7), 4-DBF-SBF and 4-DBT-SBF have also been incorporated as host for the sky blue emitter Flrpic. This time, this is 4-DBT-SBF, which presents the highest efficiency with an EQE of $10.3 \%$, a CE of $23.5 \mathrm{~cd} / \mathrm{A}$ and a PE of $16.6 \mathrm{Lm} / \mathrm{W}, 4-\mathrm{DBF}-\mathrm{SBF}$, displaying a lower performance with an EQE of $7.5 \%$, a CE of $22.2 \mathrm{~cd} / A$ and a PE of $16.4 \mathrm{Lm} / \mathrm{W}$. The $V_{\text {on }}$ of both devices are relatively high, 5.6 $\mathrm{V}$ for 4-DBF-SBF and 6.7 $\mathrm{V}$ for 4-DBT-SBF. This difference in term of host performance between green and blue phosphors highlights the strong difficulty to rationally design host materials for PhOLEDs.

4-Ph(OMe $)_{3}$-SBF and 4-PhCbz-SBF have also been studied in similar devices: ITO/CuPc(10 nm)/NPB(40 $\mathrm{nm}) / \mathrm{TCTA}(10 \mathrm{~nm}) /$ Host:Ir(ppy $)_{3}(9 \mathrm{wt} \%)(20 \mathrm{~nm}) / \mathrm{TPBi}(40 \mathrm{~nm}) / \mathrm{LiF}(1.2 \mathrm{~nm}) / \mathrm{Al}(100 \mathrm{~nm})$ for green devices and ITO/CuPc(10 nm)/NPB(40 nm)/TCTA(10 nm)/Host:FIrpic(19 wt\%)(20 nm)/TPBI (40nm)/LiF(1.2nm)/ $\mathrm{Al}(100 \mathrm{~nm})$ for blue devices. With green emitter $\operatorname{Ir}(\mathrm{ppy})_{3}$, 4-PhCbz-SBF presents a maximum EQE of $17.5 \%$, a CE of $67.9 \mathrm{~cd} / \mathrm{A}$ and a PE of $45.4 \mathrm{Lm} / \mathrm{W}$. With sky blue emitter Flrpic, the performance of 4PhCbz-SBF decreases with a maximum EQE of 6.7\%, a CE of $18 \mathrm{~cd} / \mathrm{A}$ and a PE of $11 \mathrm{Lm} / \mathrm{W}$. 4-Ph(OMe) 3- $^{-}$ SBF displays higher performance both in green and blue devices. Thus, with $\operatorname{Ir}(\mathrm{ppy})_{3}$, a maximum EQE of $20.2 \%$ is reached with a CE of $78 \mathrm{~cd} / \mathrm{A}$ and a PE of $48.1 \mathrm{Lm} / \mathrm{W}$. With Flrpic, the EQE is reported at 9.6\% (CE of $24.2 \mathrm{~cd} / \mathrm{A}$ and $\mathrm{PE}$ of $13.9 \mathrm{Lm} / \mathrm{W}$ ). Thus, the presence of the strong electron-donating trimethoxyphenyl group leads to efficient devices.

The best blue device performances in the series have been obtained using 4-SFA-SBF as host for FIrpic $(E Q E=14 \%, C E=29.4 \mathrm{~cd} / \mathrm{A}$ and $\mathrm{PE}=30.4 \mathrm{Lm} / \mathrm{W}) .^{70}$ This high performance is mainly due to the electronrich phenylacridine core which facilitates the holes injection. This feature is confirmed thanks to the higher performances reported for 4-SFA-SFA as host (EQE: $19.1 \%$, CE $41 \mathrm{~cd} / \mathrm{A}$ and PE $42 \mathrm{Lm} / \mathrm{W}$ ), clearly signing the efficiency of the phenylacridine fragment to host Flrpic. ${ }^{70}$

\section{Other dyes based on a 4-substituted SBF backbone}

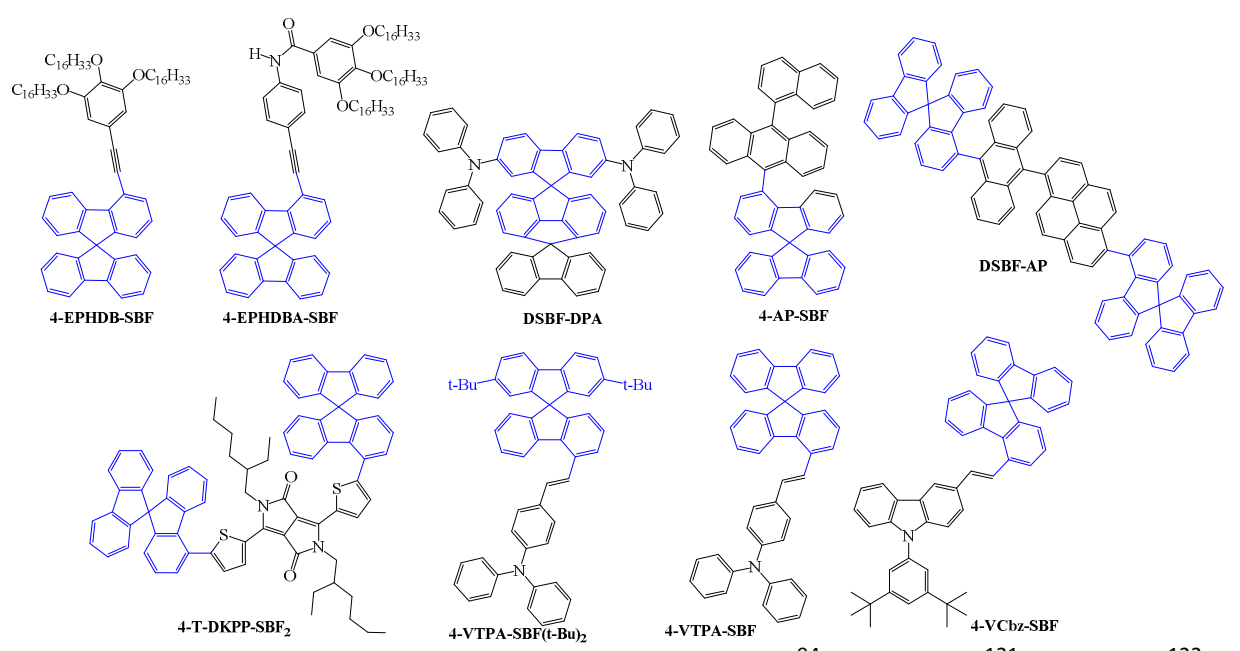

Figure 24. Molecular structures of 4-EPHDBA-SBF and 4-EPHDB-SBF, ${ }^{94}$ DSBF-DPA, $^{121}$ 4-AP-SBF, ${ }^{122}$ DSBF-AP, ${ }^{123}$ 4T-DKPP-SBF ${ }_{2}{ }^{124} 4$-VTA-SBF $(\mathrm{t}-\mathrm{Bu})_{2},{ }^{125}$ 4-VTPA-SBF and 4-VCbz-SBF ${ }^{126}$ 
Before concluding, it is important to mention that some other dyes incorporating the 4-substituted SBF scaffold have been reported for other applications than hosting phosphors in PhOLEDs. Indeed, recent works also have hilighted the potential of this platform for other applications such as blue emissive materials, ${ }^{94,123}$ blue dopant (guest) in fluorescent OLEDs, ${ }^{125,}{ }^{126}$ host in blue fluorescent OLEDs, ${ }^{122}$ hole transport material for green PhOLEDs ${ }^{121}$ or hole transport material for solar cells. ${ }^{124}$ To conclude, we wish to mention these dyes in order to well reflect the state of the art (Figure 24). 


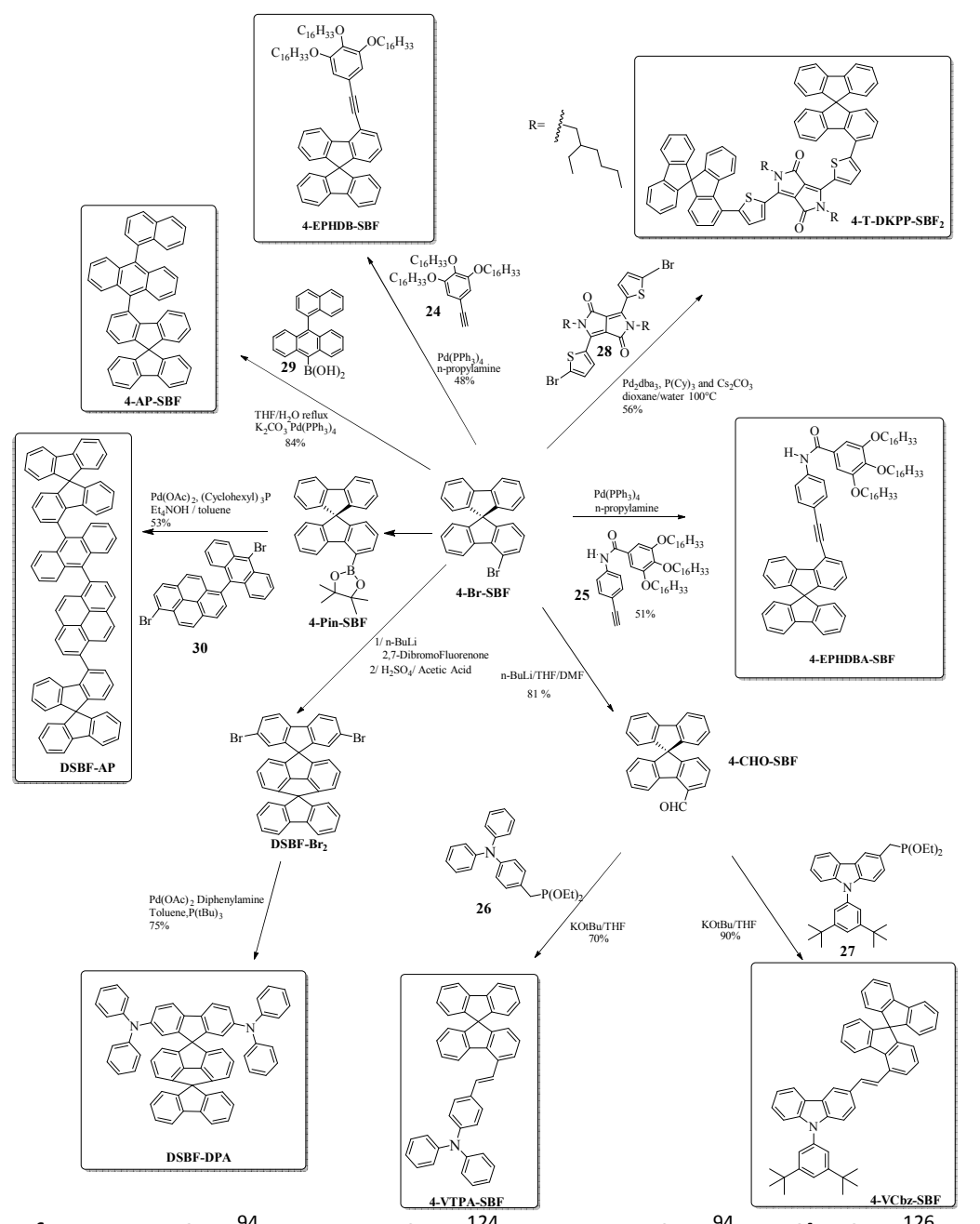

Figure 25: Synthesis of 4-EPHDB-SBF, ${ }^{94}$ 4-T-DKPP-SBF ${ }_{2}{ }^{124}$ 4-EPHDBA-SBF, ${ }^{94}$ 4-VCbz-SBF, ${ }^{126}$ 4-VTPA-SBF, ${ }^{126}$ DSBFDPA, ${ }^{121}$ DSBF-AP, ${ }^{123}$ and 4-AP-SBF ${ }^{122}$

4-Br-SBF platform is again the cornerstone of almost all the dyes reported in this last part (Figure 25). Thus, Camerel et al. have reported a convergent synthesis using the 4-SBF scaffold as connecting core. 4-EPHDB-SBF and 4-EPHDBA-SBF were synthesized in moderate yields of 48 and $51 \%$ respectively, by Sonogashira type cross-coupling reactions between 4-Br-SBF and two different ethynyl fragments either 24 (for 4-EPHDB-SBF) or 25 (for 4-EPHDBA-SBF). ${ }^{94}$ 4-T-DKPP-SBF 2 was synthesized by Leclerc et al. from the coupling of 4-Br-SBF and the bis-brominated DPP-based moiety 28 . The authors report a screening of different experimental conditions (catalyst, ligand and solvent) and the best conditions found (yield 56\%) involve the use of Tris(dibenzylideneacetone)dipalladium(0) $\left(\mathrm{Pd}_{2} \mathrm{dba}_{3}\right)$, tricyclohexylphosphine $\left(\mathrm{P}(\mathrm{Cy})_{3}\right)$ and $\mathrm{Cs}_{2} \mathrm{CO}_{3}$ in a dioxane/water mixture at a temperature of $100^{\circ} \mathrm{C}$ for 24 hours. ${ }^{124}$ A similar Suzuki coupling between 4-Br-SBF and [10-(1-Naphthyl)-9-anthryl]boronic acid 29 gives 4-AP-SBF with a high yield of $84 \% .{ }^{122}$ DSBF-AP was prepared in $53 \%$ yield by reaction of 4-PinSBF with 1-bromo-6-(9-bromo-anthracen-10-yl)-pyrene $\mathbf{3 0}$ in presence of $\mathrm{Pd}(\mathrm{OAC})_{2}, \mathrm{P}(\mathrm{Cy})_{3}$ and $\mathrm{Et}_{4} \mathrm{NOH}$ in toluene. ${ }^{123}$ Finally, the fused structure of DSBF-DPA ${ }^{121}$ was synthesized from the coupling of 4-BrSBF with 2,7-dibromofluorenone in the presence of BuLi followed by an intramolecular cyclisation on the $\mathrm{C} 5$ position of the same fluorene providing the fused structure $\mathrm{DSBF}-\mathrm{Br}_{2}$. Incorporation of the two amines was then classically performed $\left(\mathrm{Pd}(\mathrm{OAc})_{2}\right.$, diphenylamine, $\left.\mathrm{P}(\mathrm{tBu})_{3}\right)$ to give DSBF-DPA with $75 \%$. 4-CHO-SBF, ${ }^{126}$ involved in the synthesis of both 4-VTPA-SBF and that of 4-VCbz-SBF, was synthesized through the formylation of 4-Br-SBF using n-BuLi and DMF in a $81 \%$ yield. From 4-CHO-SBF and the corresponding phosphonate derivatives (26 or 27), the Horner-Wadsworth-Emmons reaction produced the corresponding compounds possessing either an arylamine (4-VTPA-SBF, yield 70\%) or $\mathrm{N}$ - 
arylcarbazole (4-VCbz-SBF, yield $90 \%) .{ }^{126}$ The synthesis of $4-\mathrm{VTPA}-\mathrm{SBF}(\mathbf{t}-\mathrm{Bu})_{2}$ is built on a similar strategy involving as key scaffold the 2',7'-di-tert-butyl-9,9'-spirobi[fluorene]-4-carbaldehyde. ${ }^{125}$

\section{Electronic Properties}

The electrochemical and optical properties of the molecules presented in this last part follow the rules detailed in the previous ones and hence will not be detailed. For example, the $\pi$-conjugation disruption between the fluorene and its C4-substituent is clearly highlighted by a blue shift in UV-Vis absorption for 4-T-DKPP-SBF 2 , 4-VTPA-SBF or 4-EPHDB-SBF compared to their C-2 isomers. ${ }^{94,124,126}$ However, and oppositely to the first parts, the molecular fragments borne by the carbon in $\mathrm{C} 4$ such as anthracene/pyrene in 4-AP-SBF, diketopyrrolopyrrole in 4-TDKPP-SBF ${ }_{2}$ or vinyl carbazole in 4-VTPASBF have high molar absorption coefficients. The resulting absorption spectra are hence strongly modified. 4-T-DKPP-SBF 2 provides an interesting example of such feature with strong absorptions between 300 and $650 \mathrm{~nm}^{124}$

To conclude, we would like to briefly state the different applications, in which such 4-substituted SBFs have been involved. First, in fluorescent OLED either as emitter (DSBF-AP) ${ }^{123}$ or as fluorescent dopant (4-AP-SBF, ${ }^{122}$ 4-VTA-SBF(t-Bu) ${ }_{2}{ }^{125}$ 4-VTPA-SBF and 4-VCbz-SBF). ${ }^{126}$

With DSBF-AP as blue emitter in the EML, the OLED has the following architecture: ITO(100nm)/ 2TNATA $(60 \mathrm{~nm}) / \mathrm{NPB}(15 \mathrm{~nm}) / \mathrm{DSBF}-\mathrm{AP}(35 \mathrm{~nm}) / \mathrm{Alq}_{3}$ or TPBi $(20 \mathrm{~nm}) / \mathrm{LiF}(1 \mathrm{~nm}) / \mathrm{Al}(200 \mathrm{~nm})$. The OLEDs start to emit light at $5.13 \mathrm{~V}$ (with $\mathrm{Alq}_{3}$ as ETL) or at $6.00 \mathrm{~V}$ (with TPBi as ETL) and reach EQE of ca $3 \%$ in both cases. The electroluminescence spectra present a maximum at 462/464 $\mathrm{nm}$ showing the efficiency of DSBF-AP as blue emitter. ${ }^{123}$

4-VTPA-SBF, 4-VCbz-SBF and 4-VTA-SBF(t-Bu) ${ }_{2}$ have been used as blue dopant (guest) in MADN (host). With EML: 4-VTPA-SBF $10 \mathrm{wt} \%$ in MADN, a maximum EQE of $3.4 \%$, LE of $3.9 \mathrm{~cd} / \mathrm{A}$ and PE of $2.4 \mathrm{Lm} / \mathrm{W}$ and $a V_{o n}$ of $5.1 \mathrm{~V}$ is reported. ${ }^{126}$ Using 4-VCbz-SBF (EML: 4-VCbz-SBF $10 \mathrm{wt} \%$ in MADN), despite a better charge injection and hence a lower $V_{\text {on }}$ of $4.1 \mathrm{~V}$, leads to a less efficient device with maximum EQE of $2.7 \%$, LE of $2.8 \mathrm{~cd} / \mathrm{A}$ and PE of $2.2 \mathrm{Lm} / \mathrm{W} .{ }^{126}$ The structurally related 4-VTPA-SBF $(t-B u)_{2}$ used in an almost identical device (EML: 4-VTPA-SBF(t-Bu $)_{2} 5 \mathrm{wt} \%$ in MADN) leads to comparable device performance: $V_{\text {on }}$ of $4.5 \mathrm{~V}$, EQE of $2.6 \%$, LE of $3.3 \mathrm{~cd} / \mathrm{A}$ and PE of $2.1 \mathrm{Lm} / \mathrm{W}^{125}$ It should be mentioned that this performance is lower than that of its 2-substituted regioisomer also studied by the authors ( $E Q E=3.7 \%, C E=4.5 \mathrm{~cd} / \mathrm{A}$ and $\mathrm{PE}=2.7 \mathrm{Lm} / \mathrm{W}$ ).

Table 8. Selected electronical and physical data for 4-AP-SBF, ${ }^{122}$ DSBF-AP, ${ }^{123}$ 4-EPHDBA-SBF, 4-EPHDB-SBF, ${ }^{94}$ 4VTPA-SBF, 4-VCbz-SBF, ${ }^{126}$ DSBF-DPA $^{121}, 4$-TDKPP-SBF ${ }_{2}{ }^{124}$ and 4-VTPA-SBF(t-Bu ${ }_{2}{ }^{125}$

\begin{tabular}{|c|c|c|c|c|c|c|c|c|c|}
\hline & 4-AP-SBF & DSBF-AP & $\begin{array}{c}\text { 4-EPHDBA- } \\
\text { SBF }\end{array}$ & $\begin{array}{c}\text { 4-EPHDB- } \\
\text { SBF }\end{array}$ & $\begin{array}{c}\text { 4-VTPA- } \\
\text { SBF }\end{array}$ & $\begin{array}{c}\text { 4-VCbz- } \\
\text { SBF }\end{array}$ & $\begin{array}{l}\text { DSBF- } \\
\text { DPA }\end{array}$ & $\begin{array}{c}\text { 4-TDKPP- } \\
\mathrm{SBF}_{2}\end{array}$ & $\begin{array}{l}\text { 4-VTPA- } \\
\text { SBF(t-Bu) }\end{array}$ \\
\hline $\begin{array}{c}\lambda_{\max , a b s} \\
(\mathrm{~nm})\end{array}$ & $\begin{array}{c}309,342,355 \\
374,394\end{array}$ & $351,379,400^{\mathrm{g}}$ & $\begin{array}{c}309,326 \\
348^{f}\end{array}$ & $\begin{array}{c}309,319 \\
341^{\mathrm{f}}\end{array}$ & $375^{a}$ & $362^{a}$ & $\begin{array}{l}309 \\
373\end{array}$ & 530,570 & $370^{a}$ \\
\hline $\begin{array}{l}\lambda_{\text {max fluo }} \\
\text { solution } \\
(\mathrm{nm})\end{array}$ & $403 / 413$ & $443^{g}$ & 371 & 401 & $448^{a}$ & $432^{a}$ & 404 & - & $468^{a}$ \\
\hline $\begin{array}{l}\lambda_{\text {max, fluo, }} \\
\text { thin film } \\
(\mathrm{nm})\end{array}$ & 415 verifier & 458 & 454 & 389 & 479 & 467 & - & - & 455 \\
\hline$\Phi_{\text {sol }}(\%)^{\mathrm{i}}$ & - & 0.83 & $\begin{array}{l}0.006 \\
(0.12)^{j}\end{array}$ & $0.37(0.39)^{j}$ & $0.95^{b}$ & $0.4^{b}$ & - & - & $0.65^{b}$ \\
\hline$\Delta \mathrm{E}^{\mathrm{opt}}(\mathrm{eV})$ & - & 2.94 & - & - & 2.91 & 2.91 & 3.12 & 2.02 & 2.93 \\
\hline $\begin{array}{l}\text { HOMO } \\
(\mathrm{eV})\end{array}$ & - & $-5.78^{c}$ & - & - & $-5.48^{c}$ & $-5.57^{d}$ & $-5.56^{e}$ & -5.65 & $-5.59^{c}$ \\
\hline $\begin{array}{c}\text { LUMO } \\
(\mathrm{eV})\end{array}$ & - & $-2.84^{h}$ & - & - & $-2.57^{c}$ & $-2.66^{d}$ & $-2.44^{d}$ & -3.75 & $-2.66^{d}$ \\
\hline
\end{tabular}


4-AP-SBF was used as a host material for the fluorescent dopant diphenyl-[4-(2-[1,1;4,1]terphenyl-4-ylvinyl)-phenyl]-amine (BD-1). With EML: 7wt\% BD-1 in 4-AP-SBF, the authors report an OLED displaying an EQE of ca $3.4 \% .{ }^{122}$

Finally, DSBF-DPA was employed as hole transporting material (HTM) in a green PhOLED $\left(E M L=\operatorname{Ir}(\mathrm{ppy})_{3}\right)$ in bis-9,9'-spirobi[fluoren-2- yl]-methanone (BSFM)) and the device performance was compared to that of a similar device using NPB instead of DSBF-DPA as HTM. ${ }^{121}$ The EQE obtained with the device using DSBF-DPA is reported at $16.5 \%$, which is much higher than that of the device using NPB (EQE $=10.4 \%$ ). The authors explain such performance improvement by the $E_{T}$ of DSBF-DPA (2.44 $\mathrm{eV})$ which is higher than that of $\operatorname{Ir}(\mathrm{ppy})_{3}(2.42 \mathrm{eV})$ preventing any quenching of the triplet exciton by DSBF-DPA (such a quenching may indeed occur using NPB as HTM, as the $E_{T}$ of NPB, $2.3 \mathrm{eV}$, is lower than that of $\left.\operatorname{Ir}(\mathrm{ppy})_{3}\right)$.

Another promising application has recently been reported by Leclerc et al. They have indeed reported the incorporation of a SBF core substituted in C4 (4-T-DKPP-SBF ${ }_{2}$ ) as end capper in a soluble electrondonor fragment for photovoltaic applications. ${ }^{124}$ Despite, the low OPV performances (lower than that of its $\mathrm{C} 2$ isomer), the authors show that the incorporation of SBF as a three-dimension platform into conjugated material backbones allows increasing the solubility despite the low density of grafted alkyl side chains and brings a more isotropic character to the charge transport properties of the final materials (hole mobilities are reported in the $6-7 \times 10^{-5} \mathrm{~cm}^{2} / \mathrm{V}$.s range). The authors also show that different molecular packing can be obtained depending of the substitution pattern (C2 vs C4) of the SBF core.

Finally, SBF based molecules have only been recently incorporated as the central core of a mesogenic molecule. $^{94}$ The grafting of $\mathrm{N}$-(ethynylphenyl) benzamide carrying hexadecyl carbon chains on a bulky dispiro[fluorene-9,11'-indeno[1,2-b]fluorene-12',9"-fluorene] core has for example allowed the emergence of strongly luminescent liquid crystalline phases. ${ }^{127}$ This strategy, which consists to attach protomesogenic fragments, on a $\pi$-conjugated backbone has hence been applied by Camerel et al. on a 4-substituted SBF scaffold leading to 4-EPHDBA-SBF and 4-EPHDB-SBF. ${ }^{94}$ This approach has allowed to tune the luminescence properties but also to control the self-organisation ability inside luminescent and fluid thin films. Of particular interest, 4-EPHDBA-SBF which was poorly emissive in solution is reported to present a higher quantum yield in the solid state, highlighting the interest of the strategy described by the authors to obtain efficient blue emitters in the solid state.

\section{Conclusion}

Through a structure properties relationhip approach, the present review reports the state of the art of an emerging family of molecules, namely the 4-substituted SBFs, regarding synthesis, physicochemical/photophysical properties and applications as host in PhOLEDs. If the substitution in position 2 of a SBF core has been widely developed to date, the substitution in position 4 is very recent (less than that 10 years) and still need to be explored. The main characteristic of this family of OSCs is the $\pi$ conjugation breaking occurring between the substituent in $\mathrm{C} 4$ and the fluorene backbone. This breaking of the conjugation is due to a large fluorene/substituent dihedral angle, which disrupts the electronic coupling between the two molecular fragments. Thus, as a function of the steric congestion induced by the substituent attached in $\mathrm{C} 4$, the intensity of the $\pi$-conjugation can be tuned. This is a key point, which will be surely developped in the future to control the intensity of the conjugation in such materials. Thanks to the spiro-bridge, excellent thermal and morphological properties are also reported for all the dyes built on a 4-substituted SBF scaffold, which are key properties for the lifetime of electronic devices. The substitution in $\mathrm{C} 4$ also leads to many other unusual features such as the deformation of the fluorene core or more interestingly the peculiar fluorescence emission. If the exact origin of the fluorescence emission of 4-substituted SBFs has not been yet fully understood and deserves a particular interest, some answers start to be very recently reported in the literature. ${ }^{95}$

The $\pi$-conjugation disruption present in 4-substituted SBF also leads to molecules possessing high triplet energy $E_{\mathrm{T}}$. This $\mathrm{E}_{\mathrm{T}}$ is to date the property, which has been the most used and particularly in 
PhOLEDs. Thus, thanks to their high $E_{T}$, 4-substituted SBFs have been successfully introduced as host for red, green and more importantly blue PhOLEDs. Some examples of high efficiency green and blue PhOLEDs have already been published but some improvements still need to be done. For example, bipolar materials built on a 4-substituted SBF core are still very rare and in the light of literature, these molecules can lead to a strong enhancement of green and blue PhOLEDs performance. ${ }^{53}$ Such molecules could also be used in single layer green or even blue PhOLEDs, which are also very rare in literature. In addition, recent works have also highlighted that the 4-substituted SBF can also be used for other applications than hosting phosphors in PhOLEDs. Indeed, compared to their 2-substituted analogues, different $\pi$-stacking can be obtained with 4-substituted SBF, which can lead to very different solid state properties. ${ }^{94,124}$ This structural particularity will be surely use in the future in the field of organic solar cells and more generally in materials science.

To conclude, 4-substituted SBFs have appeared in the last years as very interesting and promising OSCs mainly to host green and blue phosphors in PhOLEDs but also very recently for other applications such as solar cells. We are convinced that these molecules can become, as their 2-substituted counterparts, an important family of OSCs for organic electronics.

\section{Acknowledgments:}

The authors would like to highly thank all their collaborators which have strongly contribute to the developments of 4-substituted SBFs in the group. They would like to highly thank Dr D. Tondelier and B. Geffroy (Paris Saclay) for the PhOLEDs fabrications and characterizations, Dr M. Romain, Dr S. Thiery, Dr O. Jeannin, Dr C. Quinton, L. Sicard (Rennes) for synthesis, physicochemical analyses, molecular modelling, and Dr E. Jacques (Rennes) for mobility measurements. They thank the CDIFX and CRMPO (Rennes), the CINES (project 2016085032, Montpellier), the ANR (HOME-OLED project $n^{\circ} 11$ BS07-020-01 and MEN IN BLUE project n¹4-CE05-0024), the Région Bretagne and the ADEME (Dr B. Laffite).

\section{ACRONYMES used in this review}

2,7-Br - -SBF: 9,9'-Spirobi[9H-fluorene], 2,7-dibromo-

2-DBF-SBF: 2-(9,9'-spirobi[9H-fluoren]-2-yl)-dibenzofuran

2-DBT-SBF: 2-(9,9'-spirobi[9H-fluoren]-2-yl)-dibenzothiophene

2,7-DiCbz-SBF-4'-POPh $\mathbf{2}$ : 9,9'-(4'-diphenyl-phosphine oxide-9,9'-spirobi[9H-fluorene]-2,7-diyl)bis-9H-carbazole

2-Ph-SBF: 2-phenyl-9,9'-spirobi[fluorene]

2-POPh $\mathbf{2}$-SBF: diphenyl-9,9'-spirobi[9H-fluoren]-2-yl- phosphine oxide

2-4Py-SBF: 4-(9,9'-spirobi[fluoren]-2-yl)pyridine

2-5Pm-SBF: 5-(9,9'-spirobi[fluoren]-2-yl)pyrimidine

2,2'-(SBF) 2 : 2,2"'-Bi-9,9'-spirobi[9H-fluorene]

2,2'-(SBF) ${ }_{3}: 2,2^{\prime \prime}: 2$ '"',2'"'-Ter-9,9'-spirobi[9H-fluorene]

2,7,4'-(SBF) $)_{3}$ : 2,7-di(9,9'-spirofluorenyl-4-yl)-9,9'-spirobifluorene

2,7,2'-(SBF) 3 : 2,2":7",2'"'-Ter-9,9'-spirobi[9H-fluorene]

2,7,2'-(SBF) $)_{4}: 2,2^{\prime \prime}: 7^{\prime \prime}, 2$ "'":7'"',2'"'"'-Quater-9,9'-spirobi[9H-fluorene]

3-B(OH) ${ }_{2}$-SBF: 9,9'-spirobi[fluoren]-3-ylboronic acid

4-AP-SBF: 4-(10-(naphtalen-1-yl)anthracen-9-yl)-9,9'-spirobi[fluorene]

4-Br-SBF: 4-bromo-9,9'-spirobifluorene

4,4'-Br ${ }_{2}$-SBF: 4,4'-dibromo-9,9'-Spirobi[9H-fluorene]

4-DBF-SBF: 4-(9,9'-spirobi[9H-fluoren]-4-yl)-dibenzofuran

4-DBT-SBF: 4-(9,9'-spirobi[9H-fluoren]-4-yl)-dibenzothiophene

4-EPHDB-SBF: 4-((3,4,5-tris(hexadecyloxy)phenyl)ethynyl)-9,9'-spirobi[fluorene]

4-EPHDBA-SBF: N-(4-(9,9'-spirobi[fluoren]-4-ylethynyl)phenyl)-3,4,5-tris(hexadecyloxy)benzamide

4,4'-FO-SBF: 4-(9,9'-spirobi[9H-fluoren]-4-yl)- $9 H$-Fluoren-9-one

4,4'-Pin 2 -SBF: 4,4'-(9,9'-spirobi[9H-fluorene]-4,4'-diyl)bis[4,4,5,5-tetramethyl-1,3,2-Dioxaborolane]

4-Pin-SBF: 4-(9,9'-spirobi[fluoren]-4-yl)-4,4,5,5-tetramethyl-1,3,2-dioxaborolane

4-Ph-SBF: 4-phenyl-9,9'-spirobi[fluorene]

4-PhCBz-SBF: 4-N-phenyl-carbazole-9,9'-spirobi[fluorene]

4-PhOMe - -SBF: 4-(3,4,5-trimethoxyphenyl)-9,9'-spirobi[fluorene]

4-POPh $\mathbf{P}_{2}$-SBF: diphenyl-9,9'-spirobi[9H-fluoren]-4-yl-Phosphine oxide

4-4Py-SBF: 4-(9,9'-spirobi[fluoren]-4-yl)pyridine

4-3Py-SBF: 3-(9,9'-spirobi[fluoren]-4-yl)pyridine

4-2Py-SBF: 2-(9,9'-spirobi[fluoren]-4-yl)pyridine

4-5Pm-SBF: 5-(9,9'-spirobi[fluoren]-4-yl)pyrimidine

4-SFA-SFA: 10,10 '-diphenyl-4',4"-bispiro[acridine-9(10H),9'-[9H]fluorene] 
4-SFA-SBF: $10-$ phenyl-4'-(9,9'-spirobi[9H-fluoren]-4-yl)-spiro[acridine-9(10H),9'-[9H]fluorene]

4,4'-(SBF) $)_{2}$ : 4-(9,9'-spirofluorenyl-4-yl)-9,9'-spirobifluorene

4,3'-(SBF) 2 : 3,4'-Bi-9,9'-spirobi[9H-fluorene]

4,4'-(SBF) $)_{3}: 4,4^{\prime \prime}: 4^{\prime \prime \prime}, 4^{\prime \prime \prime '-T e r-9,9 '-s p i r o b i[9 H-f l u o r e n e] ~}$

4,4'-(SBF) $)_{4}: 4,4$ "':4"',4"'"':4"'"',4"'"'-Quater-9,9'-spirobi[9H-fluorene]

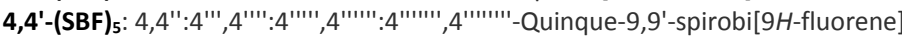

4-T-DKPP-SBF 2 : 3,6-bis(5-(9,9'-spirobi[fluoren]-5-yl)thiophen-2-yl)-2,5-bis(2-ethylhexyl)pyrrolo[3,4-c]pyrrole-1,4(2H,5H)-dione

4-VCbz-SBF: (E)-3-(2-(9,9'-spirobi[fluoren]-4-yl)vinyl)-9-(3,5-di-tert-butylphenyl)-9H-carbazole

4-VTPA-SBF: (E)-4-(2-(9,9'-spirobi[fluoren]-4-yl)vinyl)-N,N-diphenylaniline

4-VTPA-SBF(t-Bu) 2 : (E)-4-(2-(2',7'-di-tert-butyl-9,9'-spirobi[fluoren]-4-yl)vinyl)-N,N-diphenylaniline

AcOH: acetic acid

Alq3: tris(8-hydroxyquinoline)aluminum

BCP: 2,9-dimethyl-4,7-diphenyl-1,10-phenanthroline

BD-1: diphenyl-[4-(2-[1,1';4',1"]terphenyl-4-yl-vinyl)-phenyl]-amine

BSFM : bis-9,9'-spirobi[fluoren-2-yl]-methanone

(Btp) $\mathbf{2}$ Ir(acac): bis[2-(20-benzo[4,5-a]thienyl)pyridinato-N,C30] iridium(acetylacetonate)

CE: Current efficiency (in OLED or PhOLED)

$\mathrm{ClPPh}_{2}$ : chlorodiphenylphosphine

CuPc: copper phthalocyanine

DCM: dichloromethane

$\Delta \mathrm{E}^{\mathrm{el}}$ : electrochemical band gap

$\Delta \mathrm{E}^{\mathrm{opt}}$ : optical energy gap

DMF: $N, N$-Dimethylformamide

DNTPD: N,N'-diphenyl-N,N'-bis-[4-(phenyl-m-tolyl-amino)-phenyl]-biphenyl-4,4'-diamine

DSBF-DPA: N,N,N',N'-tetraphenyl-spiro(cyclopenta[de]fluorene-1,5,9',9'--bifluorene)-2',7'-diamine

DSF[2,1-c]IF: dispiro[fluorene-9,5'-indeno[2,1-c]fluorene-8',9"'-fluorene]

DSBF-AP: 1-spiro-9,9'-bifluoren-4-yl-6-(10-spiro-9,9'-bifluoren-4-yl-anthracen-9-yl)-pyrene

DSC: differential scanning calorimetry

EML: emitting layer (in OLED or PhOLED)

EQE: external quantum efficiency (in OLED or PhOLED)

$\mathrm{E}_{\mathrm{T}}$ : triplet energy

FIrpic: Bis[2-(4,6-difluorophenyl)pyridinato- $\left.C^{2}, N\right]$ (picolinato)iridium(III)

HAT-CN: Dipyrazino[2,3-f:2', 3'-h]quinoxaline 2,3,6,7,10,11-hexacarbonitrile

HOMO: Highest Occupied Molecular Orbital

HTM: Hole Transporting Material

Ir(ppy) ${ }_{2}$ acac: Bis[2-(2-pyridinyl- $N$ )phenyl-C] (2,4-pentanedionato- $\left.\mathrm{O}^{2}, \mathrm{O}^{4}\right)$ iridium(III)

$\operatorname{Ir}(\text { ppy })_{3}$ : Tris $\left[2\right.$-phenylpyridinato- $\left.C^{2}, N\right]$ iridium(III)

ITO: Indium-Tin oxide

$\mathrm{K}_{2} \mathrm{CO}_{3}$ : potassium carbonate

$\mathrm{k}_{\mathrm{nr}}$ : non radiative rate constant

$\mathrm{k}_{\mathrm{r}}$ : radiative rate constant

LiF: Lithium fluoride

Liq: 8-Hydroxyquinolinolato-lithium

LUMO: Lowest Unoccupied Molecular Orbital

MADN: 2-methyl-9,10-di(2-naphthyl)anthracene

mCP: $N, N^{\prime}$-dicarbazolyl-3,5-benzene

2-Me-THF: 2-Methyltetrahydrofuran

$\mathrm{MoO}_{3}$ : Molybdenum trioxide

NPB: N'-di(1-naphtyl)-N,N'-diphenylbenzidine

MsOH: methanesulfonic acid

n-BuLi: n-Butyllithium

OLED: organic light-emitting diode

OSC: Organic Semi-Conductor

$\mathbf{P}(\mathrm{Cy})_{3}$ : Tricyclohexylphosphine

$\mathbf{P d}_{2} \mathbf{d b a}_{3}$ : Tris(dibenzylideneacetone)dipalladium(0)

Pd(dppf) $\mathrm{Cl}_{2}$ : [1,1'-Bis(diphenylphosphino)ferrocene]dichloropalladium(II)

$\mathrm{Pd}(\mathrm{OAc})_{2}$ : Palladium(II) acetate

$\mathbf{P d}\left(\mathbf{P P h}_{3}\right)_{4}$ : Tetrakis(triphenylphosphine)palladium(0)

PE: power efficiency (in OLED or PhOLED)

PEDOT-PSS: polyethylenedioxythiophene-polystyrene sulfonate

PHC: pure hydrocarbon

$\mathrm{Ph}_{2} \mathrm{Br}$ : 2-bromo-biphenyl

PhOLED: phosphorescent organic ligth-emitting diode

(ppq) $)_{2} \operatorname{Ir}(\mathbf{a c a c})$ : bis(2,4-diphenylquinolyl-N,C2')iridium(acetylacetonate)

$\Phi_{\text {sol }}$ : quantum yield

rt: room temperature

SBF: 9,9'-spirobifluorene

SBF: spirobifluorene

Spiro-2CBP: 2,7-Bis(carbazol-9-yl)-9,9-spirobifluorene

Spiro-OMeTAD : 2,2',7,7'-Tetrakis[N,N-di(4-methoxyphenyl)amino]-9,9'-spirobifluorene

TAPC: Di-[4-(N,N-di-p-tolyl-amino)-phenyl]cyclohexane 
$\mathrm{T}_{\mathrm{d}}$ : decomposition temperature

$\mathrm{T}_{\mathrm{g}}$ : glass transition temperature

TGA: thermogravimetric analysis

TCTA: Tris(4-carbazoyl-9-ylphenyl)amine

THF: tetrahydrofuran

TMEDA: Tetramethylethylenediamine

TmPyPB: 1,3,5-Tri[(3-pyridyl)-phen-3-yl]benzene

TPBi: 2,2',2"-(1,3,5-Benzinetriyl)-tris(1-phenyl-1-H-benzimidazole)

$\mathrm{V}_{\text {on }}$ : threshold voltage (in OLED or PhOLED)

\section{REFERENCES}

1 L.-H. Xie, J. Liang, J. Song, C.-R. Yin and W. Huang, Current Organic Chemistry, 2010, 14, 2169.

2 T. P. I. Saragi, T. Spehr, A. Siebert, T. Fuhrmann-Lieker and J. Salbeck, Chem. Rev., 2007, 107, 1011.

3 M. Romain, S. Thiery, A. Shirinskaya, C. Declairieux, D. Tondelier, B. Geffroy, O. Jeannin, J. Rault-Berthelot, R. Métivier and C. Poriel, Angew. Chem. Int. Ed., 2015, 54, 1176.

4 M. Romain, D. Tondelier, J.-C. Vanel, B. Geffroy, O. Jeannin, J. Rault-Berthelot, R. Métivier and C. Poriel, Angew. Chem. Int. Ed., 2013, 52, 14147.

5 R. Mertens, The OLED Handbook: A Guide to OLED Technology, Industry \& Market, 2012 edition, 2012.

6 R. S. Sanchez and E. Mas-Marza, Solar Energy Materials and Solar Cells, 2016, 158, Part 2, 189.

7 N.-G. Park, Materials Today, 2015, 18, 65.

8 D. Thirion, C. Poriel, R. Métivier, J. Rault-Berthelot, F. Barrière and O. Jeannin, Chem. Eur. J., 2011, $17,10272$.

9 C. Poriel, J. Rault-Berthelot, D. Thirion, F. Barrière and L. Vignau, Chem. Eur. J., 2011, 17, 14031.

10 D. Horhant, J.-J. Liang, M. Virboul, C. Poriel, G. Alcaraz and J. Rault-Berthelot, Org. Lett., 2006, 8, 257.

11 C. Poriel, J. Rault-Berthelot, F. Barrière and A. M. Z. Slawin, Org. Lett., 2008, 10, 373.

12 D. Thirion, M. Romain, J. Rault-Berthelot and C. Poriel, J. Mater. Chem., 2012, 22, 7149.

13 L.-H. Xie, X.-Y. Hou, C. Tang, Y.-R. Hua, R.-J. Wang, R.-F. Chen, Q.-L. Fan, L.-H. Wang, W. Wei, B. Peng and W. Huang, Org. Lett., 2006, 8, 1363.

14 F. Barrière, C. Poriel and J. Rault-Berthelot, Electrochim. Acta, 2013, 110, 735.

15 C. Poriel, F. Barrière, D. Thirion and J. Rault-Berthelot, Chem. Eur. J., 2009, 15, 13304.

16 J.-H. Xie and Q.-L. Zhou, Acc. Chem. Res., 2008, 41, 581.

17 C. Poriel, Y. Ferrand, P. Le Maux, J. Rault-Berthelot and G. Simonneaux, Synth. Met., 2008, 158, 796.

18 X. Cheng, Q. Zhang, J.-H. Xie, L.-X. Wang and Q.-L. Zhou, Angew. Chem. Int. Ed., 2005, 44, 1118.

19 X. Cheng, S.-F. Zhu, X.-C. Qiao, P.-C. Yan and Q.-L. Zhou, Tetrahedron, 2006, 62, 8077.

20 D. Lorcy, L. Mattiello, C. Poriel and J. Rault-Berthelot, J. Electroanal. Chem., 2002, 530, 33.

21 C. Poriel, Y. Ferrand, P. Le Maux, C. Paul-Roth, G. Simonneaux and J. Rault-Berthelot, J. Electroanal. Chem., 2005, 583, 92.

22 Y. Ferrand, C. Poriel, P. Le Maux, J. Rault-Berthelot and G. Simonneaux, Tetrahedron Asymmetry, 2005, 16, 1463.

23 C. Poriel, Y. Ferrand, P. Le Maux, J. Rault-Berthelot and G. Simonneaux, Inorg. Chem., 2004, 43, 5086.

24 C. Poriel, Y. Ferrand, P. Le Maux, J. Rault-Berthelot and G. Simonneaux, Chem. Commun., 2003, 1104.

25 C. Poriel, Y. Ferrand, P. Le Maux, C. Paul, J. Rault-Berthelot and G. Simonneaux, Chem. Commun., $2003,2308$.

26 C. Paul-Roth, J. Rault-Berthelot, G. Simonneaux, C. Poriel, M. Abdalilah and J. Letessier, J. Electroanal. Chem., 2006, 597, 19.

27 C. Poriel, Y. Ferrand, P. Le Maux, J. Rault-Berthelot and G. Simonneaux, Tetrahedron Lett., 2003, 44, 1759.

28 C. Poriel, Y. Ferrand, S. Juillard, P. Le Maux and G. Simonneaux, Tetrahedron, 2004, 60, 145.

29 C. Poriel, Y. Ferrand, P. Le Maux and G. Simonneaux, Synlett., 2003, 71.

30 F. Moreau, N. Audebrand, C. Poriel, V. Moizan-Baslé and J. Ouvry, J. Mater. Chem., 2011, 21, 18715.

31 H.-D. Guo, X. M. Guo, S. R. Batten, J.-F. Song, S.-Y. Song, S. Dang, G.-L. Zheng, J.-K. Tang and H.-J. Zhang, Cryst. Growth Des., 2009, 9, 1394.

32 K.-T. Wong, Y.-L. Liao, Y.-C. Peng, C.-C. Wang, S.-Y. Lin, C.-H. Yang, S.-M. Tseng, G.-H. Lee and S.-M. Peng, Cryst. Growth Des., 2005, 5, 667.

33 C. Poriel, R. Métivier, J. Rault-Berthelot, D. Thirion, F. Barrière and O. Jeannin, Chem. Commun., 2011, 47, 11703.

34 N. Fomina, S. E. Bradforth and T. E. Hogen-Esch, Macromolecules, 2009, 42, 6440.

35 S. Y. Hong, D. Y. Kim, C. Y. Kim and R. Hoffmann, Macromolecules, 2001, 34, 6474.

36 P. Guiglion and M. A. Zwijnenburg, Phys. Chem. Chem. Phys., 2015, 17, 17854.

37 S. Karaburnaliev, M. Baumgarten, N. Tyutyulkov and K. Müllen, J. Phys. Chem., 1994, 98, 11892.

38 C.-W. Lee and Y. Lee, Chem. Mater., 2014, 26, 1616. 
39 B. Pan, B. Wang, Y. Wang, P. Xu, L. Wang, J. Chen and D. Ma, J. Mater. Chem. C, 2014, 2, 2466.

40 S. Gong, Y.-L. Chang, K. Wu, R. White, Z.-H. Lu, D. Song and C. Yang, Chem. Mater., 2014, 26, 1463.

41 L.-S. Cui, S.-C. Dong, Y. Liu, M.-F. Xu, Q. Li, Z.-Q. Jiang and L.-S. Liao, Org. Electron., 2013, 14, 1924.

42 Y. Liu, L.-S. Cui, X.-B. Shi, Q. Li, Z.-Q. Jiang and L.-S. Liao, J. Mater. Chem. C, 2014, 2, 8736.

43 Y.-M. Xie, L.-S. Cui, F.-S. Zu, F. Igbari, M.-M. Xue, Z.-Q. Jiang and L.-S. Liao, Org. Electron., 2015, $26,25$.

44 H. Sasabe and J. Kido, Chem. Mater., 2011, 23, 621.

45 M.-K. Leung, W.-H. Yang, C.-N. Chuang, J.-H. Lee, C.-F. Lin, M.-J. Wei and Y.-H. Liu, Org. Lett., 2012, $14,4986$.

46 C. Fan, Y. Chen, Z. Liu, Z. Jiang, C. Zhong, D. Ma, J. Qin and C. Yang, J. Mater. Chem. C, 2013, 1, 463.

47 K. S. Yook and J. Y. Lee, Adv. Mater., 2012, 24, 3169.

48 S. Gong, Q. Fu, W. Zeng, C. Zhong, C. Yang, D. Ma and J. Qin, Chem. Mater., 2012, 24, 3120.

49 Q. Bai, H. Liu, L. Yao, T. Shan, J. Li, Y. Gao, Z. Zhang, Y. Liu, P. Lu, B. Yang and Y. Ma, ACS Appl. Mater. Interfaces, 2016, 8, 24793.

50 J. Zhao, G.-H. Xie, C.-R. Yin, L.-H. Xie, C.-M. Han, R.-F. Chen, H. Xu, M.-D. Yi, Z.-P. Deng, Chen, Shu-Fen, S.-Y. Liu and W. Huang, Chem. Mater., 2011, 23, 5331.

51 C. Han, Z. Zhang, H. Xu, G.-H. Xie, R. Chen, Y. Zhao and W. Huang, Angew. Chem. Int. Ed., 2012, 51, 10104.

52 F. May, M. Al-Hewi, B. Baumeier, W. Kowalsky, E. Fuchs, C. Lennartz and D. Andrienko, J. Am. Chem. Soc., 2012, 134.

53 S. Thiery, D. Tondelier, B. Geffroy, E. Jacques, M. Robin, R. Métivier, O. Jeannin, J. Rault-Berthelot and C. Poriel, Org. Lett., 2015, 17, 4682.

54 C.-J. Lin, H.-L. Huang, M.-R. Tseng and C.-H. Cheng, J. Display. Tech., 2009, 5, 236.

55 Y.-X. Zhang, L. Zhang, L.-S. Cui, C.-H. Gao, H. Chen, Q. Li, Z.-Q. Jiang and L.-S. Liao, Org. Lett., 2014, $16,3748$.

56 L. Ding, S.-C. Dong, Z.-Q. Jiang, H. Chen and L. S. Liao, Adv. Funct. Mat., 2015, 25, 645.

57 H. N. Ohkuma, T., K. Shizu, T. Yasuda and C. Adachi, Chem. Lett., 2014, 43, 1017.

58 K. Nasu, T. Nakagawa, H. Nomura, C.-J. Lin, C.-H. Cheng, M.-R. Tseng, T. Yasuda and C. Adachi, Chem. Commun., 2013, 49, 10385.

59 M. Romain, D. Tondelier, B. Geffroy, O. Jeannin, E. Jacques, J. Rault-Berthelot and C. Poriel, Chem. Eur. J., 2015, 21, 9426.

60 M. Romain, D. Tondelier, B. Geffroy, A. Shirinskaya, O. Jeannin, J. Rault-Berthelot and C. Poriel, Chem. Commun., 2015, 51, 1313.

61 M. Romain, D. Tondelier, O. Jeannin, B. Geffroy, J. Rault-Berthelot and C. Poriel, J. Mater. Chem. C, 2015, 3, 9701.

62 C. Poriel, J. Rault-Berthelot, C. Quinton, S. Thiery, B. Geffroy, D. Tondelier and R. Métivier, Chem. Eur. J., 2016, 22, 17930.

63 S. Thiery, D. Tondelier, B. Geffroy, O. Jeannin, J. Rault-Berthelot and C. Poriel, Chem. Eur. J., 2016, 22, 10136.

64 C. Fan, L. Zhu, T. Liu, B. Jiang, D. Ma, J. Qin and C. Yang, Angew. Chem. Int. Ed., 2014, 53, 2147.

65 M.-K. Leung, Y.-H. Hsieh, T.-Y. Kuo, P.-T. Chou, J.-H. Lee, T.-L. Chiu and H.-J. Chen, Org. Lett., 2013, $15,4694$.

66 Y. Zheng, A. S. Batsanov, V. Jankus, F. B. Dias, M. R. Bryce and A. P. Monkman, J. Org. Chem., 2011, 76, 8300.

67 T.-L. Chiu, H.-J. Chen, Y.-H. Hsieh, J.-J. Huang and M.-k. Leung, J. Phys. Chem. C, 2015, 119, 16846.

68 J.-J. Huang, Y.-H. Hung, P.-L. Ting, Y.-N. Tsai, H.-J. Gao, T.-L. Chiu, J.-H. Lee, C.-L. Chen, P.-T. Chou and M.-k. Leung, Org. Lett., 2016, 18, 672.

69 C. Fan, Y. Chen, P. Gan, C. Yang, C. Zhong, J. Qin and D. Ma, Org. Lett., 2010, 12, 5648.

70 Z. Jiang, H. Yao, Z. Zhang, C. Yang, Z. Liu, Y. Tao, J. Qin and D. Ma, Org. Lett., 2009, 11, 2607.

71 S. Thiery, D. Tondelier, C. Declairieux, B. Geffroy, O. Jeannin, R. Métivier, J. Rault-Berthelot and C. Poriel, J. Phys. Chem. C, 2015, 119, 5790.

72 R. G. Clarkson and M. Gomberg, J. Am. Chem. Soc., 1930, 52, 2881.

73 M. Romain, M. Chevrier, S. Bebiche, T. Mohammed-Brahim, J. Rault-Berthelot, E. Jacques and C. Poriel, J. Mater. Chem. C, 2015, 3, 5742.

74 E. Jacques, M. Romain, A. Yassin, S. Bebiche, M. Harnois, T. Mohammed-Brahim, J. Rault-Berthelot and C. Poriel, J. Mater. Chem. C, 2014, 2, 3292.

75 C. Poriel, N. Cocherel, J. Rault-Berthelot, L. Vignau and O. Jeannin, Chem. Eur. J., 2011, 17, 12631.

76 N. Cocherel, C. Poriel, L. Vignau, J.-F. Bergamini and J. Rault-Berthelot, Org. Lett., 2010, 12, 452.

77 M. Romain, C. Quinton, D. Tondelier, B. Geffroy, O. Jeannin, J. Rault-Berthelot and C. Poriel, J. Mater. Chem. C, 2016, 4, 1692.

78 C. S. Hartley, J. Org. Chem., 2011, 76, 9188.

79 C. S. Hartley, Acc. Chem. Res., 2016, 49, 646.

$80 \mathrm{H}$. Yersin, Highly Efficient OLEDs with Phosphorescent Materials, Wiley-VCH:Verlag GMbH \& Co. KGaA, Weinheim, 2007. 
81 S. Thiery, D. Tondelier, C. Declairieux, G. Seo, B. Geffroy, O. Jeannin, J. Rault-Berthelot, R. Métivier and C. Poriel, J. Mater. Chem. C, 2014, 2, 4156.

82 S. Thiery, C. Declairieux, D. Tondelier, G. Seo, B. Geffroy, O. Jeannin, R. Métivier, J. Rault-Berthelot and C. Poriel, Tetrahedron, 2014, 70, 6337.

83 D. Thirion, C. Poriel, F. Barrière, R. Métivier, O. Jeannin and J. Rault-Berthelot, Org. Lett., 2009, 11, 4794.

84 H. Schenk, Acta Cryst. B, 1972, 28, 625.

85 C.-C. Lai, M.-J. Huang, H.-H. Chou, C.-Y. Liao, P. Rajamalli and C.-H. Cheng, Adv. Funct. Mat., 2015, $25,5548$.

86 G. Méhes, H. Nomura, W. Zhang, T. Nakagawa and C. Adachi, Angew. Chem. Int. Ed., 2012, 51, 11311.

87 N. Lin, J. Qiao, L. Duan, L. Wang and Y. Qiu, J. Phys. Chem. C, 2014, 118, 7569.

88 L.-S. Cui, Y.-M. Xie, Y.-K. Wang, C. Zhong, Y.-L. Deng, X.-Y. Liu, Z.-Q. Jiang and L.-S. Liao, Adv. Mater., 2015, 27, 4213.

89 K.-T. Wong, Y.-L. Liao, Y.-T. Lin, H.-C. Su and C.-C. Wu, Org. Lett., 2005, 7, 5131.

90 C.-C. Wu, T.-L. Liu, Y.-T. Lin, W.-Y. Hung, T.-H. Ke, K.-T. Wong and T.-C. Chao, App. Phys. Lett., $2004,85,1172$.

91 C. Poriel, J.-J. Liang, J. Rault-Berthelot, F. Barrière, N. Cocherel, A. M. Z. Slawin, D. Horhant, M. Virboul, G. Alcaraz, N. Audebrand, L. Vignau, N. Huby, G. Wantz and L. Hirsch, Chem. Eur. J., 2007, 13, 10055.

92 M. Belletête, M. Ranger, S. Beaupré, M. Leclerc and G. Durocher, Chem. Phys. Lett., 2000, 316, 101.

93 J.-F. Wang, J.-K. Feng, A.-M. Ren and L. Yang, Chin. J. Chem., 2005, 23, 1618.

94 S. Thiery, B. Heinrich, B. Donnio, C. Poriel and F. Camerel, J. Phys. Chem. C, 2015, 119, 10564.

95 C. Quinton, S. Thiery, O. Jeannin, D. Tondelier, B. Geffroy, E. Jacques, J. Rault-Berthelot and C. Poriel, ACS Appl. Mater. Interfaces., 2017, 9, 6194.

96 M. A. Baldo, D. F. O'Brien, M. E. Thompson and S. R. Forrest, Phys. Rev. B J1 - PRB, 1999, 60, 14422.

97 M. A. Baldo, D. F. O'Brien, Y. You, A. Shoustikov, S. Sibley, M. E. Thompson and S. R. Forrest, Nature, 1998, $395,151$.

98 D. Geuenich, K. Hess, F. Köhler and R. Herges, Chem. Rev., 2005, 105, 3758.

99 S. M. King, S. I. Hintschich, D. Dai, C. Rothe and A. P. Monkman, J. Phys. Chem. C, 2007, 111, 18759.

100 N. Cocherel, C. Poriel, O. Jeannin, A. Yassin and J. Rault-Berthelot, Dyes Pigm., 2009, 83, 339.

101 A. Schweig, U. Weidner, R. K. Hill and D. A. Cullison, J. Am. Chem. Soc., 1973, 95, 5426.

102 N. Johansson, D. A. dos Santos, S. Guo, J. Cornil, M. Fahlman, J. Salbeck, H. Schenk, H. Arwin, J.-L. Bredas and W. R. Salaneck, J. Chem. Phys., 1997, 107, 2542.

103 X. Zhou, J. He, L. S. Liao, M. Lu, X. M. Ding, X. Y. Hou, X. M. Zhang, X. Q. He and S.-T. Lee, Adv. Mater., 2000, 12, 265.

104 R. Pudzich, T. Fuhrmann-Lieker and J. Salbeck, Adv. Polym. Sci., 2006, 199, 83.

105 J. Salbeck, N. Yu, J. Bauer, F. Weissörtel and H. Bestgen, Synth. Met., 1997, 91, 209.

106 K. Naito, Chem. Mater., 1994, 6, 2343.

107 E. Baranoff and B. F. E. Curchod, Dalton Trans., 2015, 44, 8318.

108 Y. Tao, L. Ao, Q. Wang, C. Zhong, C. Yang, J. QIn and D. Ma, Chem. Asian. J., 2010, 5, 278.

109 K. E. Linton, A. L. Fischer, C. Pearson, M. A. P. Fox, L.-O. Palsson, M. R. Bryce and M. C. Petty, J. Mater. Chem., 2012, 22, 11816.

110 S. O. Jeon, K. S. Yook, C. W. Joo, H. S. Son and J. Y. Lee, Thin Solid Films, 2010, 518, 3716.

111 Y. Jahng and F. M. M. Rahman, Bull. Chem. Soc. Jpn., 2010, 83, 672.

112 L. Ying, J. Zou, W. Yang, A. Zhang, Z. Wu, W. Zhao and Y. Cao, Dyes Pigm., 2009, 82, 251.

113 C.-C. Wu, Y.-T. Lin, H.-H. Chiang, T. Y. Cho, C. W. Chen, K.-T. Wong, Y.-L. Liao, G.-H. Lee and S.-M. Peng, App. Phys. Lett., 2002, 81, 577.

114 R.-H. Lee, Y.-W. Huang, Y.-Y. Wang and H.-Y. Chang, Thin Solid Films, 2008, 516, 5062.

115 P.-T. Wu, F. S. Kim, R. D. Champion and S. A. Jenekhe, Macromolecules, 2008, 41, 7021.

116 S. E. Jang, C. W. Joo, S. O. Jeon, K. S. Yook and J. Y. Lee, Org. Electron., 2010, 11, 1059.

117 H. Nakanotani, S. Akiyama, D. Ohnishi, M. Moriwake, M. Yahiro, T. Yoshihara, S. Tobita and C. Adachi, Adv. Funct. Mat., 2007, 17, 2328.

118 S.-C. Dong, C.-H. Gao, Z.-H. Zhang, Z.-Q. Jiang, S.-T. Lee and L. S. Liao, Phys. Chem. Chem. Phys., 2012, 14, 14224.

119 S.-C. Dong, C.-H. Gao, X. D. Yuan, L.-S. Cui, Z.-Q. Jiang, S.-T. Lee and L. S. Liao, Org. Electron., 2013, $14,902$.

120 T. Liu, H. Sun, C. Fan, D. Ma, C. Zhong and C. Yang, Org. Electron., 2014, 15, 3568.

121 Y. J. Cho, O. y. Kinm and J. Y. Lee, Org. Electron., 2012, 13, 351.

122 S. E. Jang, C. W. Joo, K. S. Yook, J.-W. Kim, C.-W. Lee and J. Y. Lee, Synth. Met., 2010, 160, 1184.

123 S. Lee, B. Kim, H. Jung, H. Shin, H. Lee, J. Lee and J. Park, Dyes Pigm., 2017, 136, 255.

124 I. Bulut, P. Chavez, S. Fall, S. Mery, B. Heinrich, J. Rault-Berthelot, C. Poriel, P. Leveque and N. Leclerc, RSC Adv. , 2016, 6, 25952. 
125 K. H. Lee, S. O. Kim, J. N. You, S. Kang, J. Y. Lee, K. S. Yook, S. O. Jeon, J. Y. Lee and S. S. Yoon, J. Mater. Chem., 2012, 22, 5145.

126 K. H. Lee, S. O. Kim, K. S. Yook, S. O. Jeon, J. Y. Lee and S. S. Yoon, Synth. Met., 2011, 161, 2024.

127 S. Thiery, B. Heinrich, B. Donnio, C. Poriel and F. Camerel, J. Mater. Chem. C, 2014, 2, 4265. 